\title{
Vitamin A deficiency, anemia and infectious diseases in Northeast Thailand
}

Citation for published version (APA):

Bloem, M. W. (1989). Vitamin A deficiency, anemia and infectious diseases in Northeast Thailand. [Doctoral Thesis, Maastricht University]. Krips Repro. https://doi.org/10.26481/dis.19890203mb

Document status and date:

Published: 01/01/1989

DOI:

10.26481/dis.19890203mb

Document Version:

Publisher's PDF, also known as Version of record

\section{Please check the document version of this publication:}

- A submitted manuscript is the version of the article upon submission and before peer-review. There can be important differences between the submitted version and the official published version of record.

People interested in the research are advised to contact the author for the final version of the publication, or visit the DOI to the publisher's website.

- The final author version and the galley proof are versions of the publication after peer review.

- The final published version features the final layout of the paper including the volume, issue and page numbers.

Link to publication

\footnotetext{
General rights rights.

- You may freely distribute the URL identifying the publication in the public portal. please follow below link for the End User Agreement:

www.umlib.nl/taverne-license

Take down policy

If you believe that this document breaches copyright please contact us at:

repository@maastrichtuniversity.nl

providing details and we will investigate your claim.
}

Copyright and moral rights for the publications made accessible in the public portal are retained by the authors and/or other copyright owners and it is a condition of accessing publications that users recognise and abide by the legal requirements associated with these

- Users may download and print one copy of any publication from the public portal for the purpose of private study or research.

- You may not further distribute the material or use it for any profit-making activity or commercial gain

If the publication is distributed under the terms of Article $25 \mathrm{fa}$ of the Dutch Copyright Act, indicated by the "Taverne" license above, 
VITAMIN A DEFICIENCY, ANEMLA AND INFECTIOUS DISEASES IN NORTHEAST THALLAND 

VITAMIN A DEFICIENCY, ANEMIA AND INFECTIOUS DISEASES IN

NORTHEAST THAILAND

\section{PROEFSCHRIFT}

ter verkrijging van de graad van doctor aan de

Rijksuniversiteit Limburg te Maastricht,

op gezag van de Rector Magnificus,

Prof. dr. F.I.M. Bonke,

volgens het besluit van het College van Dekanen,

in het openbaar te verdedigen op

vrijdag 3 februari 1989 om 14.00 uur

door

MARTIN WILLIAM BLOEM

geboren te Soesterberg

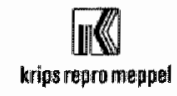


Promotores:

Prof. Dr. Ir. R.J.J. Hermus

Prof Dr. H.A. Valkenburg

Beoordelingscommissie: $\quad$ Prof. Dr. F. ten Hoor (voorzitter)

Prof. Dr. J. Flendrig

Prof. Dr. W.H.P. Schreurs

Prof. Dr. F. Sturmans

Dr. C.E. West 
Preface 9

1. Introduction 11

1.1 Rationale 11

1.2 Study objectives 12

1.3 Outline of this thesis 12

1.4 References 12

2. Vitamin A deficiency and xerophthalmia 15

2.1 Introduction 15

2.2 Biochemistry of vitamin A 15

2.2.1 Introduction 15

2.2.2 Absorption from the gut 15

2.2.3 Vitamin A metabolism in the liver 16

2.2.4 Transport of retinol in plasma and uptake by $\quad 16$

2.2.5 Intracellular metabolism 16

2.2.6 Utilization and excretion 17

2.3 Clinical classification of xerophthalmia 17

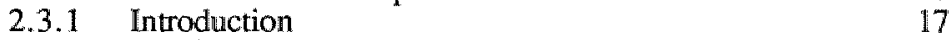

2.3.2 Night blindness 17

2.3.3 Conjunctival xerosis $(\mathrm{X} 1 \mathrm{~A}) \quad 18$

2.3.4 Bitot's spots (X1B) 18

2.3.5 Corneal xerosis (X2) 18

2.3.6 Corneal ulceration/keratomalacia (X3A/X3B) 20

2.3.7 Scars (XS) 20

2.3.8 Fundus (XF) 21

2.4 Methods of assessment of vitamin A status 21

2.5 Pathogenesis, risk factors and associations 21

2.5.1 Introduction 21

2.5.2 Dietary intake 21

2.5.3 Vitamin A deficiency and protein energy 22

2.5.4 Vitamin A deficiency and diseases 22

2.6 Eepidemiology 23

2.6.1 Prevalence 23

2.6.2 Age 23

2.6.3 Sex 23

2.6.4 Rural and urban environment 23

2.6.5 Season 23

2.6 Treatment and prevention 24

2.8 References 24 
3. Vitamin A deficiency and anemia 29

3.1 General 29

3.2 Studies in animals 29

$\begin{array}{ll}3.3 \text { Studies in man } & 29\end{array}$

3.4 Epidemiologic studies $\quad 30$

3.5 Discussion 30

3.6. References 31

4. Vitamin A deficiency in Northeast Thailand:

A prevalence study of vitamin $A$ deficiency and xerophthalmia

American journal of Epidemiology (in press)

5. Iron metabolism and vitamin $A$ deficiency in children in Northeast Thailand

American Journal of Clinical Nutrition (in press)

6. Short-term effects of a single oral massive dose of vitamin $A$ on iron metabolism

American Journal of Clinical Nutrition (accepted)

7. Mild vitamin A deficiency and risk of respiratory infection and diarrhea in preschool and school children in Northeast Thäland

(submitted)

8. General discusssion

8.1 Introduction 69

8.2 Factors affecting the vitamin A status in Northeast Thailand 69

8.2.1 The prevalence study 69

8.2.2 Host factors 70

8.2.2.1 Age $\quad 70$

8.2.2.2 Sex 70

$\begin{array}{lll}\text { 8.2.3 Agent factors } & 70\end{array}$

8.2.3.1 Vitamin A sources $\quad 70$

$\begin{array}{ll}\text { 8.2.3.2 Other nutrients } & 71\end{array}$

8.2.4 Environmentall factors 71

8.2.4.1 Season 71

8.2.4.2 Geographical and agricultural factors $\quad 72$

8.3 Vitamin A deficiency, infections, and anemia 72

8.3.1 Physiology $\quad 72$

8.3.2 Effects of infection on the vitamin A-status 72

8.3.2.1 Food intake $\quad 73$

8.3.2.2 Absorption $\quad 73$

8.3.2.3 Metabolism $\quad 73$

8.3.2 Effect of vitamin A deficiency on infections 73

8.3.3.1 Antemia and vitamin A deficiency $\quad 74$

8.4 Conclusions and recommendations 75

$\begin{array}{ll}8.5 \text { References } & 75\end{array}$

$\begin{array}{ll}\text { 9. Summary } & 77\end{array}$ 
Table of contents

10. Samenvatting $\quad 79$

$\begin{array}{ll}\text { Curriculum vitae } & 81\end{array}$

$\begin{array}{lr}\text { Appendix } & 83\end{array}$ 


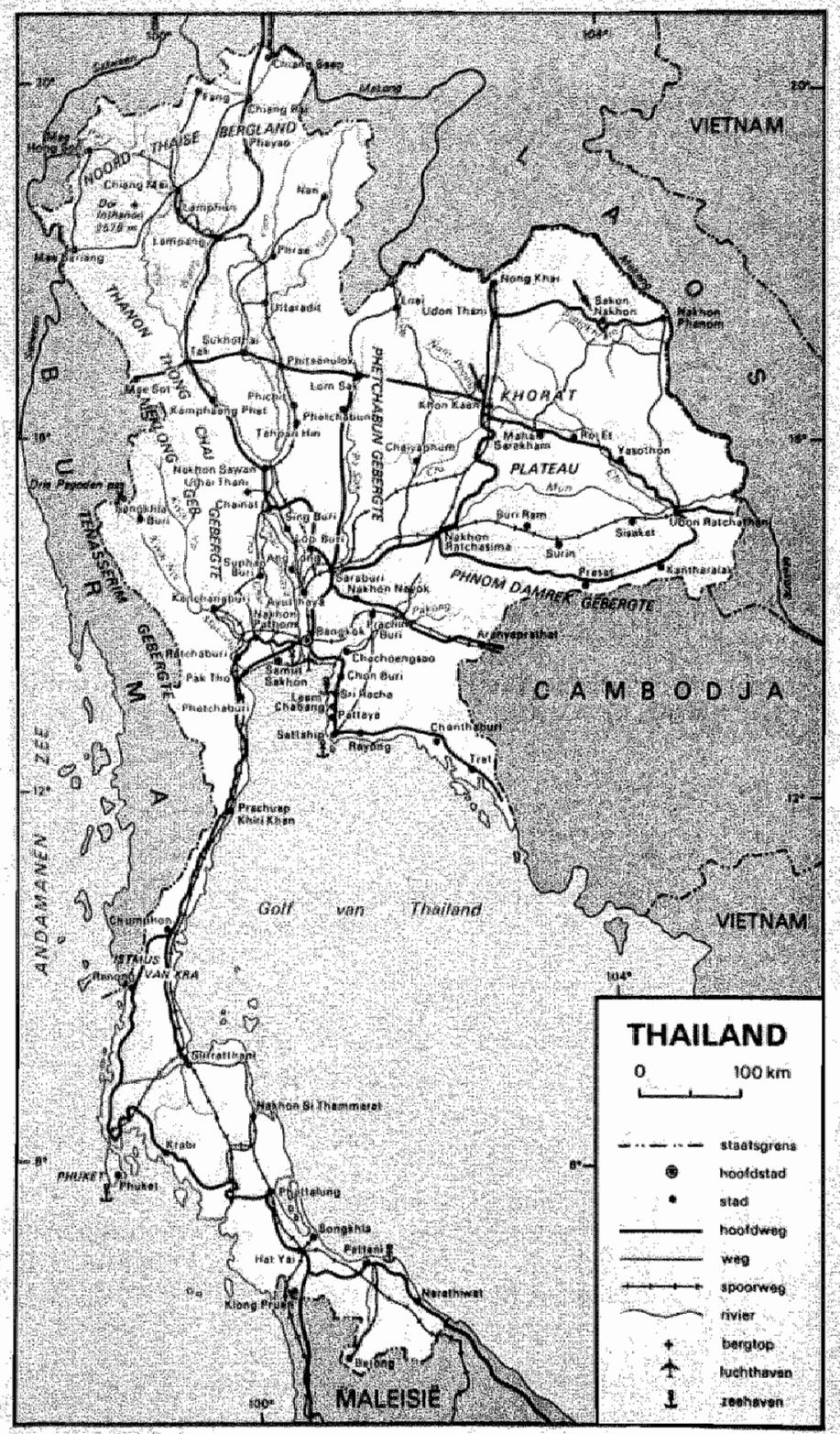

Fig 1. Thailand (bron: Landendocumentatie, Koninklijk Instituut van de Tropen, 1982) 
The research described in this thesis has been made possible by the participation and assistance of many people. I acknowledge with thanks my indebtedness to:

- The Department of Foreign Aid under the Ministry of Foreign Affairs, the Hague, The Netherlands, for financial support of the bilateral Thai/Dutch project "Nutrition Supplement Cooperation project". This project has been carried out in the scope of this project;

The Institute TNO/CIVO-Toxicology and Nutrition, for their assistance and financial support for this research;

Professor Ruud J.J. Hermus, Director TNO-CIVO Toxicology and Nutrition Institute, Zeist, and Professor Hans A. Valkenburg, Head of the Faculty of Epidemiology, Erasmus University, Rotterdam, for all their invaluable help at the beginning and during the final stage of analyzing and reporting this research;

- Professor Wil H.P. Schreurs, Head of the Department of Biochemistry, TNOCIVO Toxicology and Nutrition Institute, Zeist, for his confidence he has given me at the beginning of this research and for his continuous support and helpful suggestions during this research;

- Professor Sastri Saowakontha and other staff members of the Faculty of Medicine and the faculty of Public Health, Khon Kaen University, Thailand, for their help in the execution of the field survey;

- Drs Robbert J. Egger, Drs Andries J. Speek, Drs Eric J. van Agtmaal, Lies van de Ven en Drs Saskia Bronkhorst for all their assistance and pleasant cooperation during my stay in Thailand;

- Drs Michel Wedel and his staff for all their advise on statistical and methodological matters;

- Dr Jaap Schrijver, Dr Ir. Frans. J. Kok, Dr Jaap Odink, Dr Henk van de Berg en Drs Cor J.M. Arts for their helpful and critical suggestions during the final stage of this research;

Dirk van der Heij for critically editing this thesis and pleasant cooperation;

- the late Professor H.A.P.C. Oomen, Professor Jane Kusin, Royal Tropical Institute, Amsterdam, Netherlands, Dr Johanna ten Doesschate en Dr J.J.M. Sauter for their very helpful suggestions at the beginning of this research and especially Professor Jane Kusin for her suggestion to investigate the association between vitamin $\mathrm{A}$ deficiency and anemia;

Dr Jo J.M. Marx, hematologist, State University, Utrecht for his helpful suggestions concerning the iron metabolism;

Professor Alfred Sommer, International Center for Epidemiology and Preventive Ophthalmology, The John Hopkins School of Hygiene and Public Health, Baltimore, USA for his critically review of the results of this research in the final stage;

Sylvia A.M. Eken, my wife, for her invaluable support during my stay in Thailand:

- All the others, who have kindly contributed to the success of this research. 
Chapter 1

INTRODUCTION

\subsection{Rationale}

From 1985 to 1986 the Nutritional Supplement Cooperation project has been carried out by TNO-CIVO Toxicology and Nutrition Institute, Netherlands and the University of Khon Kaen, Thailand in the Sakon Nakhon Province in Northeast Thailand. The aim of the project was to improve the nutritional health of 6,250 preschool and school children with a nutritional supplement containing protein, vitamins and minerals. Within the scope of this project various studies have been carried out concerning vitamin A deficiency.

Although the overall nutrition status of the population in Thailand is better than that in several other countries of the Southeast Asian region and the situation has been improved in the past decade, the country has still to face nutritional problems (1). The Government's Fifth Food and Nutrition Plan (1982-1986) had the specific objective of ensuring the availability of sufficient food for all. Vitamin A deficiency and nutritional anemia are listed in this plan as two of the major nutritional problems (2). Furthermore, it has been estimated that $15.4 \%$ of 7.5 million preschool children are moderately or severely undernourished. In Khon Kaen Province in Northeast Thailand $10 \%$ of children under four years of age suffer acute "wasting malnutrition" (1).

The leading cause of blindness in preschool children in developing countries is xerophthalmia, the clinical manifestation of lack of vitamin A. Every year as many as about 5 million children develop noncormeal xerophthalmia and circa half a million children go blind $(3,4,5)$. Although no countrywide surveys have been done, the WHO has classified Thailand as a country where xerophthalmia/vitamin A deficiency is not a public health problem, but where its prevalence should be closely monitored (6). This monitoring is especially necessary among children residing in rural areas of the northeastern and northern regions $(2,7)$. Northeast Thailand, one of the poorest regions of the country is Thailand"s chronic problem area. The soil is thin and infertile and there is either a deficit or a surplus of rainfall. A study conducted in 1977 in Ubon showed that $17 \%$ of the 146 preschool children had deficient and $70 \%$ had marginal serum retinol levels $(8,9)$. According to the WHO criteria, these data reflect the possible existence of a public health problem (10). Therefore we conducted an epidemiologic survey of the prevalence of xerophthalmia and vitamin A deficiency in the Sakon Nakhon Province in Northeast Thailand.

Apart from the important role for vision, vitamin A is also required for normal growth, reproduction and resistance to infections, and it modulates the differentiation of epithelial cells (11). In the late 1970s, the group of Hodges, Mejia and Arroyave (12, 13, 14, 15) paid attention to anemia, a secondary effect of vitamin A. Already since 1922 several studies have reported hematological changes due to vitamin A deficiency occurring in both man and experimental animals. Data of a national program of vitamin A fortification, conducted in Guatemala from 1975 to 1977 , have been evaluated by the authors mentioned: all though the dietary intake of iron did not show any significant change the parameters of the iron status improved.

This association may be very important, especially in areas where anemia is highly prevalent, but where, despite endemic vitamin A deficiency, severe forms of xerophthalmia are rarely seen. Northeast Thailand seems to be such an area. A health program emphasizing the control of anemia but neglecting the vitanin A problem is bound to miss much of its impact. It was decided therefore, to investigate in Northeast Thailand the association between parameters of vitamin A deficiency and iron deficiency in various ways.

It has long been known that among children with severe vitamin $A$ deficiency mortality is extremely high, but it was only recently discovered that also mild vitamin A deficiency is associated with a high mortality and morbidity of infectious disease (16,17). Every year 
25-50 million chilaren may be suffering the physiological consequences of vitamin $\mathrm{A}$ deficiency. This led us to investigate the association between witamin $A$ deficiency and morbidity in Northeast Thailand.

\subsection{Study objectives}

1. To inwestigate in a population of children 1-8 years old in the Sakon Nakhon province in Northeast Thailand, the prevalence of xerophthalmia and vitamin A deficiency and the factors determining their level.

2. To investigate by a cross-sectional analysis the association between the parameters of the vitamin A status and those of the iron status.

3. To investigate in a group of anemic children in the age of 1-5 years and in a group of children with conjunctival xerosis aged 3-9 years the effect of a single massive dose of vitamin A (200 000 IU) on the iron status.

4. To investigate the association between vitamin A deficiency and infectious diseases by a cross-sectional a follow-up and an intervention study.

\subsection{Outline of this thesis}

Ir Chapter 2, literature on vitamin A deficiency and xerophthalmia is reviewed, with an emphasis on the situation in Thailand. Chapter 3 presents a review on the rellationship between vitamin A metabolism and hematopoiesis. In Chapter 4 the prevalence of xerophthalmia and vitamin A deficiency in the Sakon Nakhon province is described and the determinants sex, age, level of urbanization, anthropometry, biochemical parameters of the vitamin A status, and of protein status, food consumption, and socioeconomic level are discussed. Chapter 5 presents a cross-sectional analysis of the relationship between vitamin A parameters and parameters of the iron status and the results of an epidemiologic intervention study. This chapter describes the effect of a oral single high dose of vitamin A (200 $000 \mathrm{IU})$ on the iron status after two and four months in a group of anemic children aged 1-5 years. Chapter 6 reports the results of the effects, two weeks after administration, of an oral single massive dose of vitamin A (200 000 IU) on the iron status in a group of anemic and non-anemic children aged 3-9 years. Chapter 7 comprises three studies on the association between vitamin $\mathrm{A}$ deficiency and infectious diseases. Finally, conclusions and recommendations are given in the general discussion (Chapter 8).

\subsection{References}

1. WHO, Health Care in South-East Asia. WHO Regional Publications, South-East Asia Series N0. 14, 1985.

2. Food and Nutrition Policy. In: The Fifth National Economics and Social Development Plans 1982-1987, Bangkok: NESDB, 1981.

3. Sommer A. Nutritional Blindness: xerophthalmia and keratomalacia. New York: Oxford University Press, 1982.

4. World Health Organization, Control of vitamin A deficiency, xerophthalmia. Geneva: Technical Report Series 672, 1982.

5. Bauernfeind JC (eds). Vitamin A deficiency and its control. Nutrition Basic and Applied Science. Academic Press, Gainesville, Florida, 1986.

6. WHO, Prevention and control of vitamin A deficiency, xerophthalmia and nutritional blindness: Summary of a proposal for a ten-years programme of support to countries. Geneva: World Health Organization, 1985.

7. Tontisirin K, Winichagoon P. Malnutrition as a social indicator: Nutrition Problems in Thailand. Faculty of Medicine, Ramathibodi Hospital \& Institute of Nutrition Mahidol University, Bangkok: 1984. 
8. Dhanamitta S, Stoecker B, Valyasevi A. Community Approaches to Prevention of Vitamin A Deficiency. Paper presented at the IVACG Meeting, Jakarta, Indonesia, 11-13 October, 1980.

9. Charoenkiatkul S, Valyasevi A, Tontisirin $\mathrm{K}$. Dietary approaches to the prevention of vitamin A deficiency. Food and Nutrition Bulletin 1983;7:72-6.

10. Sommer A. Field guide to the detection and control of xerophthalmia. Geneva: WHO, 1982.

11. Wolbach SB, Howe PR. Tissue changes following deprivation of fat-soluble A vitamin. J Exp Med 1925;42:753-77.

12. Mejia LA, Hodges RE, Arroyave G, Viteri F, Torun B. Vitamin A deficiency and anemia in Central American children. Am J Clin Nutr 1977;30:1175-84.

13. Hodges RE, Sauberlich, HE, Canham JE, Wallace DL, Rucker B, Mejia LA, Mohanram M. Hematopoietic studies in vitamin A deficiency. Am J Clin Nutr $1978 ; 31: 876-85$.

14. Mejia LA, Arroyave G. The effect of vitamin A fortification of sugar on iron metabolism in preschool children in Guatemala. Am J Clin Nutr 1982;36:87-93.

15. Mejia LA, Arroyave G. Lack of direct association between serum transferrin and serum biochemical indicators of vitamin A intake. Acta Vitaminol Enzymol 1983;5ns:179-84.

16. Sommer A, Katz J, Tarwotjo I. Increased risk of respiratory disease and diarrhea in children with preexisting mild vitamin A deficiency. Am J Clin Nutr 1984;40:1090. 5.

17. Sommer A, Tarwotjo I, Hussaini G, Susanto D. Increased mortality in children with mild vitamin A deficiency. Lancet $1983 ; 1 i: 585-8$. 

Chapter 2

\section{VITAMIN A DEFICIENCY AND XEROPHTHALMIA}

\subsection{Introduction}

Xerophthalmia is the general term applied to all the ocular manifestations due to impaired vitamin A metabolism, from night blindness to complete comeal destruction $(1,2,3)$.

Vitamin A deficiency relates to any state in which the vitamin A status of the organism is subnormal. It includes xerophthalmia but also several other functional signs, anorexia, growth retardation, follicular hyperkeratosis, disturbance of the reproductive function, anemia, and impairment of the immune response (4).

Vitamin A stans is defined in terms of the total body reserves of vitamin $\mathrm{A}$. The status can vary from deficient, through poor and marginal, to acceptable or excessive. The liver usually contains $90 \%$ of the total body reserves of vitamin $A$, determining the protection period of an individual fed on a vitamin A-deficient diet, and consequently his vitamin status (5).

\subsection{Biochemistry of vitamin A}

\subsubsection{Introduction}

Vitamin $\mathrm{A}$ is the generic term used for all compounds that exhibit qualitatively the biological activity of retinol. Physiologically the vitamin occurs as the alcohol (retinol), the aldehyde (retinal), the acid (retinoic acid), and the ester (retinyl ester) form.

Both the alcohol and aldehyde forms are biologically active in maintaining normal reproductive and visual functions (6). Retinoic acid, however, is ineffective in these systems but is the biologically active form in somatic epithelial cells, where the vitamin influences cellular differentiation $(7,8)$.

Retinol is a fat-soluble, unsaturated, isoprenoid alcohol. It has five conjugated all-trans double bonds. It is only found in animal products, such as milk, milk fat, eggs, and liver. The liver as a storage organ is a particularly rich source. However, these products are wery expensive and are rarely eaten by poor people in developing countries (9).

Carotenoid pigments, in human nutrition especially $\beta$-carotene, are synthesized by plants; these carotenoids are the precursors of vitamin $A$. The most important sources of carotenoids are green leafy vegetables, red palm oil, yellow fruits, and the yellow varieties of maize. Carotenoids must be considered to be the major dietary source of vitamin A. In a large part of the world about two thirds of the daily intake of vitamin $A$ is consumed in its precursor form (9).

Retinoids is the general term for both the natural forms of witamin A and synthetic retinol analogues, with or without biological activity.

Retinol equivalents is the term used for all forms of vitamin $A$ and carotenoids converted into one single unit. Generally, $1 \mu \mathrm{g}$ of all-trans retinol is biologically equivalent to $6 \mu \mathrm{g}$ of $\beta$-carotene or about $12 \mu \mathrm{g}$ of mixed dietary carotenoids. An obsolescent unit for amount of vitamin $A$ is International Unit (IU); 1 IU $=0.3 \mu \mathrm{g}$ all-trans retinol (10).

\subsubsection{Absorption from the gut}

Retinyl esters in animal products and carotenoids in plants are the main sources of vitamin $A$ in the human daily diet. After ingestion carotenoids and retinyl esters are liberated in fatty globules and dispersed by bile salts.

In the upper small intestine the ester is largely hydrolyzed to retinol by a hydrolase in the pancreatic juice, incorporated into mixed micelles in the intestinal lumen, and $a b$. 
sorbed in the mucosal cells. In these cells retinol is preferentially reesterified with palmitic acid. Via the lymphatic system it is transponted by chylomicrons to the blood stream.

Before uptake by the mucosal cells, the carotenoids have to be converted into retinol in two steps. The carotenoid is cleaved at the 15,15 double bond by a dioxygenase mechanism, yiclding two molecules of retinal, which are reduced to two molecules of retinol by the enzyme retinaldehyde reductase $(11,12,13)$. In protein deficiency the activity of this enzyme is reduced, and this may explain partly the association between protein-energy malnutrition (PEM) and vitamin $A$ deficiency $(14,15,16)$.

\subsubsection{Vitamin A metabolism in the liver}

From the chylomicrons the transport medium, retinyl esters are taken up by the parenchymal cells in the liver (17). In these cells, retinyl esters are hydrolyzed and retinol. is bound by a specific cellular retinol-binding protein (cRBP). Subsequently, the retinol is reesterified and transferred to a complex storage form in association with lipid droplets. Roughly $95 \%$ of the vitamin $A$ in the body is stored in the liver, but certain amounts are also found in the kidney and depot fat. Lesser amounts are present in the plasma, small intestine, lungs, and adrenal glands (10). Within the liver, two types of cells are mainly responsible for the storage of vitamin $A$, the lipocytes and the hepatocytes. The lipocytes contains under normal physiological conditions, approximately $80 \%$ of the total vitamin $\mathrm{A}$ of the liver (18).

The mobilization of the stored retinol in the liver cell is a complex mechanism. Retinyl

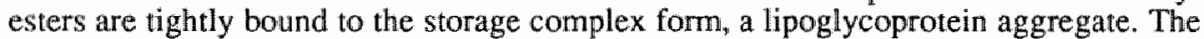
first step of the mobilization is the hydrolysis of the ester to retinol, by the same enzymatic reaction as during the hepatic uptake, which has still not been completely elucidated. Then retinol forms a protein-vitamin complex (holo-RBP) with a specific transport protein (apo-RBP) (1:1 molar ratio), Via the Golgi system, holo-RBP is released into the plasma and forms a complex with prealbumin ( $1: 1$ molar ratio), which is secreted separately by the liver. Next to this function, prealbumin is also the transport protein of the thyroid hormones in plasma $(19,20)$.

Factors that control the production and secretion of apo-RBP by the liver influence the mobilization of retinol from the liver to the target organs. One of these factors is the retinol level in plasma. In vitamin A deficiency, release of RBP is inhibited, so that plasma RBP levels fall and liver RBP levels rise. When vitamin $A$ reaches an adequate level, it stimulates the rapid secretion of RBP from the liver into the plasma. This release of RBP is not blocked by inhibitors of protein synthesis, and RBP consequently is to be considered as coming from the expanding liver pool. However, what triggers the syrthesis and release of RBP is still largely unknown. The intake of vitamin $A$ has no influence on the release of prealbumin, which is regulated independently (10).

\subsubsection{Tramsport of retinol in plasma and uptake by cells}

Retinol is transported as holo-RBP in a complex with prealbumin. When this complex reaches the target organ, it binds very tightly to specific receptors on the cell surface. (21) These receptors recognize the structure of RBP. Only retinol enters the cell and RBP is released in the blood and removed by the kidney.

\subsubsection{Intracellular metabolism}

The way vitamin A activates the processes within the cells is still unclear. When retinol has entered the cell, it forms a complex with a special protein (cRBP). Tissues seem to differ in cRBPS. These cRBPs differ from serum RBP in molecular weight immunoreactivity, affinity for prealbumin, and ultraviolet and fluorescence spectral characteristics. Different hypotheses exist for the functions of these cRBPs: these proteins may be responsible for the biological expression of vitamin A activity; they may play a role in the 
specific reaction of retinol with binding sites for retinol in the cell nucleus; and they may be involved in the transportation of retinol from one locus to another within the cell. The cell contains also a special carrier protein for retinoic acid (cRABP). The main properties of both $\mathrm{CRBP}$ and $\mathrm{CRABP}$ are largely similar (22-24).

\subsubsection{Utilization and excretion}

A proportion (1-20\%) of the ingested vitamin A is directly excreted in feces. About 60 $\%$ of the absorbed vitamin $A$ is stored, and the other $40 \%$ is rapidly metabolized and excreted in feces and urine. Some of the stored vitamin $\mathrm{A}$ is also metabolized and excreted in feces and urine. There is also a recycling process: much of the retinol released as conjugates or as a RBP complex returns to the liver. This process is vital, especially when the intake and the status of vitamin $A$ is very low (25).

\subsection{Clinical classification of xerophthalmia}

\subsubsection{Introduction}

To attack the problem of xerophthalmia it is necessary to identify the clinical aspects of the disease. Literally, xerophthalmia means "disease of the dry eye", but in the classification proposed by ten Doesschate the term is used for all ocular manifestations of impained vitamin A metabolism (1).

The excellent detailed descriptions by Oomen, McLaren, Ten Doesschate, and Sommer have clarified the clinical picture $(1,2,3,26,27)$. The WHO has published some technical reports containing the accepted classification of the disease entities (Table 1). The eye lesions can be divided into anterior and posterior signs. The anterior signs are classified as $\mathrm{X} 1 \mathrm{~A}, \mathrm{X} 1 \mathrm{~B}, \mathrm{X} 2, \mathrm{X} 3 \mathrm{~A}, \mathrm{X} 3 \mathrm{~B}$ and $\mathrm{XS}$; the posterior signs are coded $\mathrm{XN}$ and $\mathrm{XF}$ $(25,28,29)$.

TABLE 1

Clinical classification of xerophthalmia (WHO, 1982a)

\begin{tabular}{|c|c|}
\hline $\mathrm{XN}$ & Night blindness \\
\hline $\mathrm{X} 1 \mathrm{~A}$ & Conjunctival xerosis \\
\hline$X 1 B$ & Bitot's spots \\
\hline$X 2$ & Corneal xerosis \\
\hline X3A & Corneal ulceration/keratomalacia $<1 / 3$ comeal surface \\
\hline $\mathrm{X} 3 \mathrm{~B}$ & Corneal ulceration/keratomalacia $>1 / 3$ comeal surface \\
\hline XS & Corneal scar : \\
\hline$X F$ & Corneal fundus \\
\hline
\end{tabular}

aFrom Sommer (28)

\subsubsection{Night blindness $(X N)$}

Through centuries night blindness, the early sign of vitamin A deficiency, has been recognized as an illness all over the world. The Egyptians and the Greeks already knew how to cure it (30). Especially Wald and co-workers have elucidated the mechanism of this phenomenon: retinol, forms together with specific proteins, opsins, the photosensitive visual pigments of rods and cones. Lack of vitamin A makes the rhodopsin level decline and vision in dim light impaired (31-34).

Several sophisticated detection methods such as rod scotometry, dark adaptometry, and electroretinography have been developed. These methods provide the possibility of detecting impaiment of dark adaptation long before there is any complaint about night blindness. Unfortunately, these methods are not quite feasible in field surveys of 
preschool children in developing countries for several reasons: difficulties in cooperation and response and the need of expensive and delicate equipment.

However, detection of night blindness is very important in field studies, because night blindress sigrals the possibility of witamin A deficiency. Only few cases of night blindness are to be diagnosed as congenital night blindness or retinitis pigmentosa. Sommer showed in his study in Indonesia that the history method is very reliable and that the mother's word is an important tool for assessing the extent of the witamin A problem in nutrition surveys (35).

\subsubsection{Conjunctival xerosis (XIA)}

Changes in the appearance of the conjunctiva is the first anterior sign of xerophthalmia. Conjunctival xerosis comprises the following signs: dryness, "unwettability", loss of transparency, thickening, wrinkling, pigmentation, and accumulation of debris (25). Histopathologic studies have shown evidence of typical keratinizing squamous metaplasia with absence of Goblet cells (36). When conjunctival xerosis is the only clinical sign, it is irmpossible to decide whether an acute shortage of vitamin $A$ is responsible for this defect. However, in many studies a high incidence of conjunctival xerosis has been used either alone or with biochemical and dietary data to show the prevalence of vitamin A deficiency.

\subsubsection{Bitot's spots (XIB)}

Although in 1860 the Russian physician Hubbenet was the first to draw attention to these spots, the description given in 1863 by the French army doctor Bitot is the best known, and as a result his name has been attached to this defect $(37,38)$.

The spots rise quite superficially above the general surface of the conjunctiva. The spots can be removed and a xerotic conjunctival bed with a rough surface will then show up. In most cases the spots are situated on the temporal bulbar conjunctiva and not on the nasal side. However, nasal involvement is far more frequent in cases with active deficiency (39). Classically, Bitot's spots have a triangular shape, the base of which parallels the limbus, but normally their shape varies considerably (37). The appearance of Bitot's spots is the most common clinical sign used in prevalence surveys (40-42). The cause and significance of these spots have been questioned, because they have been reported to be found in the absence of vitamin A deficiency. Therefore, many workers have devoted much energy to finding a simple method of distinguishing between active and non-active cases, but so far these attempts have not been very successful. However, Sommer concluded that Bitor's spots accompanied by night blindness, extratemporal involvement, and punctate keratopathy, especially in preschool children, highly suggest an active disease. These spots are bound to be occur in at least some of the members of communities living on inadequate diets. "Therefore, the sign is useful for obtaining an insight in the seriousness of a vitamin A prob]em in a certain community (39).

\subsubsection{Corneal xerosis $(X 2)$}

The clinical classification (Table 2) suggests a sharp distinction between cases with and without corneal involvement. When a slit lamp-binocular microscope is used, superficial punctate lesions (small areas of epithelial change which look slightly opaque) can be seen long before changes are visible with the naked eye. The punctate keratopathy is mostly seen in the inferonasal quadrant of the cornea. The predilection for this place has still not been explained. High-dose systemic vitamin $A$ therapy can cure all affected lesions within one week, while low-dose systemic therapy did not show any improvement over a two-month period (26). When xerophthalmia progresses punctate keratopathy becomes confluent, and the cornea shows a dry, granular, hazy. Iusterless, and peau d'orange surface, which is usually most prominent inferiorly. 
TABLE 2

Current methods of vitamin $A$ assessment $(43)$.

\begin{tabular}{|c|c|c|}
\hline Method & Advantages & Disadvantages \\
\hline Liver biopsy & $\begin{array}{l}\text { Most accurate estimate of } \\
\text { vitamin } A \text { body stores }\end{array}$ & $\begin{array}{l}\text { Does not assess amount of } \\
\text { vitamin A actually available } \\
\text { to peripheral target tisstes } \\
\text {-Highly invasive, tissue gen- } \\
\text { erally avalable only from } \\
\text { autopsy (not representative of } \\
\text { population at large) } \\
\text {-Potential problen with obtain- } \\
\text { ing a representative sample of } \\
\text { liver }\end{array}$ \\
\hline Relative Dose Response & $\begin{array}{l}\text { Indirect indicator of vitamin } \\
\text { A liver stores, far less in- } \\
\text { vasive than biopsy }\end{array}$ & $\begin{array}{l}\text {-Requires two blood drawings } \\
5 \text { hours apart which is diffi- } \\
\text { cult to manage in field setting, } \\
\text { (a new approach with promise re- } \\
\text { quires a single blood drawing with- } \\
\text { out the } 5 \text { hour wait benween ad- } \\
\text { ministration and blood collection) } \\
\text {-Storage, handling and analysis of } \\
\text { serum sample can be problematic } \\
\text { and expensive } \\
\text {-Where AIDS is prevallent collec- } \\
\text { tion of blood samples may prowe } \\
\text { difficult }\end{array}$ \\
\hline
\end{tabular}

Serum retinol concentration

Immunoassay for RBP

Clinical signs of Xerophthalmiat

Conjunctival Impression

Cytology (43)
Noninvasive, represents tissue dysfunction

Estimates circulating vitamin $\mathrm{A}$ levels

Correlates with serum levels at high nomal down to mild deficiency

-Minimally invasive, no blood mequired

- Reflects physiologic function/ vitamin A status

- Minimal equipment/supplies

required

-Stable sample under routine

field conditions
-Reflects liver stores only after moerate to severe depletion -Invasive

-Storage, handling, and analysis can be problematic and expensive -Where AIDS is prevalent collection of blood samples may prove difficult

-Fails to distinguish holo from apo-RBP

-As a result, does not parallet moderate to severe deficiency when apo-RBP levels may remain normal

-Requires trained clinical examiners

-Requires wery large sample size for communily assessment

-Epitheltal "memory" may cause persistent or recurrent abnormalities despite aculely normal liver and serum levels 
Corneal xerosis responds wery quilckly (2-5 days) to treatment. The plaques peel off, sometimes leaving superficial erosion which quickly heals. The comea regains its nor mal appearance in 1-2 weeks.

\subsubsection{Conneal ulceration/ keratomalacia $(X 3 A / X 3 B)$}

Ulceration/keratomalacia indicates the irreversible changes of the comea. The stromal defects take several forms $(1,2,3,26,36)$, Ulcers are classically circular, with steep margins and sharp demarcations. These ulcers are not similar to ulcers of bacterial origin; corneal ulceration due to vitamin A deficiency is found at the periphery of the cornea, but large ulcers and areas of stromal loss may extend centrally or involve the entire comea. This stage of ulceration is a rapid one: the corneal structure melts into a cloudy dead-white or dirty yellowish gelatinous mass, the lens can extrude and loss of vitreous substance may occuri, resulting in loss of the globe.

When treated promptly with a high dose of vitamin A, the child's eye and life can be saved even at this stage. Small ulcers can heal with surprisingly little scarring. Therapy of ulceration/keratomalacia of less than one-third of the comeal surface generally spares the central pupillary zone. Treatment of stage X3B is essential for saving the other eye.

\subsubsection{Scars (XS)}

Corneal scars are never specific for xerophthalmia, because the causes may be manifold (trauma, infection). Depending on the stage of xerophthalmia different kinds of scars can develop: according to their density scars are classified as nebula, macula or leucoma. When the iris has prolapsed, there is a leucoma adherens and the pupil has lost its round shape. Keratomalacia can heal as staphyloma, descemetocele, and phthisis bulbi.

\section{TABLE 3}

Cut off criteria that have been proposed for interpreting indicators of vitcmin A status(43)

\section{Individual Assessment}

Relative Dose Response $(44,45)$

$<10 \%$

$\geq 10, \leq 20 \%$

Normal

$>20 \%$

Inconclusive

Deficient

Hepatic Vitamin A Concentration $(\mu \mathrm{g} / \mathrm{g})(46)$

$\geq 20$

$<20$

Serum Vitamin A Concentration $(\mu \mathrm{g} / \mathrm{dl})(26)$ $\geq 20$

$\geq 10,<20$

$<10$
Normal

Deficient 


\subsubsection{Fundus (XF)}

In xerophthalmia the fundus undergoes some slight changes. Small white retinal lesions are described in some cases of vitamin A deficlency. From a public health point of view this sign is of no interest.

\subsection{Methods of assessment of vitamin A status}

Table 2 shows the current methods of witamin A assessment, with the advantages and disadvantages of each (43). Interpretive criteria are listed in Table 3 . To assess whether xerophthalmia is a problem of public health magnitude in a certain area the following criteria have been chosen by the WHO (Table 4). Only some of the clinical signs described are sufficiently objective and easily recognized to be useful in a prevalence study. The biochemical criterion is indicative of a serious vitamin $A$ deficiency and may be used alone to determine the vitamin A status of the population. It is not a criterion of xerophthalmia, but in association with the clinical criteria it is a strong indicator for the existence of xerophthalmia in a certain area $(28,29)$.

\section{TABLE 4}

Criteria for assessing the public health significance of xerophthalmia and vitamin $A$ deficiency, based on the prevalence among children less than 6 years old $(28)$.

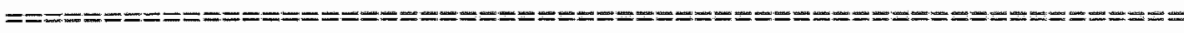
Criterion

prevalence

\section{Clinical}

Night blindness $(\mathrm{XN}) \quad 1.0 \%$

Bitot's spots (X1B) $\quad 0.5 \%$

Corneal xerosis and/or ulceration/keratomalacia $(\mathrm{X} 2+\mathrm{X} 3 \mathrm{~A}+\mathrm{X} 3 \mathrm{~B}) \quad 0.01 \%$

Xerophthalmia-related comeal scars (XS) $\quad 0.05 \%$

Biochemical

Serum retinol less than $100 \mu \mathrm{g} / 1(0.35 \mu \mathrm{mol} / \mathrm{l}) \quad 5.0 \%$

\subsection{Pathogenesis, risk factors and associations}

\subsubsection{Introduction}

Xeroplnthalmia is the result of a nutrient deficiency. Although lack of vitamin A must be considered to be the basic primary cause of xerophthalmia, other factors such as a poor nutritional status of the mother during pregnancy and lactation, delayed supplementary feeding, protein-energy malnutrition, dietary intake in general, and infectious diseases are also important in its pathogenesis. The influence of the environment, such as season and level of urbanization, on these causal processes complicates the genesis of xerophthalmia even more.

\subsubsection{Dietary intake}

In poor communities, particularly in countries with a rice diet, dietary intake of vitamin $A$ is low. Due to ignorance and/or poverty, parents feed their children mainly rice, which does not contain any carotene. 
The difficulties may start as early as in pregnancy. Serum retinol lewels in pregnant women of lower socioeconomic groups are low, especially during the third trimester of pregnanoy, when even night blindness can occur. The milk of these mothers is low in vitamin $\mathrm{A}(47)$. Consequently, livers of chilldren bom from these undernourished mothers have a low content of vitamin A. These children start life with a handicap of poor stores and a low intake of this vitamin during breast feeding as well.

If the mother has a normal vitamin A status, the child's liver stores at birth suffice for the first 6 months, and breast feeding will provide protection against the development of xerophthalmia. After this period, supplementary feeding is necessary to meet the vitamin A requirements of the infant.

\subsubsection{Vitamin A deficiency and protein-energy malnutrition}

Vitamin A deficiency usually does not occur as an isolated problem, but is almost invariably accompanied by protein-energy malnutrition. With some exceptions, it can be stated that children whose diets are deficient in proteins, are likely to be deficient in other nutrients as well. Next to the dietary factor, protein-energy malnutrition interferes with several metabolic processes of vitamin A metabolism. The absorption of vitamin $A$ and carotenoids, the cleavage of carotenoids into retinol in the intestinall mucosa, the synthesis of RBP and prealbumin, and the storage of lipoglycoprotein for retinylesters are all impaired in hypoproteinemia $(14,15,16)$.

It has been known for a long time that vitamin $A$ affects growth (48). When serum retinol levels are compared with anthropometric measurements, xerophthalmia appears to be associated with stunting rather than with wasting. However, severity of corneal involvement is associated with wasting, and as wasting is independent of age, it can be used for identifying children with a high risk of corneal involvement (49).

Lack of vitamin A evidently lies at the root of early stages of xerophthalmia, but its role in the pathogenesis of keratomalacia remains less clear. Some studies even suggest that protein deficiency governs keratomalacia $(26,50,51)$. However, Sommer showed in his study in Indonesia that even the most severe corneal alterations were compatible with normal indices of protein and anthropometric status, but not with normal serum retinol levels (52). He suggested that protein and, in particular, vitamin A status have an effect on the pathogenesis of keratomalacia.

\subsubsection{Vitamin A and diseases}

There is an important synergistic relationship between illnesses in childhood and vitamin A deficiency $(53,54)$. A number of diseases, such as respiratory tract infections, chicken pox, measles, tuberculosis and diarrhea, have been associated with xerophthalmia. Several factors, such as anorexia, impaired absorption, poor diet, and decreased capacity of transport or storage of vitamin A, urinary losses, and infectious diseases, can be responsible for vitamin $A$ deficiency.

A sick child looses its appetite and consequently will not eat enough to satisfy its vitamin A requirement. Illness reduces the ability to absorb and therefore diminishes the utillization of the vitamin A available in the food. During illness the child's need for vitamin A increases and consequently, with a reduced intake, the liver stores become exhausted.

Because deficiency of vitamin $\mathrm{A}$ in experimental animals is found to be associated with infection, the vitamin is often called 'anti-infective vitamin' $(55,56)$. The interactions between bacteria, rickettsiae, viruses, protozoa, and helminths on the one hand and vitamin A on the other hand are synergistic (57). Decreased synthesis of proteins (e.g. interferon, lysozyme, specific antibodies), decreased production or maturation of cells (e.g. phagocytes, lymphocytes) and degenerative transformation of epithelial tissues may explain the increased susceptibility to infection during vitamin A deficiency $(58,59)$. During the past decade, great efforts have been put forth in preventing nutritional blindness. However, recent studies established that among children with mild xerophthalmia there is also a higher 
mortality rate and a higher prevalence of respiratory diseases and diarthea than among nonxerophthalmic children $(60,61)$. Consequently, it seems to be important to obtain mote evidence on this association in areas with subclinical vitamin A deficiency.

\subsection{Epidemiology}

\subsubsection{Prevalence}

In the 1960 s, Oomen was the first to investigate the morbidity of xerophthalmia in Asia (62). In collecting his data, he utilized hospital records, impressions of physicians, data on food production, and knowledge of dietary practices. Together with McLaren and Escapine, he produced the first report, on magnitude and worldwide distribution of xerophthalmia (62). This report was of immense value, and since its publication the problem has been tackled all over the world. Few data on Thailand are available; although a countrywide survey has never been carried out, the WHO has classified Thatland as a country where xerophthalmia is not a public health problem, but where the situation "needs to be closely monitored".(63)

\subsubsection{Age}

Xerophthalmia can occur at any age, but each age category has its own pathogenic factors and manifestations. The most vulnerable are children between 1 and 6 years. Comeal involvement is mainly confined to the age group of $1-3$ years $(1,64)$. In this stage of life, children are growing fast and have high physiological requirements of vitamin $A$.

\subsubsection{Sex}

Most surveys have shown that xerophthalmia is more prevalent among males than among females $(1,3,28,64)$. The physiological explanation is not clear. In the early stages of xerophthalmia, the sex difference in prevalence is most pronounced. The age distribution in the severe stages is even in both males and females. It is therefore suggested that the sex difference can be better explained by cultural factors than by any intrinsic sexlinked factor (26).

\subsubsection{Rural and urban environment}

Xerophthalmia is confined to the lower socioeconomic levels of the society. Dilferences in prevalence between rural and urban areas can be partly explained by differences in socioeconomic levell between rural and urban communities. However, during the past decade, there has been a rapid increase in migration of the poor from the rural environment to the urban slums. It is very difficult to evaluate the impact of migration on prevalence of xerophthalmia and to estimate whether it will reduce or increase the problem $(25,26)$.

\subsubsection{Season}

In the pathogenesis of xerophthalmia, dietary intake, general nutritional and health stattus, and the presence of systemic infections are very important. Consequently, annual periodicity in any or all of these factors may result in seasonal fluctuations in xerophthalmia incidence. Seasonal variation is described in prevalence studies all over the world $(48,65,66)$. However, where the illness is highly endemic, seasonal fluctuations will probably be masked, and xerophthalmia will occur all over the year $(1,26)$. 


\subsection{Treatment and prevention}

The first stage in effective treatment is prompt recognition of the child at risk, namely: a. those who already show evidence of active xerophthalmia (XN-X3B); b. severely ill and malnourished children from communities where xerophthalmia is known to occur, whether or not the children give clinical evidence of vitamin A deficiency (28).

The second stage is the immediate administration of massive doses of vitamin $\mathrm{A}(200$ $000 \mathrm{JU})$. The third stage is treatment of any underlying systemic illnesses and protein-energy malnutrition. The final stage is to prevent any recurrence.

Except for some unusual cases secondary to liver disease, cystic fibrosis, eccentric diets. and the like, which can occur anywhere in the world, xerophthalmia is overwheimingly located in developing countries. Its long-term control is obviously in improvement of socioeconomic conditions. This will result in a higher standard of living, and consequently families will spend more money on energy and nutrients in their diets. In the mean time, however, the problem must be combatted along several strategies: supplementation of green leafy vegetables; massive dose programs; and fortification of foods. The results of the different strategies look very promising $(66,67,68,69,70,71,72,73,74)$

\subsection{References}

1. tenDoesschate J. Causes of blindness in and around Surabaya, East Java, Indonesia. Thesis, University Jakarta 1968.

2. McLaren DS. Nutritional Ophthalmology. Academic Press. London, 1981.

3. Moore T. Vitamin A. Elsevier, Amsterdam, 1957.

4. Bauernfeind JC (edit) Vitamin A deficiency and its control. Academic Press, 1986.

5. WHO/USAID. Vitamin A deficiency and xerophthalmia. WHO Technical Report Series no. 590 World Health Organization, Geneva, 1976.

6. Thompson JN. The role of vitamin $A$ in reproduction. In "The Fat-soluble Vitamins" (HF DeLuca and JW Suttle, eds)Univ of Wisconson Press. Madison 1969: $267-281$.

7. Sporn MB, Robberts AB. Role of retinoids in differentiation and carcinogenesis. Cancer Res 1983;43:3034-40.

8. Wolbach SB, Howe PR, Tissue changes following deprivation of fat soluble A vitamin. J Exp Med 1925;42:753-77.

9. FAO/WHO. Requirements of vitamin A, thiamine, riboflavine, and niacin. Report of a joint FAO/WHO Expert Group. WHO Technical Report Series no. 362. World Health Organization, Geneva, 1967.

10. DeLuca LM, Glover J, Heller J, Olson JA, Underwood, B. Recent advances in the Metabolism and Function of Vitamin $A$ and their Relationship to Applied Nutrition, International Vitamin A Consultative Group, Nutrition Foundation, Washington, DC, 1979.

11. Goodman DS, Huang HS. Biosynthesis of vitamin A with rat intestinal enzymes. Science 1965; 149:879-80.

12. Olson JA, Hayaishi O. The enzymatic cleavage of B-carotene into vitamin A by soluble enzymes of rat liver and intestine. Proc Natl Acad Sci USA 1965;54:1364-70.

13. Goodman DS. Biosynthesis, absorption and hepatic metabolism of retinol. In "The retinoids" (MB Sporn, and DS Goodman, eds), Vol. 2 pp. 41-88. Academic Press, New York, 1984.

14. Arroyave $\mathrm{G}$, Calcano $\mathrm{M}$. Descenso de los nivelos sericos de retinol y su proteina de enlace (RBP) durante las infecciones. Arch Latinoam Nutr 1979;29:233-60.

15. Ingenbleek $Y$, VandenSichriek HG, DeNayer $P$, DeVisscher $M$. The role of retinolbinding protein in protein-calorie malnutrition. Metab Clin Exp 1975;24:633-41.

16. Smith FR, Suskind R, Thanangkul O, Leitzmann C, Goodman DS, Olson RE. Plasma vitamin $A$, retinol-binding protein and prealbumin concentrations in protein 
calorie malnutrition. III. Response to varying dietary treatment Am I Clin Nutr $1975 ; 28: 732-8$.

17. Underwood BA, Siegel H, Weisell RC, Dolinski M. Liver stores of vitamin A in a normal population dying suddenly or rapidly from unnatural causes in New York City. Am J Clin Nutr 1970;23:1037-42.

18. Olson JA, Gunning D. The storage form of vitamin $A$ in rat liver cells. I Nutr $1983 ; 113: 2184-91$.

19. Smith FR, Goodman DS. Retinol-binding proteins and the regulation of vitamin A transport. Fed Proc, Fed Am Soc Exp Biol 1979;38:2504-9.

20. Goodman DS. Plasma retinol-binding protein. In "The Retinoids" (MB Sporn, AB Roberst, and DS Goodman, eds), Vol 2, pp 41-88. Academic Press, New York, 1984.

21. Heller $J$. Interactions of plasma retinol-binding protein with its receptor. Specific binding of bovine and human retinol-binding protein to pigment epithelial cells from bovine eyes. J Biol Chem 1979;198:562-71.

22. Chytil $F$, Ong DE. Cellular retinyl- and retinoic acid-binding proteins in vitamin $A$ action Fed Proc 1979;38:2510-4.

23. Chytil F, Ong DE. Cellular retinol-and retinoic acid binding proteins. In "The Retinoids" (MB Sporn, AB Robberts, and DS Goodman, eds), Vol2 pp 89-123 Academic Press, New York, 1984.

24. Ross AC, Goodman DS. Intracellular binding proteins for retinol and retinoic acid: comparison with each other and with serum retinol-binding protein. Fed Proc Fed Am Soc Exp Biol 1979:38:2515-8.

25. World health Organization. "Vitamin A Deficiency and Xerophthalmia," Tech Rep Ser No 590. WHO, Geneve, 1976.

26. Sommer A. Nutritional blindness: xerophthalmia and keratomalacia. Oxford University press, New York, 1982.

27. Wittpenn J, Sommer A. Clinical Aspects of vitamin A deficiency in "Vitamin A deficiency and its control" (JC Baurenfeind eds). pp 177-206. Academic Press, 1986.

28. Sommer A. Field guide to the detection and control of xerophthalmia. World Health Organization, Genewa, 1982.

29. World Health Organization. "Control of Vitamin A Deficiency and Xerophthalmia", Tech Rep Ser No 672. WHO, Geneva 1982.

30. Wolf $\mathrm{G}$. A historical note on the mode of administration of vitamin $A$ for the cure of nightblindness. Am J Clin Nutr 1978;31:290-2.

31. Dowling JE, Wald $G$. The role of vitamin $A$ acid. Vitam Hom 1960; 18:515???

32. Dowling JE, Wald $\mathrm{G}$. Vitamin A deficiency and nightblindness. Proc Natl Acad Sci USA $1958 ; 44: 648-61$.

33. Wald $G$. The visual function of the vitamin $A$. Vitam Horm, NY 1960;18:417-???

34. Wald G. The photoreceptor process in vision. Am J Ophthalmol 1955;40:18:41.

35. Sommer A, Hussaini G, Muhilal H, Tarwotjo I, Susanto D, Saoroso JS. History of - nightblindness: A simple tool for xerophthalmia screening. Am J Clin Nutr $1980 ; 33 ; 887-9$.

36. Sauter JJM. Xerophthalmia and measles in Kenya. Thesis, University of Gronin gen, Drukkerij van Denderen, BV, Groningen, 1976.

37. Bitot $C$. Sur une lesion conjunctivale non encore décrite, coincidant avec l'héméralopie. Gaz Hebd Med Chir 1863;10:284-8.

38. Hubbenet M. Observations sur l'hemaralopie. Ann Ocul $1860 ; 44: 293$.

39. Sommer A, Emran N, Tjakrasudjatma S. Clinical characteristics of vitamin A responsive and nonresponsive Bitot's spots. Am J Ophthalmol 1980;90:160-71.

40. Brink EW, Davey W, Perera A, et al. Vitamin A status of children in Sri Lanka. Am J Clin Nutr 1979;32:84-91.

41. Sommer A, Quesada J, Doty M, Faich G. Xerophthalmia and anterior segment blindness among preschool-age children in El Salvador. Am J Ophthalmol $1975 ; 80: 1066-72$. 
42. Tandon $B N$, Ramachandran $K$, Nath LM, et al. Vitamin $A$ nutritional status of nural community of Khol Block in Harayana, North India. Am I Clin Nutr $1975 ; 28: 1436-42$.

43. Wittpenn JR, West KP, Keenum D et al. Assessment of vitamin A status by impression cytology, training manual. ICEPO, Dana Center for Preventiwe Ophthamology. Ballimore, Marylland, 1988.

44. Loerch JD, Underwood BA, Lewis KC. Response of plasma levels of vitamin A to a dose of vitamin $A$ as an indicator of hepatic vitamin $A$ reserves in rats. $J$ Nutr $1979 ; 109: 778-86$

45. Amedee-Manesme O, Mourey MS, Hanck A, Therasse J. Vitamin A relative dose and response test: validation by intravenous injection in children with liver disease. Am J Clin Nutr 1987;46:1166-68.

46. Olson JA. New approaches to methods for the assessment of nutritionall status of the individual. Am J Clin Nutr 1982;35:1166 8.

47. Gopolan C, Venkatachalam PS, Belvady P. Studies of Vitamin A deficiency in children Am J Clin Nutr 1960;8:833-40.

48. Moore T, Vitamin A. Elsevier, Amsterdam, 1957.

49. Tarwotjo I, Tilden R, Pettiss, et al. Interactions of community nutritional status and xerophthalmia in Indonesia. Am J Clin Nutr 1983;37:645-51.

50. Kuming BS, Politzer WM. Xerophthalmia and protein malnutrition in Bantu children. Br J Ophthalmol 1967;51:649-66.

51. Smith FR, Suskind R, Thanankul O, Leitzmann C, Goodman DS, Olson RE. Plasma vitamin A, retinol-binding protein and prealbumin in protein calorie malnutrition. III. Response to varying dietary treatment. Am J Clin Nutr 1975:28:732-8.

52. Sommer A, Muhilal I. Nutritional factors in corneal xerophthalmia and keratomalacia. Arch Ophthalmol 1982;100:399-403

53. Petersen RA, Petersen VS, Robb RM. Vitamin A deficiency with xerophthalmia and night blindness in cystic fibrosis. Am J Dis Child 1968;116:662-65.

54. Smith FR, Goodman DS. The effects of disease of the liver, thyroid and kidneys in the transport of vitamin $A$ in human plasma. J Clin Invest 1971;50:2426-36.

55. Beaver DL. Vitamin A deficiency in the germ-free rat. Am J Pathol 1961;38:33557.

56. Green HN, Mellanby E. Vitamin A as an antiinfective agent. Br Med J 1928;2:6916.

57. Scrimshaw NS, Taylor CE, Gordon JE. "Interactions of Nutrition and Infection" WHO Monogr Ser No 57. World Health Organization, Geneva, 1968.

58. Bang BG, Bang FB, Foard MA. Lymphocyte depression induced in chickens on diets deficient in vitamin A and other components. Am J Pathol 1972;68:147-62.

59. Bhaskaram C, Reddy V. Cell-mediated immunity in iron and vitamin-deficient children Br Med J 1975;3:522.

60. Sonmer A, Tarwotjo I, Hussaini G, Susanto D. Increased mortality in children with mild vitamin A deficiency. Lancet 1983;ii:585-8.

61. Sonmer A, Katz J, Tarwotjo I. Increased risk of respiratory disease and diarthea in children with preexisting mild vitamin A deficiency. Am J Clin Nutr 1984:40:1090-5.

62. Oomen HAPC, McLaren DS, Escapini H. A global survey on xerophthalmia. Trop Geogr Med 1964;16:271-316.

63. WHO, Prevention and control of vitamin A deficiency, xerophthalmia and nutritional blindness: Summary of a proposal for a ten-years programme of support to countries. Geneva: World Health Organization, 1985.

64. Oomen HAPC. The incidence of xerophthalmia in Java in relation to age and sex. Doc Med Geogr Trop 1957,9:357-68.

65. Oomen HAPC, tenDoesschate J. The periodicity of xerophthalmia in South and East Asia. Ecol Food Nutr 1973;2:207-18. 
66. Sinha DP, Bang FB. Seasonal variation in signs of vitamin A deficiency in rural West Bengal children. Lancet 1973;ii:228-30.

67. Oomen HAPC, Grubben GJH. Tropical leaf vegetables in human nutrition. Konin klijk Instituut van de Tropen, Amsterdam, 1977.

68. McLaren DS, Shirajian E, Tchalian M, Khoury G. Xerophthalmia in Jordan. Am J Clin Nutr 1965; 17:117-30.

69. Srikantia $\mathrm{SG}_{3}$ Reddy $\mathrm{V}$. Effect of a single massive dose of vitamin $\mathrm{A}$ on senum and liver levels of the vitamin. Am J Clin Nutr 1970;23:114-8.

70. Susheela TP. Studies on serum vitamin A levels after a single massive oral dose. Indian J Med Res 1969;57:2151-60.

71. WHO, The prevention of Xerophthalmia. WHO Chronicle 1973:27:28-

72. Solon FS, Popkin BM, Fernandez TL, Latham MC. Vitamin A deficiency in the Philippines: A study of xerophthalmia in Cebu. Am J Clin Nutr 1978;31:360-8.

73. Solon FS, Fernandez TL, Latham MC, Popkin BM. An evaluation of strategies to control vitamin A deficiency in the Philippines. Am J Clin Nutr 1979;32:1445-53.

74. Solon FS, Guirriec R, Florentino R, Latham MC, Williamson DF, Aguilar J. Fortification of monosodium glutamate with vitamin $\mathrm{A}$ : The Philippine experience. Food Technol 1985:39:71-7. 



\section{VITAMIN A DEFICIENCY AND ANEMIA}

\subsection{General}

Human deficiency of vitamin $A$ and nutritional anemias continue to be serious problems in developing countries. Deficiency of iron, folate, vitamin $\mathrm{B}_{12}$, and PEM have traditionally been associated with nutritional anemias. However, since as early as 1922 several publications support the hypothesis that anemia can also be considered to be a secondary complication of vitamin A deficiency. The evidence has been found in studies both in animals and in man, and in epidemiologic studies.

\subsection{Studies in animals}

In 1922, Findlay and Mackenzie reported that rats on a diet deficient in vitamin A developed patches of gelatinous degeneration in their bone marrow, and that in animals which had survived longest the hematopoietic tissue thad been replaced almost completely by fibrous stroma (1). A subsequent study by Wolbach and Howe did not show characteristic changes in the bone marrow; however, in a few cases, reduction in hematopoietic cells was apparent (2).

Several studies have reported anemia in vitamin A-dleprived animals, but other studies have reported polycythemia instead of anemia. To understand the thematologic changes induced by lack of vitamin $A$ in rats, one must know that this deficiency causes an imbalanced water regulation; particularly a decrease in extracellular water is one of the signs of severe vitamin A deficiency $(17,21)$. This phenomenon can lead to hemoconcentration and can be misinterpreted as polycythemia. Koessler et all. were the first to call attention to this phenomenon (3). Early in their experiment, rats developed low levels of hemoglobin and low erythrocyte counts, but when the vitamin A deficiency progressed, the animals became dehydrated and hematocrit and hemoglobin levels increased. When small amounts of vitamin A were fed to the deficient rats, their weight increased rapidly but the blood cell picture showed a slower improvement. From this experiment it was concluded that without the presence of vitamin $A$ blood regeneration cannot take place and that addition of small quantities of vitamin $A$ to the diet of animals whose vitamin A reserve has been exhausted will result in the formation of new blood cells. In 1929, Sure et al, observed anemia in early deficiency, which proceeded to increases in hemoglobin concentration and erythrocyte counts when manifested symptoms of xerophthalmia be came apparent (8). These changes of early deficiency were also reported by Frank in 1934 (5). McLaren et al. carried out two experiments with Wistar albino rats to investigate the hematological changes due to vitamin $\mathrm{A}$ deficiency as soon as grow th retardation occurs $(9)$. They concluded that vitamin A deficiency causes hemoconcentration through retardation of growth and not through its action on hematopoietic tissues. All contradictory reports can be explained by the interference of vitamin A with the erythropoiesis which may be masked by abnormal fluid losses during severe vitamin A deficiency which results in hemoconcentration $(10,11,12)$.

From these animal studies it can be concluded that vitamin $\mathrm{A}$ is likely to be essential for normal hematopoiesis, but that hemoconcentration due to severe vitamin A deficiency can mask the effect.

\subsection{Studies in man}

In 1933, Blackfan and Wolbach reviewed 13 case reports on vitamin A deficiency in infants (4). At that time, a method of biochemical measurement of vitamin $A$ was not yet available; therefore, diagnosis of hypovitaminosis $A$ was based on clinical, ocular findings in six infants and histological changes - keratinized epithelial cells in one or more epithelial lined structures - in the remaining seven. One of the secondlary effects of vitamin A 
deficiency they listed was anemia, accompanied by hemosiderosis of spleen and liver and by atrophy of spleten and bone marrow after prolonged deficiencies. Wagner conducted in 1940 a study of experimental human witamin A deficiency (6). It took 188 days before the ten human subjects became "deficient". During the experiment hemoglobin levels and erythrocyte counts fell; poikilocytosis and anisocytosis were also noted. Wagner concluded that hematopoiesis was impaired. Hodges et al. reported a similar clinical study in 1971 with eight human wolunteers maintained on very low vitamin A intakes for 357 to 771 days. An unexpected finding in this group of subjects was the development of a moderate degree of anemia that was refractory to medicinal iron but responsive to vitamin A (22). This interesting result has led to a series of studies, particularly,by Hodges, Mejia, and Arroyave elucidating this association.

\subsection{Epidemiologic studies}

Hodges et al. reanalyzed international surveys conducted in developing countries between 1954 and 1968; they selected data from nonpregnant and nonlactating women, aged $15-45$ years from regions or countries where the average iron intake was fairly adequate: $14 \mathrm{mg}$ or more per day. They found a strong relationship between serum levels of vitamin $A$ and blood levels of hemoglobin (15).

Mohanram et al. reported in 1977 an intervention study with daily oral supplements of $8000 \mu \mathrm{g}$ retinol palmitate for a period of $2-3$ weeks. After supplementation, levels of hemoglobin, hematocrit and serum iron increased significantly (13). In the same year Mejia et al. retrospectively analyzed data from Nutrition surveys performed by the Institute of Nutrition of Central America and Panama (INCAP). Serum retinol levels showed positive significant correlations with levels of serum iron and hemoglobin. In children with inadequate intake of iron, as classified by both dietary information and socioeconomic level, no correlation was found between retinol and serum iron. Children with an adequate intake showed a significant positive correlation between plasma retinol levels and serum iron (14).

To investigate whether an increased vitamin $A$ intake by a community with a high prevalence of vitamin A deficiency would have a beneficial impact on the iron status, Mejia et al. evaluated data of a national program of vitamin A fortification, conducted in Guatemala from October 1975 to November $1977(18,19)$. After 6 months of fortification, elevation of serum levels of iron was accompanied by a simultaneous elevation of TIBC. Another interesting observation was that the levels of serum ferritin declined during this period. The authors concluded that in witamin A deficiency stored iron is increased and that intervention with vitamin A may affect the level of the glycoprotein, transferrin, which will lead to an enhanced availability of iron for hematopoiesis. After two years of vitamin A fortification, however, there was an overall improvement of the iron nutritional parameters. As may be expected in normal conditions of iron metabolism, the levels of serum iron, percent transferrin saturation (\%ST), and serum ferritin rose significantly, while the levells of Total Fe binding capacity (TIBC) decreased.

\subsection{Discussion}

Although most of the studies mentioned are consistent with respect to the relation between iron metabolism and vitamin A deficiency, the biochemicall basis for the interaction has still not been elucidated. The following mechanisms may provide plausible explanations:

a) vitamin A may be essential for normal differentiation of the red cell;

b) lack of vitamin A may be responsible for a block in reticuloendothelial iron release;

c) vitamin A may directly or as a result of one or more of the mechanisms mentioned, affect absorption of iron from the gut.

Regardless of the mechanism, the association between vitamin A deficiency and anemia can be important, especially in areas such as Northeast Thailand, where anemia is prevalent, but where severe forms of xerophthalmia have not frequently been found, al- 
though biochemical vitamin $\mathrm{A}$ deficiency is highly prevalent. The impact of a program that emphasizes attack of anemia but neglects the vitamin A problem, is bound to be scanty. The association between anemia and witamin $A$ hawe been studied in Northeast Thailand in various experimens under real-life conditions.

\subsection{References}

1. Findlay GM, Mackenzie RD. The bone marrow in deficiency disentses. J Pathl $1922 ; 25: 402-3$.

2. Wolbach SB, Howe PR. Tissue changes following deprivation of fatsoluble A vitamin J Exptl 1925;42:753-77.

3. Koessler KK, Maurer $S$, Loughllin $R$. The relation of anaemia primary and secondary, to vitamin A deficiency. JAMA 1926;87:476-82.

4. Blackfan KD, Wolbach SB. Vitamin A deficiency in infants. J Pediatr 1933;3:679706.

5. Frank M. Beitrag zur Hamatologie der A-Avitaminose. Monatrisschrift für Kinderheilkunde 1934;60:350-5.

6. Wagner KH. Die Experimentele Avitaminose A beim Menschen. Hoppe-Seyler Z Physial Chem 1940;264:153-89.

7. O'Toole BA, Fradkin R, Warkany J, Wilson JG, Mann V. Vitamin A deficiency and reproduction in Rhesus monkeys. J Nutr 1974;104:1513-23.

8. Sure B, Kirk MC, Walker DJ. The effect of Avitaminosis on hematopoietic finction. J Biol Chem 1929;83: 375-408.

9. McLaren DS, Tchalian M, Ajans ZA. Biochemical and hematological changes in the vitamin A-deficient rat. Am J Clin Nutr 1965;17:131-8.

10. Nockels $C F$, Kienholz $\mathrm{EW}$. Influence of Vitamin $\mathrm{A}$ deficiency on testes, bursa fabricius, adrenal and hematocrit in cockerels. J Nutr 1967;92:384-8.

11. Amine $\mathbb{E K}$, Corey J, Hegsted DM, Hayes $\mathrm{KC}$. Comparative hematology during deficiencies of iron and vitamin $A$ in the rat. J Nutr 1970;100:1033-40.

12. Corey JE, Hayes $\mathrm{KC}$. Cerebrospinal fluid pressure, growth and haematology in relation to retinol status of the rat in acute vitamin $A$ deficiency. J Nutr $1972 ; 102: 1585-94$.

13. Mohanram M, Kulkarni KA, Reddy V. Hematological studies in vitamin A-deficient children. Int J Vit Nutr Res 1977;47:389-93.

14. Mejia $L A$, Hodges RE, Arroyave $G$, Viteri F, Torun B. Vitamin A deficiency and anemia in Central American children. Am $『$ Clin Nutr 1977;30:1175-84.

15. Hodges RE, Sauberlich, HE, Canham JE, Wallace DL, Rucker B, Mejia LA, Mohanram M. Hematopoietic studies in vitamin A deficiency. Am J Clin Nutr $1978: 31: 876-85$.

16. Mejia LA, Hodges RE, Rucker RB. Clinical signs of anemia in vitamin A deficient rats. Am J Cllin Nutr 1979;32:1439-44.

17. Mejia LA, Hodges RE, Rucker RB. Role of vitamin A in absorption, retention and distribution of iron in the rat. J Nutr 1979; 109:129-37.

18. Mejia LA, Arroyave $\mathrm{G}$. The effect of vitamin A fortification of sugar on iron metabolism in preschool children in Guatemala. Am J Clin Nutr 1982;36:87-93.

19. Mejia LA, Arroyave G. Lack of direct association between serum transferrin and serum biochemical indicators of vitamin A nutriture. Acta Vitaminol Enzymol. 1983;5ns:179-84.

21. Dower D, Koeffler HP. Retinoic acid enhances growth of human early erytroid progenitor cells in vitro. I Clim Invest 1982;69:1039-41.

21. Mahant $\mathbb{L}$, Eaton HD. Effect of chronic hypovitaminosis A on water metabolism in the weanling rat. J Nutr 1976;106:1817-26.

22. Hodges RE, Kolder H. Experimental vitamin A deficiency in human volunteers. In: Summary of Proceedings, Workshop on Biochemical and Clinical Criteria for Determining Human Vitamin A Nutriture. Food and Nutrition Board, National Academy of Sciences, 28-29 January, 1971:10-6. 



\title{
Vitamin A deficiency in Northeast Thailand: A prevalence study of vitamin A deficiency and xerophthalmia.
}

\author{
Martin W. Bloem I,M.D., Michel Wedel ${ }^{2}, M . S c .$, Robbert J. Egger ${ }^{2}, M . S c .$, Andries J. \\ Speek 1,M.Sc., Kusuma Chusilp ${ }^{3}$,M.D., Sastri Saowakontha ${ }^{3}$, M.D.,Ph.D., \\ W.H.P.Schreurs 2 ,Ph.D.,D.SC.
}

\begin{abstract}
${ }^{1}$ TNO Division of Nutrition and Food Research, TNO-CIVO Toxicology and Nutrition Institute, Department of Clinical Biochemistry, Zeist, Netherlands

2 TNO Division of Nutrition and Food Research, TNO-CIVO Toxicology and Nutrition Institute, Department of Nutrition, Zeist, Netherlands

${ }_{3}$ Khon Kaen University, Faculty of Medicine/ Central Research Division,

Khon Kaen, Thailand
\end{abstract}

Abstract An epidemiologic survey of the prevalence of xerophthalmia and vitamin $A$ deficiency was conducted in May and June 1985 in a multistage random sample of 1,772 children, 1-8 of age from 16 rural villages and the capital city of the Sakon Nakhon province in Northeast Thailand. Data of clinical eye examinations were available for $92 \%$ $(\mathrm{n}=903)$ of the eligible children aged 1-5 years, history of night blindness was obtained from a reliable source for $93 \%(\mathrm{n}=1644)$ of the whole sample; ; and biochemical data were available for $60 \%(1060)$ of the children examined. The distribution of clinical signs of xerophthalmia and serum retinol levels differed between the rural and urban areas in the urban area, no signs of xerophthalmia or deficient serum retinol levels were found in the preschool children examined. The prevalence of night blindness in the rural area was $1.3 \%$ in children aged 1.5 years $(95 \%$ confidence interval $(\mathrm{CI})=0.7-1.9)$; Bitot's spots were seen in $0.4 \%(95 \% \mathrm{CI}=0.1-1.0) ; 12.7 \%(95 \% \mathrm{CI}=9.9-15.5)$ showed deficient serum retinol levels $(<0.35 \mu \mathrm{mol} / \mathrm{L})$. Of the children aged 1.8 years, $9.6 \%(95 \% \mathrm{Cl}=$ 7.8 - 11.4) showed deficient serum retinol levels. In the rural area, the prevalence of night blindness, Bitot's spots, and deficient serum retinol levels indicates a problem of public health importance according to of the World Health Organization criteria.

Key words Xerophthalmia; Vitamin A deficiency; child.

\section{Introduction}

Vitamin $A$ deficiency is considered one of the major nutritional problems in Thailand. This is especially true among preschool children residing in rural areas of the northeastern and northern regions $(1,2)$. Although the World Health Organization has given high priority to the elimination of vitamin A deficiency ${ }_{n}$ xerophthalmia, the clinical manifestation of lack of vitamin $A$, is still the leading cause of blindness in children in developing countries (3-6).

Thailland, one of the few nations of Southeast Asia that has never been a colony, is sandwiched between Burma to the west and Laos and Kampuchea to the east. In the south the country neighbors Malaysia. The population of about 50 million people lives in four geographically defined regions: Central, North, Northeast, and South. The country has an agriculture based economy; a full 80 per cent of the population is engaged in agriculture. Among the Association of South-East Asian Nations, Thailand is the largest net food exporter. The major food items produced, consumed and exported are rice, maize, 
legumes, sugar, chicken, fish, beef, pork, and fruits. Thailand imports dairy products, wheat flour, and some fruits (1).

The Northeast, a region called 'Issan', has been Thailand"s chronic problem area. The soil is thin and infertile, and there is either a deficit or a surplus of rainfall. Because of inadequate transportation facilities, few industries settled there.

Thailand has been classffied by the World Health Organization as a country where xerophthalmia and witamin $A$ deficiency are not public health problems, but where their prevalence should be closely monitored (5). Although countrywide ocular surveys have not been done, the World Health Organization based their classification on the following surveys: In 1962, the United States Interdepartmental Committee on Nutrition for National Defense survey reported 0.2 per cent Bitot's spots in a randomized sample in Thailand of 5000 persons of all ages (7). The mean serum retinol level of this sample was $23.7 \mu \mathrm{g} / \mathrm{dl}$. Clinical disease appears to be fairly widespread, although severe eye lesions were seldomly seen. A subsequent study, in the early $1970 \mathrm{~s}$ in Chiangmai indicated that vitamin $A$ deficiency was still common among children and showed a strong association with protein-energy malnutrition (PEM). Over 50 per cent of patients with severe PEM had xerophthalmia, and 10 per cent developed keratomalacia (8). In Bangkok, cases were not very common, but the vitamin A status was inadequate in children of low-income families (9). A survey in 1977, carried out in Ubon, a province in the Northeast, indicated that 17 per cent of 146 preschool children showed deficient serum retinol levels. As much as 70 per cent of the children studied had marginal serum vitamin $A$ levels $(10,11)$.

The present study reports the prevalence of xerophthalmia and vitamin A deficiency and their association with several factors related to nutrition and health in the Sakon Nakhon province in Northeast Thailand.

\section{Materials and methods}

This study was part of the Nutrition Supplement Cooperation Project performed by the TNO-CIVO Toxicology and Nutrition Institute and the University of Khon Kaen between March 1985 and July 1986 in the Sakon Nakhon province in Northeast Thailand. The aim of the project was to improve the nutritional health of 6250 preschool and school children with a nutritional supplement containing protein, vitamins, and minerals. This study was carried out at the baseline examination of the project.

A total of 16 rural villages were randomly selected for the study, and the urban area was represented by four districts in the city of Sakon Nakhon. The study population comprised 1,772 children, $1-8$ years of age. Children, aged $6-8$ years were selected as a random sample from 16 rural and 4 urban primary schools; children aged 3-5 years were all eligible children aged from the adjacent day-care centers; and children aged 1-2 years were selected from four villages randomly chosen from the 16 rural villages. We concentrated on children aged 1-5 years because of the World Health Organization criteria and because night blindness cannot be reliably assessed in a child under one year. Children attending primary school in a rural area come from the main village and some of the small villages in that region. Children who attend day-care centers come primarily from the main village.

Two teams consisting of a pediatrician, a project physician, two biochemists, two nutritionists, and six fieldworkers visited and examined the children. For the examination, children gathered in the Buddhist temple or local primary school, where their weight, height, left mid upper arm circumference, and triceps skinfold were recorded by the nutritionist and a fieldworker. Their general health status was assessed by the pediatrician. Blood was obtained by a biochemist and fieldworker. Only the eyes of children aged $1-5$ years were examined by the project physician, who used a handlight and magnifying lens. Standard diagnostic criteria for xerophthalmia were used (6).

The age distribution of the population surveyed was as follows: $12-23$ months (4.8 per cent); $24-35$ months (4.6 per cent); $36-47$ months (14.9 per cent); $48-59$ months (17.0 
per cent); $60-71$ months ( 14.2 per cent); $72-83$ months (21.6 per cent); and older than 83 months (23.0 per cent). A total of 1,772 children aged 1.8 years were included in the study. 1,420 children were selected from the 16 rural villages and 352 children lived in the urban area. The eyes of 903 (92 per cent) of the 982 eligible children aged $1-5$ years were examined. History of night blindness was obtained from a reliable source for 1,644 (93 per cent) of the eligible children aged $1-8$ years. Biochemical data were obtained from a random subsample of 1,060 (60 per cent) of both the rural and urban children examined.

Clinical, socioeconomic, dietary, and biochemical data were obtained between the begimning of May and mid-June. The socioeconomic status of the families of a subsample of 122 randomly selected children aged 3-8 years was assessed and was classified by combining information on the educational level, occupation, age, income, and landholding of the parents. The median annual income of urban families was more than three times higher than that of rural families (US $\$ 2,238$ /year vs. US $\$ 664 /$ year). The dietary survey, using a 24-hour recall method, was conducted in the same period by two nutritionists with 108 study children randomly selected from the study population.

Capillary blood was taken by puncture of the palmar surface of a fingertip. A total amount of $300 \mu l$ of blood could be collected in $75-\mu l$ capillaries treated with heparine. Plasma and cells were separated in a microhematocrit centrifuge. Plasma was collected in a $0.4-\mathrm{ml}$ sample vial and was stored in the dark at $-20^{\circ} \mathrm{C}$ for analysis within two months. The following biochemical analyses were carried out from a randomized subsample of 1,060 children from the 1,772 eligible children: all-trans retinol in plasma by high-performance Liquid chromatography (HPLC) according to Speek et al.(12); retinol-binding protein (RBP) in plasma by the single radial immunodiffusion technique according to Mancini et al (13); albumin in plasma according to the bromocresolgreen method of Doumas et al (14), with the Boehringer kit No 263869 (Boehringer Mannheim GmbH, Mannheim, FRG); prealbumin in plasma by the single radial immunodiffusion technique described by Mancini et al. (13), with the relevant specific antiserum of Behring (Behring Werke AG, Marburg, FRG); hemoglobin in whole blood of 1,698 children according to the cyanmethemoglobin method of Van Kampen et al. (15), with Boehringer kit No 124729 ; serum iron by flameless atomic absorption spectrometry with a Perkin Elmer type

\section{Table 1}

Prevalence of night blindness (XN), signs of wrinkling, dryness, and pigmentation $(X 1 A)$, and Bitot's spots (XIB) in sampled communities of Northeast Thailand by age and level of urbanization, May 1985.June 1985.

\begin{tabular}{|c|c|c|c|c|c|c|c|c|}
\hline \multirow[t]{2}{*}{$\begin{array}{l}\text { Age } \\
\text { (months) }\end{array}$} & \multicolumn{2}{|c|}{$\begin{array}{l}\text { Number of subjects } \\
\text { examined }\end{array}$} & \multicolumn{2}{|c|}{$\begin{array}{l}\text { XN } \\
\% \text { prevalence }\end{array}$} & \multicolumn{2}{|c|}{$\begin{array}{l}\text { X1A } \\
\text { \% prevalence }\end{array}$} & \multicolumn{2}{|c|}{$\begin{array}{l}\mathrm{X} 1 \mathrm{~B}^{\circ} \\
\text { of prevalence }\end{array}$} \\
\hline & rural & urban & nural & urban & maral & urban & nural & urban \\
\hline $12-23$ & 82 & & 1.2 & & 5.3 & & 0.0 & \\
\hline $24-35$ & 77 & & 2.6 & & 6.6 & & 0.0 & \\
\hline $36-47$ & 204 & 51 & 1.0 & 0.0 & 9.2 & 6.5 & 0.5 & 0.0 \\
\hline $48-59$ & 237 & 56 & 1.3 & 0.0 & 14.3 & 0.0 & 0.4 & 0.0 \\
\hline $60-71$ & 206 & 37 & 1.0 & 0.0 & 24.7 & 6.4 & 0.5 & 0.0 \\
\hline $72-83$ & 275 & 58 & 2.2 & 0.0 & & & & \\
\hline $84-95$ & 292 & 69 & 0.7 & 0.0 & & & & \\
\hline Trotal & 1373 & 271 & 1.3 & 0.0 & 16.2 & 3.9 & 0.4 & 0.0 \\
\hline
\end{tabular}

* Percentages of children X1A and X1B are based on a total number of 903 children. 
Table 2

Mean serum retinol levels and percentage of children with deficient $(<0.35 \mu \mathrm{mol} / \mathrm{L})$ and marginal $(\geq 0.35,<0.70$ umollL) serum retinol levels in the Sakon Nakhon province, according to age, sex and degree of urbanization, May 1985-June 1985.

\begin{tabular}{|c|c|c|c|c|c|c|c|c|c|}
\hline \multirow{3}{*}{$\begin{array}{l}\text { Age } \\
\text { (months) }\end{array}$} & \multirow{2}{*}{\multicolumn{2}{|c|}{$\begin{array}{l}\text { Number of } \\
\text { children }\end{array}$}} & \multicolumn{7}{|c|}{ Serum retinol level (umol/L) } \\
\hline & & & \multirow{2}{*}{$\begin{array}{l}\text { Mean (SD) } \\
\text { boys }\end{array}$} & \multirow{2}{*}{\multicolumn{2}{|c|}{$\begin{array}{l}\text { Mean (SD) } \\
\text { girls }\end{array}$}} & \multicolumn{2}{|c|}{ Deficient (\%) } & \multicolumn{2}{|c|}{ Márginal $(\%)$} \\
\hline & boys & girls & & & & boys & girls & boys & girls \\
\hline \multicolumn{10}{|l|}{ RURAL } \\
\hline $1.2-35$ & 65 & 62 & $0.52(0.22)$ & 0.54 & $(0.32)$ & 20.0 & 27.4 & 60.0 & 56.5 \\
\hline $36-71$ & 192 & 218 & $0.75(0.26)$ & 0.81 & $(0.33)$ & 12.0 & 6.9 & 31.8 & 32.6 \\
\hline $72-107$ & 153 & 162 & $0.74(0.25)$ & 0.79 & $(0.30)$ & 3.3 & 5.6 & 43.8 & 32.1 \\
\hline \multicolumn{10}{|l|}{ URBAN } \\
\hline 36.71 & 48 & 52 & $0.90(0.23)$ & 0.87 & $(0.22)$ & 0.0 & 0.0 & 20.8 & 23.1 \\
\hline $72-107$ & 54 & 54 & $0.73(0.22)$ & 0.78 & $(0.21)$ & 3.7 & 1.9 & 44.4 & 42.6 \\
\hline
\end{tabular}

430 AAS instrument equipped with HGA 500 atomizer (16); transferrin in plasma by the radial immunodiffusion technique mentioned previously.

All data were collected on precoded forms and were checked for accuracy and completeness before shipping to the TNO-CIVO Institute, where the information was processed with the BMDP statistical package and comprised mainly $t$ tests to detect differences in continuous variables between groups and $\chi^{2}$ tests to investigate the relation of categorical variables.

\section{Results}

Table 1 shows the results of the clinical eye examination. There was a difference in prevalence of signs of xerophthalmia between the urban and rural areas. Night blindness was found in 1.3 per cent (95 per cent confidence interval $(\mathrm{CI})=0.7-1.9$ ) of the rural population, but was not found in children from the urban area. The eyes of 0.4 per cent (95 per cent $\mathrm{Cl}=0,1-1.0$ ) of the rural population had Bitot's spots. Dryness, loss of transparency, thickening, wrinkling, and pigmentation of the conjunctiva were commonly present in 16.2 per cent (95 per cent $\mathrm{Cl}=13.7-18.7$ ) of children from the rural area, where prevalence increased with age, but not in the urban children ( 3.9 per cent $(95$ per cent $\mathrm{Cl}=0.7-7.1)$ ), where the distribution over younger and older subjects was almost equal.

The results of measuring the vitamin A status by determination of serum retinol levels are presented in table 2 for 1,060 children. The mean and standard deviation as well as the percentage of children classified as deficient (serum retinol level $<0.35 \mu \mathrm{mol} / \mathrm{liter}$ ) or marginal (serum retinol level $\geq 0.35,<0.70 \mu \mathrm{mol} / \mathrm{iter}$ ) are presented according to age, sex, and rural or urban status. In the rural area, 12.7 per cent ( 95 per cent $\mathrm{CI}=9.9-15.5$ ) of the preschool children ( $n=537$ ) showed deficient serum retinol levels. In the age group 3-5 years $(n=410), 9.3$ per cent (95 per cent $\mathrm{CI}=6.5-12.1$ ) showed deficient serum retinol levels, while among the urban preschool children $(n=100)$, no deficient serum retinol levels were found. Of the urban school children examined $(n=108), 2.8$ per cent (95 per cent $\mathrm{Cl}=0.0-5.9$ ) had serum retinol levels less than $0.35 \mu \mathrm{mol} / \mathrm{liter}$. Male and female children aged 3-5 years in the rural area had significantly lower levels $(p<0.001$ and $\mathrm{p}<0.05$, respectively) than children of that age group from the urban area. In the rural area, senum retinol levels were significantly lower $(\mathrm{p}<0.05)$ in male children than in fe- 
male children in the age group 3-5 years. In the other age groups, no significant differ ences were found for rual or urban status or for sex. The percentages of marginal serum retinol levels were much higher for both rural and urban children than the percentages of deficient levels but showed similar differences for rural and urban status for sex.

Table 3.

Anthropometric and biochemical data in children with and without night blindness (XN) of sampled communities of Northeast Thailand, May 1985-June 1985.

\begin{tabular}{|c|c|c|c|c|c|c|}
\hline \multirow[t]{2}{*}{ Variable } & \multicolumn{3}{|c|}{ Night blindness } & \multicolumn{3}{|c|}{ Without night blindness } \\
\hline & $\begin{array}{l}\text { Number of } \\
\text { children }\end{array}$ & Mean & (SD) & $\begin{array}{l}\text { Number of } \\
\text { children }\end{array}$ & Mean & $(\mathrm{SD})$ \\
\hline Age (years) & 18 & 5.2 & $(2.0)$ & 1626 & 5.3 & $(1.8)$ \\
\hline Height (cm) & 18 & 98.7 & (13.1) & 1613 & 101.8 & $(11.4)$ \\
\hline Weight (kg) & 18 & 14.3 & $(3.5)$ & 1615 & 15.0 & (3.3) \\
\hline Muac $(\mathrm{cm})$ & 18 & 15.2 & $(1.0)$ & 1612 & 15.2 & $(1.2)$ \\
\hline Retinol $(\mu \mathrm{mol} / \mathrm{L})$ & 10 & $0.57^{*}$ & $(0.23)$ & 997 & 0.74 & $(0.29)$ \\
\hline $\operatorname{RBP}(\mathrm{mg} / \mathrm{L})$ & 11 & 25.0 & $(7.8)$ & 968 & 27.4 & $(8.8)$ \\
\hline Albumin $(g / L)$ & 10 & 41.1 & $(2.8)$ & 940 & 41.6 & $(5.0)$ \\
\hline Prealbumin (mg/L) & 11 & 205.0 & $(89.6)$ & 948 & 201.1 & $(60.8)$ \\
\hline Ln transferrin $(\mathrm{g} / \mathrm{L})$ & 11 & 1.1 & $(0.2)$ & 953 & 1.0 & $(0.3)$ \\
\hline Fe-serum $(\mu \mathrm{mol} / \mathrm{L})$ & 9 & $9.7^{* *}$ & (3.6) & 889 & 13.8 & $(6.3)$ \\
\hline
\end{tabular}

* $\mathrm{P}<0.05,{ }^{* *} \mathrm{P}<0.01, \mathrm{Ln}=$ naturall log-transformed values.

There were significant differences in serum retinol levels $(0.17 \mu \mathrm{mol} / \mathrm{L}, p<0.05)$ and serum iron $(4.1 \mu \mathrm{mol} / \mathrm{L}, \mathrm{p}<0.01)$ between children with and those without night blindness (table 3 ). When only the rural children were used for analysis, the differences in mean serum retinol and serum iron was respectively $0.16 \mu$ mol/L $(p<0.1)$ and 3.4 $\mu \mathrm{mol} / \mathrm{L}(\mathrm{P}<0.05)$. Serum albumin, transferrin, prealbumin and $\mathrm{RBP}$ levels did not differ significantly between children with and those without night blindness. In cases with signs of conjunctival xerosis, a significant difference of $1.4 \mu$ mol/liter of serum iron $(p<0.05)$ was observed. No other significant differences in biochemical variables were measured between children with and those without signs of conjunctival xerosis (data not shown).

Figure 1 presents the state of nutrition related to the prevalence of conjunctival xerosis, night blindness, and classified serum retinol levels. There were no significant differences between clinical or biochemical evidence of vitamin A deficiency and protein energy malnutrition as classified by anthropometric status, assessed by the standard devianion score of the World Health Organization (17). 
Figure 1

Nutritional status, assessed by the SD-score of WHO and vitamin A status in 1060 children, aged 1-8 years in Northeast Thailand, May 1985-June 1985.

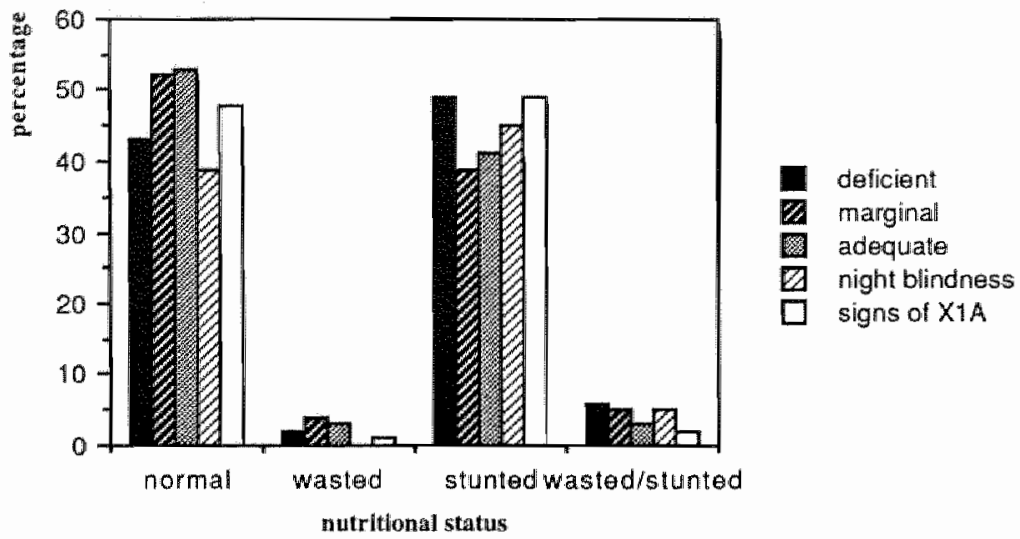

Table 4.

Fat and vitamin A intake of a sample of 108 children from Northeast Thailand according to degree of urbanization, and age, May 1985-June 1985.*

\begin{tabular}{|c|c|c|c|c|}
\hline \multirow[t]{2}{*}{ Age (years) } & \multicolumn{2}{|c|}{ Fat, mean $(S D)$} & \multicolumn{2}{|c|}{ Vitamin A, mean (SD) } \\
\hline & $\mathrm{g} / \mathrm{day}$ & $\%$ energy & $\mathrm{IIJ} /$ day & $\mathscr{R D A}$ \\
\hline \multicolumn{5}{|l|}{ Urban } \\
\hline $\begin{array}{l}3 \times 5(n=20) \\
6 \times 8(n=23)\end{array}$ & $\begin{array}{l}36.1(13.3) \\
33.2(21.3)\end{array}$ & $\begin{array}{l}32.5(8.2) \\
25.1(12.6)\end{array}$ & $\begin{array}{l}852(674) \\
765(489)\end{array}$ & $\begin{array}{l}88 \% \\
66 \%\end{array}$ \\
\hline \multicolumn{5}{|l|}{ Rural } \\
\hline $\begin{array}{l}3-5(n=29) \\
6-8(n=36)\end{array}$ & $\begin{array}{l}13.7(9.1) \\
14.2(11.9)\end{array}$ & $\begin{array}{l}13.1(8.3) \\
12.7(9.7)\end{array}$ & $\begin{array}{l}548(413) \\
492(483)\end{array}$ & $\begin{array}{l}57 \% \\
42 \%\end{array}$ \\
\hline
\end{tabular}

* In tho statistical analysos values were log-transformed because of skewed distributions. Urban and rural values in the 3-5 years group differed significantly $(\mathrm{P}<0.01)$. \#recommended daily allowances $=$ recom mended daily allowances (WHO).

Mean daily intake of fat and the percentage of the contribution of fat to energy intake were lower among rural children than among urban children ( $<<0.01$ ) (table 4). With the exception of rural children 6-8 years, mean daily protein intake was adequate (data not shown). Daily consumption of vitamin A, both in the urban and rural areas, was below the recommended daily allowances. Furthermore, the intake of vitamin $A$ in the urban area was significantly $(\mathrm{p}<0.01)$ higher than in the rural area.

Figure 2 shows socioeconomic status, defined as low, intermediate, and high in relation to the classification of serum retinol levels. In the rural area, all cases with deficient serum retinol levels were from parents of low socioeconomic status. All rural children 
from families with a high social status showed adequate levels. The situation in the urban area was different: All cases with deficient serum retinol levels belonged to the intermediate class. Children of families of low socioeconomic status hat either marginal or adequate levels of vitamin A. Marginal serum retinol levels were prevalent among 18.2 per cent of the children of the high socioeconomic class.

\section{Discussion}

The distribution of clinical signs of xerophthalmia and of serum retinol levels differs markedly between the rural and urban areas in the Sakon Nakhon province in Northeast Thailand. No relevant signs of xerophthalmia were observed in the urban area but the sample was small. Although the mean serum retinol level of the urban children is low compared with the levels in Western countries, only 2 per cent of the urban children aged 6-8 years had deficient serum retinol levels, while none of those aged 3-5 years had deficient levels. In the urban preschool children, mean serum retinol levels were significantly higher than in the children from the rural area. It may be concluded that xerophthalmia is not a major nutritional disease in the urban area of the Sakon Nakhon province, but that the urban school children should be monitored for this disease.

Figure 2

Socioeconomic level and vitamin A status of 122 children, aged $3-8$ years in Northeast Thailand, May 1985-June 1985.

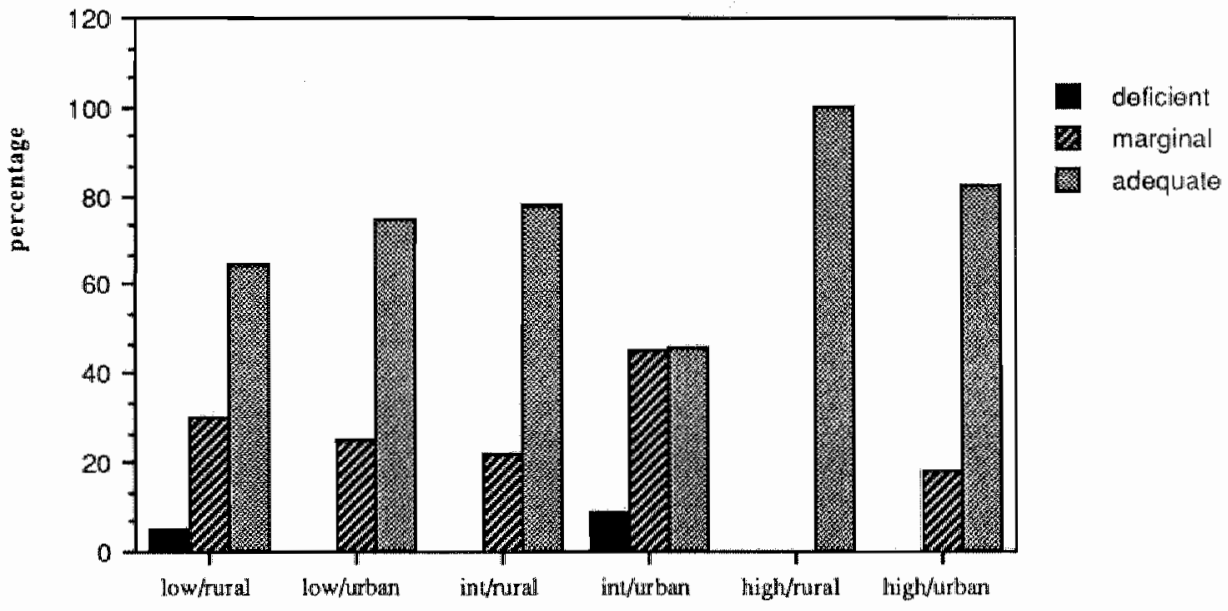

socheconomic status

"The situation in the rural area, however, is far less reassuring. Prevalence was 1.2 times and 0.8 times the World Health Organization criteria for night blindness and Bitot's spots, respectively. Severe forms of xerophthalmia were not observed, although the prewalence of deficient serum retinol levels was 2.2 times the World Health Organization criteria. These data suggest that vitamin A deficiency is a problem of public health significance in the rural area of the Sakon Nakhon province. Moreover, 82.5 per cent of the ru* 
ral study population comprised children in day-care centers and primary schools. Educiafion in Thailand is compulsory, but it is possible that some of the poorest children in the hinterland of the main village do not, or less frequently, attend day-care centers; this may be so, but to a lesser extent, for primary school children. This may have resulted in an underestimation of prevalence of vitamin A deficiency among school children, particularly preschool children.

We found a close association between history of night blindness and vitamin A status, which confirms data from Indonesia $(18,19)$. Therefore we stress that history of night blindness in Northeast Thailand is an important tool for vitamin A deficiency/ xerophthalmia screening.

Minor abnormalities of the conjunctiva such as dryness, unwettability, loss of transparency, thickening, wrinkling, and pigmentation are not recommended as criteria for conmunity diagnosis (4). We found a lack of association between serum retimol levels and these signs and thus confirm that they are no good criteria for vitamin A deficiency.

An interesting observation was that children with night blindness or signs of conjunctival xerosis had significant lower serum iron levels. We have investigated the apparent association between vitamin A status and iron in further detail (20).

There was no association between protein energy malnutrition and vitamin $A$ status, suggesting that vitamin A deficiency in Northeast Thailand is due to a lack of vitamin A and is not secondary to protein malnourishment.

There are few data available on the correlation between dietary intake and vitamin $\mathrm{A}$ status $(21,22)$. The results of the statistical analysis of food consumption data agree with the clinical and biochemical observations mentioned previously. In the urban area, children aged $6-8$ years have a lower vitamin $A$ intake than children in day-care centers. There is a significant difference in both fat and vitamin $A$ intake between the urban and rural children, which explains the difference in vitamin A status between children in the two areas. It has long been established that the level of dietary fat is important in facilitating absorption of carotenoids (23). At least 65 per cent of the vitamin A activity of the diets originates from carotenoids. Studies conducted in developing countries, where dietary fat usually represents a low percentage of the total energy intake, demonstrated significantly increased absorption of dietary carotenoids when a small supplement of fat was given $(24,25)$. However on an individual level Reddy et al. indicated that only a minimal amount of fat is needed for the intestinal utilization of dietary vitamin A (26).

Another plausible explanation of the difference in prevalence of vitamin A deficiency between the urban and rural areas might be socioeconomic differences. In the rural area, there is evidently a positive relation between socioeconomic status and the serum vitamin A level. Interestingly, in the urban area, all children with deficient serum vitamin $A$ levels were found to be from families of the intermediate socioeconomic group. This may be because in the intermediate class, where socioeconomic status is based mainly on the parents' total income, many mothers are working outside the home. Solon et al. (27) have made similar observations in Cebu in the Philippines and suggested that the presence of the mother at mealtime is important for stimulating young children to consume vitamin $A$ rich vegetables.

\section{Conclusions}

1) Xerophthalmia/vitamin A deficiency seems to be a public health problem in the rural area of the Sakon Nakhon province in Northeast Thailand according to World Health Organization criteria;

2) In the urban area, xerophthalmia/vitamin A deficiency does not seem to be a public health problem, although school children should be monitored for this disease;

3) History of night blindness is an important tool for screening xerophthalmia;

4) Health education should promote the intake of vitamin A, especially B-carotene rich vegetables and, to a lesser extent, of fat in the rural area; 
5) In the rural area, children from the low socioeconomic class are more susceptible to xerophthalmia than children from a the high socioeconomic class.

\section{Acknowledgments}

The current investigation was carried out within the scope of the bilateral Thai-Netherlands Nutrition/Health Development Program in Northeast Thailand with financial support of the Dutch Government and under the name "Nutrition Supplement Cooperation Project". The authors thank Dr. J Schrijver, Professor RJJ Hermus, TNO-CIVO Toxicology and Nutrition Institute, Zeist, and Professor HA Valkenburg, Erasmus University, Rotterdam for their assistance.

\section{References}

1. Food and Nutrition Policy. In: The Fifth National Economics and Social Developm ment Plans 1982-1987, Bangkok: NESDB, 1981.

2. Tontisirin K, Winichagoon $P$. Malnutrition as a social indicator: nutrition problems in Thailand. Faculty of Medicine, Ramathibodi Hospital \& Institute of Nutrition, Mahidol University, Bangkok: 1984.

3. World Health Organization, Control of vitamin A deficiency, xerophthalmia. Geneva: WHO, Technical Report Series no. 672, 1982.

4. Sommer A. Field guide to the detection and control of xerophthalmia. Geneva: WHO, 1982.

5. World Health Organization, Prevention and control of vitamin A deficiency, xerophthalmia and nutritional blindness: summary of a proposal for a ten-years programme of support to countries. Geneva: WHO, 1985.

6. Sommer A. Nutritional Blindness: xerophthalmia and keratomalacia. New York: Oxford University Press, 1982.

7. Interdepartmental Committee on Nutrition for National Defense. Reports for nutri* tion surveys, The Kingdom of Thailand. Oct-Dec.,1960. Washington, DC: Department of Defense, 1962.

8. Smith FR, Suskind R, Thanangkul O, Leitzmann C, Goodman DS, Olson RE. Plasma vitamin $A$, retinol-binding protein and prealbumin concentration in protein and calorie malnutrition. III. Response to varying dietary treatments. Am J Clin Nutr 1975;28:732-8.

9. Suthutvoravoot $\mathrm{S}$, Olson J A. Plasma and liver concentrations of vitamin $A$ in a nor mal population of urban Thai. Am J Clin Nutr 1974:27:883-91.

10. Dhanamitta S, Stoecker B, Valyasevi A. community approaches to prevention of vi. tamin A deficiency. Paper presented at the IV ACG Meeting, Jakarta, Indonesia, 11. 13 October, 1980.

11. Charoenkiatkul S, Valyasevi A, Tontisirin K. Dietary approaches to the prevention of vitamin A deficiency. Food Nutr Bull 1983;7:72-6.

12. Speek AJ, Wongkam, Limratana N, Saowakontha, Schreurs WHP. Microdetermination of vitamin $A$ in human plasma using high-performance liquid chromatography with fluorescence detection. J Chromatogr Biomed Appl 1986;382:284-9.

13. Mancini $\mathrm{G}$, Carbonara $\mathrm{AD}$, Heremans $J \mathrm{~F}$. Immunochemical quantitation of antigens by single radial immunodiffusion. Immunochemistry, Pergamon Press, 1965:23554.

14. Doumas BT, Watson W, Biggs HG. Albumin standards and the measurement of serum albumin with bromcresol green. Clin Chim Acta 1971;31:87-96.

15. VanKampen EJ, Zijlstra WG. Standardization of hemoglobinometry II. The hemiglobincyanide method. Clin Chim Acta 1961;6:538-44. 
16. Zettner $A$, Mensch $A H$. The use of atomic absorption spectroscopy in hemoglobinometry. I. The determination of iron in hemoglobin. Am I Clin Pathol $1967 ; 48: 225 \cdot 8$.

17. World Health Organization. Measuring Change in Nutritional Status. Geneva: WHO, 1983.

18. Sommer A, Hussaini G, Muhilal I, et al. History of nightblindness, a simple tool for xerophthalmia screening. Am J Clin Nutr 1980;33:887-91.

19. Gupta MC, Tandon BN. Nightblindness as a tool for xerophthalmia screening. Am J Clin Nutr 1981:34:1985.

20. Bloem MW, Wedel M, Egger $R$, et al. Iron metabolism and vitamin A deficiency in Northeast Thailand. Am J Clin Nutr (in press).

21. Tarwotjo I, Sommer A, Soegiharto T, et al. Dietary practices and xerophthalmia among Indonesian children. Am J Clin Nutr 1982;35:574-81.

22. West KP, Chirambo M, Katz J et al. Breast-feeding, weaning patterns, and the risk of xerophthalmia in southern Malawi. Am J Clin Nutr 1986;44:690-7.

23. FAO/WHO Requirements of vitamin $\mathrm{A}$, thiamine, riboflavine and niacin. Report of a Joint FAO/WHO Expert Group. Geneva: WHO, Technical Report Series no. 362 , 1967.

24. Roels OA, Trout M, Dujacquier R. Carotene balances on boys in Ruanda where vitamin A deficiency is prevalent. J Nutr 1958;65:115-27.

25. Roels OA, Djaeni $S$, Trout ME, et al. The effect of protein and fat supplements on vitamin A-deficient Indonesian children. Am J Clin Nutr 1963;12:380-7.

26. Reddy V, Sivakumar D. Studies on vitamin A absorption. Indian J Pediatr 1972;9:307-10.

27. Solon FS, Popkin BM, Fernandez TL, Latham MC. Vitamin A deficiency in the Philippines: a study of xerophthalmia in Cebu. Am J Clin Nutr 1978*31:360-8. 


\title{
Iron metabolism and vitamin A deficiency in children in Northeast Thailland
}

\author{
Martin W. Bloem I, M.D., Michel Wedel ${ }^{2}$, M.Sc., Robbert J.Egger , M.Sc., Andries J. \\ Speek, M.Sc., Jaap SchrijuerI, Ph.D., Sastri Saowakontha 3 ,3M.D., and \\ Wil H.P.Schreurs, Ph.D.,D.SC.
}

${ }^{1}$ TNO Division of Nutrition and Food Research, TNO-CIVO Toxicology and Nutrition Institute, Department of Clinical Biochemistry, Zeist, Netherlands

2TNO Division of Nutrition and Food Research, TNO-CIVO Toxicology and Nutrition Institute, Department of Nutrition, Zeist, Netherlands

${ }^{3}$ Khon Kaen University, Faculty of Medicine/Central Research Division, Khon Kaen, Thailand

\begin{abstract}
To investigate the association between vitamin $A$ and iron metabolism two studies were carried out: a cross-sectional study and an intervention trial. The cross-sectional analyses was carried out among 1060 children, aged 1-8 years. Levels of hematocrit, serum iron, ferritin, and saturation of transferrin correlated significantly with both retinol and retinol-binding protein (RBP). Only RBP showed a significant positive correlation with hemoglobin. Both retinol and RBP showed a significant negative correlation with transferrin. Multiple regression analysis was used to adjust for effects of age, sex, parameters of the protein nutritional status, and infections. Retinol remained significantly associated with hematocrit $(b=0.88, p<0.05)$, serum iron $(b=3.417, p<0.001)$, transferrin $(b=-0.123, p<0.01)$, ferritin $(b=0.387, p<0.001)$, and saturation of transferrin (\%ST) $(b=0.548, p<001)$. In all models RBP was significantly associated with the parameters of the iron status.

To obtain further evidence as to whether this observed association is a causal one, an intervention trial was carried out. After collection of the baseline data of 300 children, 166 children with a hemoglobin level $<7.5 \mathrm{mmol} / \mathrm{L}$ were selected. A random subsample of 78 children received capsules by oral route containing $200000 \mathrm{IU}$ vitamin $\mathrm{A}$; the other children served as controls. Although seasonal influences diminished the impact of the intervention considerably, two months after supplementation significant differences adjusted for age, were found for retinol, RBP, serum iron and saturation of transferrin between the supplemented and the control group. After four months none of the parameters were found to be significantly different between the supplemented and the control group.

In an area like Northeast Thailand, where severe forms of xerophthalmia are rarely seen but biochemical vitamin A deficiency is highly endemic, this relationship may well be important; Periodic massive dose programs of vitamin A may play a role in improving the iron status as well.
\end{abstract}

Keywords Vitamin A, iron, Vitamin A supplementation, intervention, Northeast Thailand.

\section{Introduction}

Vitamin $\mathrm{A}$ and its derivatives are important not only for normal functioning of the eye but also for normal differentiation of several tissues. Since the study of Findlay and Mackenzie in 1922, several reports have suggested an interrelation between vitamin $A$ and iron metabolism. These early studies have demonstrated a reduction of hematopoietic cells in the bone marrow and also have evidenced hemosiderosis in the liver and spleen in vitamin $\mathrm{A}$-deficient subjects(1-4). Further studies have reported anemia in man and animal deprived of vitamin $A(5,6)$. These studies have been contradicted by other reports, which observed polycythemia instead of anemia $(7,8)$. Subsequent studies have shown that alterations in the water balance due to severe vitamin A deficiency lead to dehydration 
which may mask anemiat (8). An array of epidemiologic studies indicated that vitamin $A$ deficiency and anemia often coexist, and that there are significant associations between serum retinol and biochemical indicators of the iron status (9-12). This association may have a great potential impact.

In Northeast Thailand, preschool children have been reported to consume about one third of the Recommendied Daily Allowances of vitamin A (13). The prevalence of anemia in rural Northeast Thailand is $40 \%$ on the awerage (13). A recent prevalence study in Northeast Thailand showed that $12.6 \%$ of the preschool children in the rural areas had deficient and $50 \%$ had marginal serum retinol levels (14). Strikingly, children with night blindness as well as children with conjunctival xerosis had significantly lower levels of serum iron than normal subjects. Differences in the parameters of the protein status were not significant (14). This observation prompted us to investigate the association between vitamin $A$ and iron metabolism.

\section{Materials and methods}

\section{Study population}

The study was part of the Nutrition Supplement Co-operation project (NSC project) of TNO CIVO Toxicology and Nutrition Institute, Zeist, Netherlands and the University of Khon Kaen, Thailand between March 1985 and July 1986 in the Sakorn Nakhon province in Northeast Thailand. The aim of the project was to improve the nutritional health of 6250 children, aged $1-8$ years, with a nutritional supplement containing protein, vitamins, and minerals. Within the framework of the NSC project several satellite studies have been carried out, two of which are subject of this paper.

Cross-sectional study. The baseline data from these studies were used. The study population comprised 1772 children, aged 1.8 years; 1420 children were selected from 16 rural villages and 352 children from the urban area. Hemoglobin and hematocrit data were available from 1698 children ( $96 \%$ of total). Of a random subsample of 1060 children (60\%) other biochemical parameters were determined. A complete set of biochemical data was available on 863 children ( $49 \%$ of the original sample).

Intervention trial. A controlled intervention trial was carried out in the northern part of the Sakorn Nakhon province. From four villages 300 children aged $1-5$ years were randomly selected for the study. Hemoglobin and hematocrit were determined and a subsample $(n=166)$ of all eligible children with a hemoglobin level $<7.5 \mathrm{mmol} / \mathrm{L}$ were selected for the interwention study. The day after the baseline examination $(T=0)$ standard capsules were given to a random selection of 78 children; the other children from the subsample served as controls. The capsule nipple was snipped off and the contents $(200000$ $I U$ vitamin $A$ and 40 IU vitamin $E$ ) were squeezed out into the child's mouth. After two $(\mathrm{T}=2)$ and four $(\mathrm{T}=4)$ months children were reexamined by the same procedure.

\section{Methods}

Two teams consisting of a pediatrician, a project physician, two biochemists, two nutritionists, and six field-workers visited and examined children aged 1.5 years. For each examination, children were gathered in the local Buddhist temple or primary school, where their weight, height, and mid-upper arm circumference (muac) were recorded by the nutritionist and a field-worker. Standard deviation scores (Z-scores) for weight for height (ZWH) and height for age (ZHA) were calculated according to the guidelines of the World Health Organization (WHO) (15-17). The children were classified as normal $(\mathrm{ZWH}>-2.00$ and $\mathrm{ZHA}>-2.00)$, wasted $(\mathrm{ZWH}<-2.00$ and $\mathrm{ZHA}>-2.00)$, stunted $(\mathrm{ZWH}>-2.00$ and $\mathrm{ZHA}<2.00$ ), or wasted and stunted $(\mathrm{ZWH}<2.00$ and $\mathrm{ZHA}<2.00$ ). The pediatrician - who knew both the local disease pattern and vernacular symptom descriptions, and spoke the local tongue - performed the general clinical examination and 
used questionnaires to obtain information about history of respiratory disease and diarrhea.

Respiratory diseases were defined by history of clinically significant respiratory complaints, only accompanied by fever, such as respiratory difficulties, cough, runining nose, during the interval ( 2 or 3 months) between the examinations. Diarthea was defined as a history of four or more loose stools per day at any time during the interval 2 or 3 months) between the examinations.

Blood was taken by a biochemist and a field-worker, and eyes were examined by the project physician with a hand-light and a magnifying lens. For xerophthalmia, standard diagnostic criteria were used (18).

\section{Biochemical analyses}

Capillary blood was taken by puncture of the palmar surface of a fingertip. A total amount of $300 \mu \mathrm{l}$ of blood was collected in heparinized $75-\mu$ l capillaries. Plasma and cells were then separated in a microhematocrit centrifuge. Plasma was collected in at 0.4-ml sample wial and stored in the dark at $-20^{\circ} \mathrm{C}$ for analysis within two months. The following biochemical analyses were carried out: all-trans retinol in plasma by high-performance liquid chromatography (HPLC) according to Speek et al. (19); retinol-binding protein $(\mathrm{RBP})$ in plasma by the single radial immunodiffusion technique according to Mancini et al. (20); albumin in plasma according to the bromcresol green method of Doumas et al.(21), with Boehringer kit No 263869 (Boehringer Mannheim GmbH, Mannheim, FRG); prealbumin in plasma by the single radial immunodiffusion technique described by Mancini et al. (20), with the relevant specific antiserum of Behring (Behring Werke $A G$, Marburg, FRG); hemoglobin in whole blood of 1698 children according to the cyanmethemoglobin method of van Kampen et al. (22) with Boehringer kit No 124729 ; serum iron by flameless atomic absorption spectrometry with a Perkin Elmer type 430 AAS instrument equipped with a HGA 500 atomizer (23); transferrin in plasma by the radial immunodiffusion technique mentioned previously; ferritin in plasma by immunoradiometric assay according to Addison et al. (24).

\section{Statistical analysis}

All data were collected on pre-coded forms, and checked at least twice for accuracy and completeness before shipping to the data management facility at the CIVO-TNO Institutes, where the data were analyzed with the BMDP and GENSTAT statistical packages $(25,26)$.

Cross-sectional study. The statistical analyses comprised simple correlations between biochemical indicators of the vitamin $A$ and the iron status respectively. Since the distribution of transferrin, ferritin, and transferrin saturation was skewed, natural log transformed (Ln) values for these biochemical variables were used. A complete set of biochemical data from 863 children remained for analyses. Age, sex, protein status and morbidity possibly influence the association between vitamin $A$ and anemia. To adjust for the effect of these variables multiple regression analyses were carried out with the different iron parameters as dependent variables and the factors mentioned above and as well as retinol or RBP as independent variables. Dummy variables were used to represent Sex $(1=$ boys; 2 =girls $)$ and morbidity $(1=y e s ; 2=$ no $)$ in the models.

Intervention trial. Statistical analyses comprised two separate analyses of variance of the measurements at $\mathrm{T}=0, \mathrm{~T}=2$ and $\mathrm{T}=0, \mathrm{~T}=4$ respectively, to examine the effects of treatment. In the analysis the differences in intra and inter individual variation was accounted for; the effects were adjusted for age, included into the analysis as a co-variable. Means and standard errors of differences given in the results are age-adjusted. Pooled standard errors of the differences of the measurements at 2 and 4 months with those at $T=0$ for the control and supplemented group are presented (table 4). After follow-up varying numbers of children in the supplemented and control groups had to be excluded from further analyses due to failure of follow-up (drop-outs), blood collection, or bio- 
chemical determinations. The biochemical parameters of the drop-outs did not differ significantly from subjects included in the study, except for the red blood cell count and, consequently, for mean corpuscular wolume (MCV) and mean corpuscular hemoglobin $(\mathrm{MCH})$. These differences were $0.4 \times 10^{12} / \mathrm{L}, 7 \mathrm{~L}$, and 0.2 fmol respectively.

Table 1.

Biochemical and anthropometric indicators of the iron and vitamin A status of children aged 1-8 years by sex.

\begin{tabular}{|c|c|c|c|c|c|c|}
\hline \multirow[t]{2}{*}{ Paramelers } & \multicolumn{3}{|l|}{ Boys } & \multicolumn{3}{|l|}{ Girls } \\
\hline & Number & Mean & SD & Number & Mean & SD \\
\hline \multicolumn{7}{|l|}{ Biochemical } \\
\hline Retinal (umol/h) & 512 & $0.72^{* *}$ & $(0.26)$ & 548 & 0.76 & $(0.30)$ \\
\hline $\operatorname{RBP}(\mathrm{mg} / \mathrm{L})$ & 497 & $26.7^{*}$ & $(7.7)$ & 535 & 27.9 & $(9.5)$ \\
\hline $\mathrm{Hb}$ (mmol/L) & 839 & 7.0 & $(0.96)$ & 859 & 7.0 & $(0.95)$ \\
\hline $\mathrm{Ht}(\%)$ & 832 & 36.7 & $(2.8)$ & 859 & 36.7 & $(2.8)$ \\
\hline Se Fe $(\mu$ mol/L) & 462 & 14.0 & $(0.5)$ & 497 & 14.0 & $(6.5)$ \\
\hline Transferrin $(\mathrm{g} / \mathrm{L})$ & 486 & 3.1 & $(1.5)$ & 532 & 3.0 & (2.1) \\
\hline$\%$ ST & 463 & 22.8 & $(14.6)$ & 502 & 23.8 & (13.4) \\
\hline Perritin $(\mu \mathrm{g} / \mathrm{L})$ & 454 & $34.7^{*}$ & $(24.3)$ & 510 & 41.7 & $(32.0)$ \\
\hline Prealbumin (mg/L) & 484 & 201.1 & $(63.1)$ & 528 & 203.8 & $(60.5)$ \\
\hline Albumin $(g / L)$ & 493 & 41.6 & $(4.3)$ & 514 & 41.6 & $(5.6)$ \\
\hline Anthropometric & & 9 & & & $\%$ & \\
\hline Normal & 430 & 49.9 & & 510 & 57.4 & \\
\hline Wastod & 28 & 3.3 & & 28 & 3.1 & \\
\hline Sunted & 373 & 43.3 & & 313 & 35.2 & \\
\hline Wasted \& stunted & 30 & 3.5 & & 38 & 4.3 & \\
\hline
\end{tabular}

"p<0.0.5," $p<0.01$

\section{Results}

Cross-sectional study Table 1 shows the biochemical indicators (mean and standard deviation) of the iron and vitamin $A$ status and the nutritional characteristics by sex. Table 2 shows the correlations between the iron and vitamin A status parameters. The levels of hematocrit, serum iron, ferritin, and saturation of transferrin were found to correlate weakly but significantly with both retinol and RBP levels. "There was a significant positive correlation between hemoglobin and RBP. Transferrin showed significant negative correlations with both retinol and RBP.

Table 3 presents the results of the multiple regression analyses of the models, in* cluding retinol. The results of the models, including RBP, in stead of retinol were similar and are not tabulated. There is a significant positive association of retinol with hematocrit, serum iron, ferritin and saturation of transferrin (\%ST), when adjusted for the associations of those variables with age, sex, albumin, and prealbumin. A difference of $1 \mu \mathrm{mol} / \mathrm{L}$ in retinol between children was associated with a $0.88 \%$ difference in hematocrit and a $3.42 \mu \mathrm{mol} / \mathrm{L}$ difference in serum iron, when adjusted for differences in age, sex, albumin, prealbumin and morbidity data. Adjusted for the same confounders, higher levels of retinol were associated with lower levels of transferrin, higher levels of ferritin and a higher $\%$ ST $(0.88$ times lower, 1.47 times higher and 1.73 times higher respectively for every $\mu$ mol/L increase in retinol). Similarly, a difference of $1 \mathrm{mg} / \mathrm{L}$ RBP was associated 
with a $0.018 \mathrm{mmol} / \mathrm{L}$ difference in hemoglobin, a $0.06 \%$ difference in hematocrit and a $0.102 \mu \mathrm{mol} / \mathrm{L}$ difference in serum iron. Higher levels of RBP are accompanied by higher levels of ferritin (1.02 times higher for every $\mathrm{mg} / \mathrm{L}$ increase in RBP), \% ST (1.02 times higher for every $\mathrm{mg} / \mathrm{L}$ increase in $\mathrm{RBP}$ ), and transferrin (1.01 times lower for every $\mathrm{mg} / \mathrm{L}$. increase in RBP). Age had a significant positive association with hematocrit, serum iron, ferritin and \%ST, and a significant negative association with transferrin. Albumin was significantly positively related to hemoglobin and hematocrit, and prealbumin with hemoglobin and transferrin. Prealbumin had a significant negative association with serum iron, ferritin and \%ST. The percentage of variaace explained was, however, rather small (from 5 to $12.6 \%$ ) in all models.

\section{Table 2}

Correlation coefficients between biochemical indicators of vitamin A status and indicators of iron status.

\begin{tabular}{|c|c|c|c|c|}
\hline & \multicolumn{2}{|c|}{ Retinol $(\mu \mathrm{mol} / \mathrm{L})$} & \multicolumn{2}{|c|}{$\operatorname{RBP}(\mathrm{mg} / \mathrm{L})$} \\
\hline & $N$ & $r$ & $\mathbf{N}$ & $r$ \\
\hline Hemoglobin (mmol/L) & 1056 & 0.015 & 1025 & $0.188^{* * * *}$ \\
\hline Hematocrit (\%) & 1049 & $0.062^{*}$ & 1024 & $0.154^{* * *}$ \\
\hline Serum iron $(\mu \mathrm{mol} / \mathrm{L})$ & 921 & $0.172^{* * * *}$ & 935 & $0.135^{* * *}$ \\
\hline Ln ferritin $(\mu g / L)$ & 936 & $0.114^{* * *}$ & 950 & $0.183^{* * *}$ \\
\hline Ln transferrin $(g / L)$ & 988 & $-0.094^{* * *}$ & 1008 & $-0.082^{* * *}$ \\
\hline Ln $\% S T(\%)$ & 921 & $0.192^{* * *}$ & 935 & $0.171^{* * *}$ \\
\hline
\end{tabular}

${ }^{*} \mathrm{p}<0.05,{ }^{* *} \mathrm{p}<0.01,{ }^{* * * *} \mathrm{p}<0.001, \mathrm{Ln}=$ values transformed by natural logarithms).

\section{Table 3}

Multiple regression equations (regression coefficient and $S E$ ) with hermoglobin, hematocrit, serum iron, transferrin, ferritin, and saturation of transferrin (\%ST) as dependent variables

\begin{tabular}{|c|c|c|c|c|c|c|}
\hline \multirow{2}{*}{$\begin{array}{l}\text { Independent } \\
\text { variable }\end{array}$} & \multicolumn{2}{|c|}{ Dependent variable } & \multirow[b]{2}{*}{$\begin{array}{l}\text { Serum Fe } \\
\text { (umol/L) }\end{array}$} & \multirow[b]{2}{*}{$\begin{array}{l}\text { Transferrin } 1 \\
\text { (g/L) }\end{array}$} & \multirow[b]{2}{*}{$\begin{array}{l}\text { Ferritin } 1 \\
(\mu g / L)\end{array}$} & \multirow[b]{2}{*}{$\begin{array}{l}\% \mathrm{sT}^{1} \\
\%\end{array}$} \\
\hline & $\begin{array}{l}\mathrm{Hb} \\
\text { (mmollL) }\end{array}$ & $\begin{array}{l}\mathrm{H} \\
(\text { ow }\end{array}$ & & & & \\
\hline$Y$-intercept & 5.35 & 30,38 & 7.17 & 1.212 & 2.230 & 1.818 \\
\hline Age(years) & $\begin{array}{l}0.009 \\
(0.017)\end{array}$ & $\begin{array}{l}0.215^{4 * * *} \\
(0.05)\end{array}$ & $\begin{array}{l}0.7^{4 * * * 4} \\
(0.1)\end{array}$ & $\begin{array}{l}-0.015^{4} \\
(0.006)\end{array}$ & $\begin{array}{l}0.091^{\circ *} \\
(0.018)\end{array}$ & $\begin{array}{l}0.070^{* * *} \\
(0.01)\end{array}$ \\
\hline Sex & $\begin{array}{l}-0.0001 \\
(0,06)\end{array}$ & $\begin{array}{l}0.072 \\
(0.19)\end{array}$ & $\begin{array}{l}0,09 \\
(0.41)\end{array}$ & $\begin{array}{l}-0.030 \\
(0.022)\end{array}$ & $\begin{array}{l}0.16^{*} \\
(0.06)\end{array}$ & $\begin{array}{l}0.097^{\prime \prime} \\
(0.048)\end{array}$ \\
\hline Retinol(umol/L) & $\begin{array}{l}0.106 \\
(0.110)\end{array}$ & $\begin{array}{l}0.88^{\circ} \\
(0.37)\end{array}$ & $\begin{array}{l}3.417^{* * *} \\
(0.86)\end{array}$ & $\begin{array}{l}-0.123^{64} \\
(0.043)\end{array}$ & $\begin{array}{l}0.387^{m * n a} \\
(0.11)\end{array}$ & $\begin{array}{l}0.548^{4 * 4} \\
(0.094)\end{array}$ \\
\hline Albumin $(g / L)$ & $\begin{array}{l}0.018^{* i *} \\
(0.006)\end{array}$ & $\begin{array}{l}0.066^{2+\infty} \\
(0.022)\end{array}$ & $\begin{array}{l}-0.0591 \\
(0.054)\end{array}$ & $\begin{array}{c}-0.0014 \\
(0.0025)\end{array}$ & $\begin{array}{l}0.0118 \\
(0.0070)\end{array}$ & $\begin{array}{l}0.005 \\
(0.006)\end{array}$ \\
\hline Preallbumin (mg/L) & $\begin{array}{l}0.0015^{* * *} \\
(0.0005)\end{array}$ & $\begin{array}{l}0.0004 \\
(0.0016)\end{array}$ & $\begin{array}{r}-0.0048 \\
(0.004)\end{array}$ & $\begin{array}{l}0,00077^{* * *} \\
(0.0002)\end{array}$ & $\begin{array}{l}0.00052 \\
(0.0005)\end{array}$ & $\begin{array}{l}-0,0019^{*} \\
(0,0004)\end{array}$ \\
\hline Diarrhea & $\begin{array}{l}0.054 \\
(0.064)\end{array}$ & $\begin{array}{l}0.014 \\
(0.216)\end{array}$ & $\begin{array}{l}0.974^{*} \\
(0.492)\end{array}$ & $\begin{array}{l}0.036 \\
(0.024)\end{array}$ & $\begin{array}{l}0.0155 \\
(0.067)\end{array}$ & $\begin{array}{l}0.095 \\
(0,055)\end{array}$ \\
\hline Resp infections & $\begin{array}{l}0.149 \\
(0.097)\end{array}$ & $\begin{array}{l}0.623 \\
(0.328)\end{array}$ & $\begin{array}{l}1.127 \\
(0.762)\end{array}$ & $\begin{array}{l}0.017 \\
(0.037)\end{array}$ & $\begin{array}{l}0.174 \\
(0.104)\end{array}$ & $\begin{array}{l}0.102 \\
(0,084)\end{array}$ \\
\hline
\end{tabular}

* $p<0.05 ;{ }^{* * *} \mathrm{p}<0.01,{ }^{* * *} \mathrm{p}<0.001,1$ values transformed by naturall logarithms.

Intervention trial The nutritional status of the study population, assessed with the SD score of the WHO, did not differ significantly between sexes or between intervention and 
control groups at the start of the intervention study. A high proportion (ca.40\%) were classified as stunted (15-17). Table 4 shows the means of biochemical variables for the different study periods. Two months after intervention with the vitamin A capsules, serum retinol and RBP levels were significantly higher in the supplemented than in the control group. However, serum retinol levels markedly increased in both groups. The means of serum iron and \%ST were significantly higher in the intervention than in the control group two months after supplementation. Changes in level of the other variables did not differ significanty between the intervention and the control group (Table 4). Except for serum transferrin, prealbumin, RBC and ferritin, significant increases could be observed for all measured biochemical parameters in both the supplemented and the control group. Four months after interwention, there were no significant differences left between both groups (Table 4). Except for transferrin, prealbumin, and MCHC, all biochemical parameters had increased compared with the initial data; Serum transferrin and prealbumin were significantly lower than during the baseline examination.

Table 4

Biochemical variables adjusted for age before and two and four months after intervention with a vitamin A supplement.

\begin{tabular}{|c|c|c|c|c|c|c|}
\hline \multirow[t]{2}{*}{ Variable } & \multirow{2}{*}{$\begin{array}{l}\text { Number of } \\
\text { children }\end{array}$} & \multirow{2}{*}{$\begin{array}{l}\text { Baseline } \\
\text { Mean }\end{array}$} & \multicolumn{2}{|c|}{2 months } & \multicolumn{2}{|c|}{4 months } \\
\hline & & & Mean & $\mathrm{SED}^{*}$ & Mean & SED \\
\hline \multirow[t]{2}{*}{ Retinol $(\mu \mathrm{mol} / \mathrm{L})$} & \& 64 & 0.49 & $0.85^{\mathrm{ab}}$ & 0.028 & $0.64^{a}$ & 0.023 \\
\hline & 65 & 0.49 & $0.72^{a}$ & & $0.62^{1}$ & \\
\hline \multirow[t]{2}{*}{$\mathrm{RBP}(\mathrm{mg} / \mathrm{L})$} & s 70 & 23.9 & $28.1^{\mathrm{ab}}$ & 0.86 & 25.6 & 0.78 \\
\hline & $\begin{array}{l}\text { c } 65 \\
\text { s } 60\end{array}$ & $\begin{array}{l}24.0 \\
8.4\end{array}$ & $\begin{array}{l}24.1 \\
12.9^{\mathrm{ab}}\end{array}$ & 0.48 & $\begin{array}{l}24.4 \\
12.7^{\mathrm{a}}\end{array}$ & 0.46 \\
\hline Fe-serum $(\mu \mathrm{mol} / \mathrm{L})$ & c 61 & 8.8 & 10.0 & & $11.3^{a}$ & \\
\hline \multirow[t]{2}{*}{ Transferrin $(g / L)$} & \& 69 & 3.9 & $2.8^{\mathrm{a}}$ & 0.22 & $2.4^{\mathrm{a}}$ & 0.22 \\
\hline & c 64 & 3.9 & $2.7^{\mathrm{a}}$ & & $2.4^{a}$ & \\
\hline \multirow[t]{2}{*}{ Ferritin $(\mu \mathrm{g} / \mathrm{L})$} & s 61 & 24.6 & 20.2 & 2.06 & $31.2^{\mathrm{a}}$ & 3.67 \\
\hline & c 57 & 24.2 & 27.2 & & $36.7^{a}$ & \\
\hline \multirow[t]{2}{*}{$\% \mathrm{ST}$} & $s 60$ & 12.1 & $20.2^{\mathrm{ab}}$ & 1.19 & $24.0^{\circ}$ & 1.33 \\
\hline & c 61 & 12.4 & $17.0^{\mathrm{a}}$ & & $22,4^{\mathrm{a}}$ & \\
\hline \multirow[t]{2}{*}{ Prealbumin (mg/L) } & $\$ 63$ & 243.0 & $225.4^{\mathrm{at}}$ & 9.47 & 201.0 & 8.76 \\
\hline & c 60 & 243.3 & 197.0 & & 193.1 & \\
\hline \multirow[t]{2}{*}{$\mathrm{Hb}(\mathrm{mmol} / \mathrm{L})$} & s 71 & 6.94 & $7.20^{\mathrm{a}}$ & 0.51 & $7.14^{\mathrm{at}}$ & 0.59 \\
\hline & c 61 & 6.94 & $7.20^{\mathrm{a}}$ & & $7.18^{\mathrm{a}}$ & \\
\hline \multirow[t]{2}{*}{$\mathrm{Ht}(1)$} & s 71 & 0.35 & $0.36^{\mathrm{a}}$ & 0.0024 & $0.36^{\mathrm{a}}$ & 0.0030 \\
\hline & c 61 & 0.35 & $0.36^{\mathrm{a}}$ & & $0.36^{\mathrm{a}}$ & \\
\hline \multirow[t]{2}{*}{$\operatorname{RBC}\left(10^{12} / \mathrm{L}\right)$} & s 62 & 4.36 & $4.20^{\mathrm{g}}$ & 0.079 & $4.18^{\mathrm{a}}$ & 0.093 \\
\hline & c 49 & 4.46 & $4.15^{\mathrm{a}}$ & & $4.01^{\mathrm{a}}$ & \\
\hline \multirow[t]{2}{*}{$\operatorname{MCV}(n)$} & s 62 & 80.5 & $86.3^{\mathrm{ata}}$ & 1.86 & $89.4^{\mathrm{a}}$ & 2.03 \\
\hline & c 49 & 78.8 & $86.2^{\mathrm{a}}$ & & $89.4^{a}$ & \\
\hline \multirow[t]{2}{*}{$\mathrm{MCH}$ (fmol) } & s 62 & 1.59 & $1.75^{\mathrm{a}}$ & 0.042 & $1.76^{\mathrm{a}}$ & 0.046 \\
\hline & c 49 & 1.57 & $1.72^{\mathrm{a}}$ & & $1.78^{\mathrm{ia}}$ & \\
\hline \multirow[t]{2}{*}{ MCHC (mmol/L) } & s 71 & 19.8 & $20.2^{\mathrm{a}}$ & 0.21 & 19.7 & 0.21 \\
\hline & c 61 & 19.7 & $20.0^{\mathrm{an}}$ & & 19.8 & \\
\hline
\end{tabular}

a significant difference with 0 months, $b_{\text {significant difference with the control group. }} \mathrm{SED}=$ Pooled standard error of the difference between control and intervention group for $T=2$ respectively $T=4 . c$ $\Rightarrow$ control -group, $s=$ supplemented-group. 


\section{Discussion}

After the association between vitamin $\mathrm{A}$ and iron had first been mentioned it has taken some years until the subject became of interest. In the late 1970 s, several workers, especially Mejia, Hodges, Arroyave and co-workers, tried to elucidate this relationship $(8,10$ $12,27,28$. In an experiment involving a vitamin A-deficient group of otherwise healthy volunteers an association between iron metabolism and hypovitaminosis $A$ was established. The experimental group developed an anemia that was refractory to medicinal iron but responsive to vitamin $\mathrm{A}(8,29)$. The same workers described significant correlations between serum retinol levels and hemoglobin among non-pregnant, non-lactating women by reevaluating data of a nutrition survey. An evaluation of the data resulting from a national program of vitamin $A$ fortification conducted in Guatemala showed that the parameters of iron status improved although iron intake did not significantly change during the period of fortification (11). Mejia et al observed that after 6 months of vitamin A fortification parameters of the iron status had improved. Because the levels of total ironbinding capacity (TIBC) increased and the levels of ferritin declined, it seems that after fortification there was an increase in the availability of serum iron by depletion of the iron stores for hematopoiesis. After two years of vitamin A fortification an overall significant improvement of all iron nutritional parameters was observed: serum iron, \%ST and ferritin had increased significantly and TIBC had decreased. A plausible explanation of this phenomenon is that vitamin $A$ enhances both hematopoiesis and the availability of serum iron by depletion of the iron stores. This may trigger the improvement of dietary iron absorption and, as a consequence, might lead, after two years of fortification, to elevated levels of ferritin and a decrease of TIBC levels as may be expected in nomal iron metabolism (11).

The results of our cross-sectional study confirm the data of the epidemiologic studies mentioned $(9,11)$ which show that there is a relationship between biochemical indicators of vitamin $A$ and iron nourishment. Although there were significant correlations between $\mathrm{RBP}$ and retinol $(R=0.625, \mathrm{p}<0.001)$, between hemoglobin and hematocrit $(R=0.603$, $\mathrm{p}<0.001)$, and between RBP and hemoglobin $(\mathrm{R}=0.188, \mathrm{p}<0.001)$, we could not find a correlation between retinol and hemoglobin. The population examined comprised children with low hemoglobin levels as a result of both iron deficiency and vitamin A deficiency. While protein synthesis may explain the association between hemoglobin and RBP, vitamin A seems to be essential for a proliferation of the red blood cells which is expressed in the association between retinol and hematocrit. The correlations in our study were weak but correspond with those in the cross-sectional study of Mejia et al. (10).

Anemia provoked by vitamin A deficiency resembles hypochromic anemia. However. unlike in iron deficiency anemia, ferritin levels in vitamin $A$ deficiency anemia are normal (10). Furthermore, vitamin A does not change directly absorption of iron from the gastrointestinal tract (28). Another possible mechanism is that lack of vitamin A decreases the lewel of transferrin and consequently diminishes the transport of iron. However, a subsequent study from Mejia et al. could not confirm any association between sertum transferrin and vitamin $A$ deficiency when the data were adjusted for differences in protein status (12). The prevailing hypotheses explaining this association are: vitamin $A$ influences the differentiation of the red cell (30); and/or vitamin A deficiency is responsible for a 'blockade of reticuloendothelial iron deposits, thus inhibiting their mobilization; and/or vitamin A deficiency increases the susceptibility to infectious diseases and consequently to an impaired hematopolesis .

Dietary data, collected from a subsample of 108 children of the cross-sectional population, will be published elsewhere (31). As compared with the FAO/WHO Recommended Daily Allowances all children showed a highly imadequate intake of energy, calcium, iron (except urban children', vitamin A, thiamin, riboflavin, and niacin. Mean daily protein intake was equal to or higher than the calculated requirements (31). An inadequate intake of both iron and vitamin $A$ could also have influenced the association found.

Cross-sectional studies like the present one cannot proof the causative relation between vitamin $A$ and anemia. Moreover, controlled studies to investigate this phenomenon were 
never been reported. Our intervention trial was conducted to investigate whether a single high oral dose of vitamin A could improve the iron status.

For various parts of the world it has been described that dietary intake of vitamin $A$ can fluctuate during the year (32-34). The dietary data showed that \pm 50 per cent of available vitamin $A$ comes from vegetables and fruits. Fnuits and vegetables have only rather short seasons in which they are normally eaten. 33 per cent of the iron intake, however, comes from rice and 49 per cent from animal products and consequently will show less variation during the year. Only 16 per cent comes from vegetables and fruits. The baseline examination of this study was carried out in May 1985 , just at the end of the dry season. In the subsequent two months mangoes became more available, which are very rich in carotene. The serum levels of retinol and RBP measured increased significantly both in the supplemented $(73 \%)$ and in the control group $(47 \%)$. Although the increase in the supplemented group was significantly greater than in the control group, seasonal effects of dietary intake may have masked an even greater impact of the intervention with vitamin $A$ on iron metabolism, since there may be a level of vitamin A intake above which a further increase of dietary intake does not further enhance the effect on iron metabolism.

The standard capsules, which contain $200000 \mathrm{IU}$ vitamin $\mathrm{A}$ and $40 \mathrm{IU}$ vitamin $\mathrm{E}$, are recommended by the WHO for prevention of xerophthalmia and vitamin A deficiency. This dose protects cliildren against xerophthalmia for a period of four to six months. This may explain that differences in retinol and RBP between both groups, which were present after two months were no longer significant after four months when the supplementation started losing its effect. Consequently, it could be expected that serum iron and \% ST were significantly higher in the supplemented group than in the control group two months after intervention. Four months after intervention, the supplemented group still had higher levels of serum iron and \% ST than the controls, but the levels in the controls were also significantly higher at 4 months than at 2 months after the baseline examination so that differences between the supplemented and the control group were not significant any more.

A possible explanation for the association between vitamin $A$ and iron is that lack of vitamin $A$ immobilizes iron, stored in the reticuloendothelial system (RES) $(3,7)$. In fact, a drop in ferritin levels, although not of statistical significance, was observed two months after the supplementation, giving support to this explanation. A direct effect of vitamin $A$ on enhancement of iron absorption has not been observed (28). The initial depletion of iron stores and consequently increased iron utillization, however, may have triggered the dietary iron absorption mechanism, which may have subsequently led to the observed higher levels of ferritin after four months.

The association between vitamin $A$ and infections could also hawe had its impact on the results of the intervention study. Several reports show that vitamin $A$ can reduce the susceptibillity to infectious diseases. We have observed similar associations (35). However, infections can lower the biochemical levels of both iron and vitamin A. Therefore, we have adjusted for morbidity data in the cross-sectional analyses. Although children with history of diarthea or respiratory disease had significantly lower levels of both serum iron and retinol than children without these disorders, similar significant associations between vitamin $A$ and iron parameters were found in both groups. During the two months of follow-up after supplementation the intervention group had a lower incidence of respiratory diseases ( 0.65 times) as well as diarrhea ( 0.57 times) than the control group (35). However, the differences were not significant due to the low number of children surveyed.

Although we cannot completely exclude the role of the interaction between vitamin $\mathrm{A}$ and infections, our results suggest that the association between vitamin $A$ and iron metabolism is a causal one. Furthermore, results of two studies recently conducted in Guatemala (Mejia et al.) and in Indonesia (Muhilal et al.) support those found in our intervention study (personal communication). Intervention with vitamin A can play a role in improving utilization of avallable iron in children in developing countries, especially in the annual dry season when all food is in short supply. Considering that every year millions of children suffer from the physiological consequences of lack of vitamin $\mathrm{A}$, it is im- 
portant to pay serious attention to this association in planning nutritional health programs (36)

\section{References}

1. Findlay GM, Mackenzie RD. The bone marrow in deficiency diseases. J Pathl. $1922 ; 25: 402-3$.

2. Wolbach SB, Howe PR. Tissue changes following deprivation of fatsoluble A vitamin J Exptl 1925:42:753-77.

3. Koessler $\mathrm{KK}$, Maurer $\mathrm{S}$, Loughlin $\mathrm{R}$. The relation of anemia, primary and secondary, to vitamin A deficiency. JAMA 1926;87:476-82.

4. Blackfan KD, Wolbach SB. Vitamin A deficiency in infants, J Pediatr 1933;3:679. 706.

5. Frank M. Beitrag zur Hamatologie der A-Avitaminose. Monatrisschrift fur Kinderheilkunde 1934;60:350-5.

6. Wagner KH. Die Experimentele Avitaminose A beim Menschen. Hoppe-Seyler Z Physiol Chem 1940:264:153-89.

7. O'Toole BA, Fradkin R, Warkany $J$, Wilson JG, Mann $V$. Vitamin A deficiency and reproduction in Rhesus monkeys. J Nutr 1974;104:1513-23.

8. Hodges RE, Sauberlich, HE, Canham JE, Wallace DL, Rucker B, Mejia LA, Mo. hanram M. Hematopoietic studies in vitamin A deficiency. Am J Clin Nutr $1978 ; 31: 876-85$.

9. Mohanram M, Kulkarni KA, Reddy V. Hematological studies in vitamin A-deficient children. Int J Vit Nutr Res 1977;47:389-93.

10. Mejia LA, Hodges RE, Arroyave $G$, Viteri $F$, Torun B. Vitamin A deficiency and anemia in Central American children. Am J Clin Nutr 1977;30:1175-84.

11. Mejia LA, Arroyave G. The effect of vitamin A fortification of sugar on iron metabolism in preschool children in Guatemala. Am J Clin Nutr 1982;36:87-93.

12. Mejia LA, Arroyave $G$. Lack of direct association between serum transferrin and serum biochemical indicators of vitamin A nutriture. Acta Vitaminol Enzymol 1983;5ns: 179.84.

13. Tontisirin K, Winichagoon P. Malnutrition as a social indicator: Nutrition Problems in Thailand, Faculty of Medicine, Ramathibodi Hospital Institute of Nutrition Mahidol University , Bangkok, Thailand, 1984.

14. Bloem MW, Wedel M, Egger RJ, Speek A, et al. Vitanin A deficiency in Northeast Thailand: A prevalence study of vitamin A deficiency and xerophthalmia. Am J Epidemiol (accepted)

15. World Health Organization. Measuring change in nutritional status. Geneva: World Health Organization, 1983.

16. Dibley MJ, Goldsby JB, Staehling NW, Trowbridge FL. Dewelopment of normalized curves for the international growth reference: historical and technical considerations. Am J Clin Nutr 1987;46:736-48.

17. Dibley MJ, Staehling NW, Nieburg P, Trowbridge FL. Interpretation of Z-score anthropometric indicators derived from the international growth reference. $\mathrm{Am} J$ Clin Nutr 1987;46:749-62.

18. Sommer A. Field guide to the detection and control of xerophthalmia, 2 nd ed. Geneva: World Health Organization, 1982.

19. Speek AJ, Wongkam LN, Saowakontha S, Schreurs WHP. Microdetermination of vitamin $A$ in human plasma using-performance liquid chromatography with fluoresence detection. J Chromatogr Biomed appl 1986;382:284-9.

20. Mancini $G$, Carbonara $A D$, Heremans JF. Immunochemical quantitation of antigens by single radial immunodiffusion. Immunochemistry, Pergamon Press, 1965:23554.

21. Doumas BT, Watson W, Biggs HG. Albumin standards and the measurement of serum albumin with bromcresol green. Clin Chim Acta 1971;31:87-96. 
22. Kampen El van, Zijlstra WG. Standardization of hemoglobinometry II. The hemiglobincyanide method. Clin Chim Acta 1961;6:538-44.

23. Zettner A, Mensch AH. The use of atomic absorption spectroscopy in hemoglobinometry. I. The determination of iron in hemoglobin. Am J Clin Pathol $1967: 48: 225-8$.

24. Addison GM, Beamish $M R$, Hales $C N$, et al. An immunoradiometric assay for ferritin in the serum of normal subjects and patients with iron deficiency and iron overload. J Clin Pathol 1972;25:326-32.

25. Dixon WJ. BMDP-statistical software, University of California Press, Berkely, Los Angeles, London, 1985.

26. Alvey N. Genstat, a General Statistical Program, Rothamsted Experimental Station, Harpenden, England, 1977.

27. Mejia LA, Hodges RE, Rucker RB. Clinical signs of anemia in vitamin A deficient rats. Am J Clin Nutr 1979;32:1439-44.

28. Mejia LA, Hodges RE, Rucker RB. Role of vitamin A in absorption, retention and distribution of iron in the rat. J Nutr 1979;109:129-37.

29. Hodges RE, Kolder H. Experimental vitamin A deficiency in human volunteers. In: Summary of Proceedings, Workshop on Biochemical and Clinical Criteria for Determining Human Vitamin A Nutriture. Food and Nutrition Board, National Academy of Sciences, 28-29 January, 1971:10-6.

30. Douer D, Koeffler HP. Retinoic acid enhances growth of human early erytroid progenitor cells in vitro. J Clin Invest 1982;69:1039-41.

31. Egger RJ, Hofhuis EH, Sukonthanyakorn B, et al. Nutritional health in Northeast Thailand. Food intake in preschool and primary school children in Sakhon Nakhon province. (submitted).

32. Moore, T. Vitamin A. Amsterdam: Elsevier, 1957.

33. Oomen HAPC, Ten Doesschate J. The periodicity of xerophthalmia in South and East Asia. Ecol Food Nutr 1973;2:207-17.

34. Sinha DP, Bang FB. Seasonal variation in signs of vitamin A deficiency in rural West Bengal children. Lancet 1973;2:228-30.

35. Bloem M, Wedel M, Egger RJ, et al. Mild Vitamin A deficiency and risk of respiratory infection and diarrhea in preschool and school children in Northeast Thailand. (submitted).

36. Sommer A. Massive Dosages of Vitamin A in Developing Countries. Abstract International Symposium on elevated Dosages of Vitamins Benefits and Hazards, Interlaken, Swiss, Sept. 7-9, 1987. 


\title{
Short-term effects of a single oral massive dose of vitamin $\mathrm{A}$ on anemia
}

\author{
Martin W. BloemI, M.D., Michel Wedel2, M.Sc., Eric J. van Agtmaal , M.Sc.. \\ Andries J. Speekl, M.Sc., Sastri Saowakomha ${ }^{3}$, M.D.PhD., and Wil H.P.Schrears. \\ PhD,D.Sc.
}

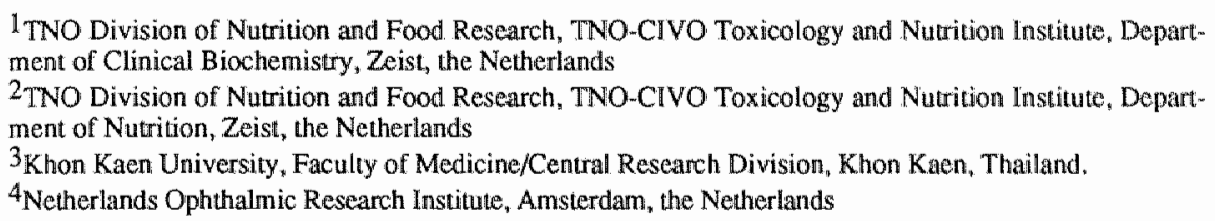

Abstract A group of 134 school children aged 3-9 years, with signs of conjunctival xerosis, from the rural area of the Sakon Nakhon Province in Northeast Thailand were selected for a controlled study on the short-term effects ( 2 weeks) of a single oral high dose of vitamin $A$ on iron metabolism. After collection of the baseline data, within villages children were randomized to receive the capsules $(n=65)$ or to serve as controls $(\mathrm{n}=69)$. Two weeks after supplementation significant increases of retinol, retinol-binding protein, hemoglobin, hematocrit, serum iron and saturation of tramsferrin, were found in the supplemented group as compared with the control group. Ferritin levels didn't change significantly. These short-term changes completely exclude seasonal effects and change in morbidity. This study provides further evidence for a causal association between vitamin $A$ and iron metabolism. It is concluded that in areas where vitamin A deficiency is endemic periodic massive vitamin A dose programs can improve the iron status of the population as well.

Key words Vitamin A, Vitamin A supplementation, iron, vitamin A-iron interaction, Northeast Thailand.

\section{Introduction}

Iron deficiency anemia and hypovitaminosis A are still two of Thailand's major public health problems (1). A possible association between iron and vitamin $A$ has been sug. gested in the early studies about lack of vitamin A (2). Only since the past decade, however, serious attention has been given to this relationship (2-7). According to the most recent estimate of the magnitude of physiological consequences of hypovitaminosis $A, 25$. 50 million children may be suffering from this nutritional deficiency (8). Consequently, if this association with iron turns out to be a causal one, intervention with vitamin $A$ will exert even a greater impact on public health by simultaneously lowering the prevalence of anemia in areas where vitamin $A$ deficiency is endemic.

Vitamin A deficiency is still a major public health problem in the rural areas of the Sakon Nakhon province in Northeast Thailand (9). Of the preschool children in this region $12.6 \%$ are found to have deficient serum retinol levels $(<0.35 \mu \mathrm{mol} / \mathrm{L})$ and $1.3 \%$ to be night blind. Cross-sectional analyses of the baseline data of 1,060 children from this region show that vitamin $\mathrm{A}$ status is statistically, significantly associated with the iron status (10). A causal relationship is thighly probable but not yet proven (11).

A study about the effects of a single oral high dose of vitamin A $(200000 \mathrm{IU})$ on parameters of iron metabolism in a group of anemic preschool children showed significant. improvements of serum iron and the saturation of transferrin at 2 months but not at 4 
monthis after supplementation (10). Effects on themoglobin levels were not observed. This may have been due to seasonal influences and the length of the study period, which act as potential confounders.

To evade these seasonal problems, the present study was set up to investigate the effects within 2 weeks of a single high oral dose, in accordance to the W.H.O. recommendations on vitamin $\mathrm{A}$, on the iron status of children aged $3-9$ years in rurall Northeast Thailand.

\section{Materialls and methods}

The study was carried out between May and July 1986 in the Sakon Nakhon province in Northeast Thailand. From three villages in the northern part of the province 134 children were randomly selected for the study on base of signs of conjunctival xerosis. A team consisting of a pediatrician, a project physician, two biochemists, two nutritionists, and six fieldworkers visited and examined children aged $3-9$ years. The mean age of the children was 6.5 years old. At baseline examination, children were gathered in the Buddhist temple, where their weight, height, and left mid upper armcircumference (muac) were recorded by the nutritionist and a fieldworker. Their general health status was assessed by the pediatrician; blood was obtained by a biochemist and fieldworker; eyes were examined by the project physician with a handlight and a magnifying lens. Standard diagnostic criteria were used for xerophthalmia (11).

Capillary blood was taken by puncture of the palmar surface of the fingertip. A total amount of $300 \mu \mathrm{l}$ of blood could be collected in heparinized $75-\mu 1$ capillaries. Plasma and cells were then separated in a microhematocrit centrifuge. Plasma was collected in a 0.4 $\mathrm{ml}$ sample vial and stored in the dark at $-20^{\circ} \mathrm{C}$ for analyses within two months.

The following biochemical analyses were carried out: all-trans retinol in plasma by high-performance liquid chromatography (HPLC) according to Speek et al.(12); retinolbinding protein ( $R B P$ ) in plasma by the single radial immunodiffusion technique according to Mancini et al (13); prealbumin in plasma by the single radial immunodiffusion technique described by Mancini et al. (13), with the relevant specific antiserum of Behring (Behring Werke AG, Marburg, FRG); hemoglobin in whole blood to the cyanmethemoglobin method of Van Kampen et al. (14) with Boehringer kit No 124729; serum iron by flameless atomic absorption spectrometry with a Perkin Elmer type 430 AAS instrument equipped with HGA 500 atomizer (15); transferrin in plasma by the radial immunodiffusion technique mentioned previously; ferritin in plasma by immuno radiometric assay according to Addison et al. (16).

The intervention group was randomized on an individual basis. The standard capsules were given, after baseline examination, to a random selection of 65 out of the 134 children. The capsule nipple was snipped off and the contents (200 000 IU vitamin $A$ and 40 IU vitamin $\mathrm{E}$ ) were squevezed out into the child's mouth.

After two weeks children were reexamined by the same procedure. After follow-up warying numbers of children in the supplemented and control groups had to be excluded from further analyses due to failure of follow-up, blood collection, or biochemical determinations. The mean of the biochemical parameters of the drop-outs did not differ significantly from subjects included in the study.

All data were collected on precoded forms, and checked at least twice for accuracy and completeness before shipping to the data management facility at the CIVO-TNO Institutes, where the information was analyzed with the BMDP and GENSTAT statistical packages $(17,18)$. Statistical analyses comprised analysis of variance of the differences between measurements at baseline and two waeks after, to examine the effect of the treatment; the differences in intra and inter individual variation was accounted for; the effects were adjusted for age, included into the analysis as a co-variable. Means and standard deviations given in the results are age-adjusted. 
Table 1

Means of anthropometric variables of children of the control and supplemented group

\begin{tabular}{|c|c|c|c|c|c|c|}
\hline \multirow{2}{*}{ Variable } & \multicolumn{3}{|c|}{ Supplemented group } & \multicolumn{3}{|c|}{ Control group } \\
\hline & Nimber & Mean & (SD) & Number & Mean & (SD) \\
\hline Age (years) & 64 & 6.61 & $(1.66)$ & 69 & 6.45 & $(1.44)$ \\
\hline Height (cm) & 63 & 94.2 & $(33.4)$ & 67 & 97.5 & $(28.8)$ \\
\hline Weight (kg) & 63 & 14.8 & $(5.0)$ & 67 & 14.7 & $(4.7)$ \\
\hline Mid-upper arm circumference (mm) & 63 & 14.3 & $(3.0)$ & 67 & 14.5 & $(2.0)$ \\
\hline Triceps skinfold (mm) & 63 & 6.3 & $(1.5)$ & 67 & 6.2 & (1.5) \\
\hline Nutritional Status & & 9 & & & $\%$ & \\
\hline Normal & 17 & 12.1 & & 16 & 12.4 & \\
\hline Wasted & 3 & 2.4 & & 5 & 3.9 & \\
\hline Stunted & 34. & 26.4 & & 39 & 30.2 & \\
\hline Wasted \& stunted & 8 & 6.2 & & 7 & 4.0 & \\
\hline \multicolumn{7}{|l|}{$\underline{\operatorname{Sex}}$} \\
\hline Boy & 38 & 28.4 & & 41 & 30.6 & \\
\hline Girl & 27 & 20.1 & & 28 & 20.9 & \\
\hline
\end{tabular}

\section{Results}

The nutritional status of the study population at the baseline examination was assessed by the SD scores belonging to the WHO recommendations (19). Table 1 shows the comparative data for anthropometric parameters, sex distribution and nutritional status for the control group and intervention group. There was no significant difference between the nutritional status of boys and girls; $55 \%$ of the boys and $58 \%$ of the girls were stunted; 4 $\%$ of the boys and $9 \%$ of the girls were wasted; $15 \%$ of the boys and $6 \%$ of the girls were both wasted and stunted (data not shown). Table 2 shows the means of the biochemical variables before and after intervention in the supplemented and the control group. Two weeks after intervention serum retinol and RBP were significantly higher in the supplemented group than in the control group. The same trend was found for levels of prealbumin. Improvement of the iron status was found on basis of serum iron, saturation of transferrin, and hemoglobin in the supplemented group, levels being significantly higher than those of the control group. No change was observed for ferritin; transferrin increased equally in both the supplemented and the control groups; hematocrit decreased in the control group only, the difference between control and treatment groups being significant after two weeks. 
Table 2

Means of biochernical variables, adjusted for age before and wo weeks after intervention with vitumin $A$.

\begin{tabular}{|c|c|c|c|c|}
\hline Variable & $\begin{array}{l}\text { Number of } \\
\text { children }\end{array}$ & Baseline & $\begin{array}{l}2 \text { weeks after } \\
\text { supplementation }\end{array}$ & $\begin{array}{l}\text { Pooled } \\
\text { SD }\end{array}$ \\
\hline Retinol (jmot/L) & $\begin{array}{l}s^{*} 50 \\
\text { c } 45\end{array}$ & $\begin{array}{l}0.60 \\
0.61\end{array}$ & $\begin{array}{l}0.75^{\mathrm{ab}} \\
0.54^{\mathrm{a}}\end{array}$ & 0.14 \\
\hline $\operatorname{RBP}(\mathrm{mg} / \mathrm{L})$ & $\begin{array}{l}\text { s } 58 \\
\text { c } 53\end{array}$ & $\begin{array}{l}24.1 \\
24.8\end{array}$ & $\begin{array}{l}28.6^{\mathrm{ab}} \\
22.8\end{array}$ & 6.1 \\
\hline Fesserum (umol/L) & $\begin{array}{l}341 \\
\text { c } 35\end{array}$ & $\begin{array}{l}10.2 \\
10.6\end{array}$ & $\begin{array}{l}15.6^{a b} \\
12.0\end{array}$ & 3.7 \\
\hline Transferin $(g / L)$ & $\begin{array}{l}\text { s } 57 \\
\text { c } 52\end{array}$ & $\begin{array}{l}2.0 \\
2.0\end{array}$ & $\begin{array}{l}2.2^{\mathrm{a}} \\
2.1^{\mathrm{a}}\end{array}$ & 0.4 \\
\hline Ferritin $\left(\mu \mathrm{g} / \mathrm{L}_{*}\right)$ & $\begin{array}{l}\text { s } 51 \\
\text { c } 48\end{array}$ & $\begin{array}{l}42.1 \\
42.6\end{array}$ & $\begin{array}{l}47.1 \\
48.7\end{array}$ & 21.3 \\
\hline ST $(M)$ & $\begin{array}{l}\text { s } 36 \\
\text { c } 34\end{array}$ & $\begin{array}{l}20.8 \\
21.6\end{array}$ & $\begin{array}{l}26.4^{a b} \\
22.6\end{array}$ & 6.9 \\
\hline$H \mathrm{H} \cdot(\mathrm{mmol} / \mathrm{L})$ & $\begin{array}{l}\text { s } 58 \\
\text { c } 54\end{array}$ & $\begin{array}{l}7.2 \\
7.2\end{array}$ & $\begin{array}{l}7.4^{a b} \\
7.2\end{array}$ & 0.37 \\
\hline Hit $(\%)$ & $\begin{array}{l}\text { s } 58 \\
\text { c } 54\end{array}$ & $\begin{array}{l}37.2 \\
37.1\end{array}$ & $\begin{array}{l}37.1^{b} \\
36.1\end{array}$ & 1.7 \\
\hline Prealbumin (mg/L) & $\begin{array}{l}\text { s } 58 \\
\text { c } 53\end{array}$ & $\begin{array}{l}148.9 \\
149.7\end{array}$ & $\begin{array}{l}197.3^{\mathrm{ab}} \\
171.8^{\mathrm{a}}\end{array}$ & 33.3 \\
\hline
\end{tabular}

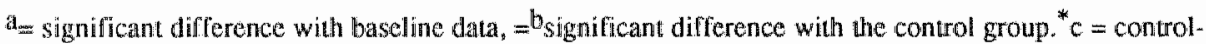
group, $s$ = supplemented-group.

\section{Discussion}

Few studies have accurately investigated the effect of intervention with vitamin $A$ on improvement of the iron metabolism. Mejia and Arroyave evaluated a vitamin $A$ fortifiGation program, and observed an improvement of the iron status (7). Mohanram observed that intervention with vitamin $A$ led to increased hemoglobin levels (6). Recently two different intervention studies have been carried out. Muhilal et al. (20) conducted a conmolled intervention trial with fortified commercially marketed monosodium glutamate with vitamin $A$. They demonstrated a rise in hemoglobin values in the supplemented group by $1 \mathrm{gm} / \mathrm{dl}$. Mejia and Chew (21) reported the results of a well designed study of different intervention strategies. Four groups of anemic children were supplemented for two months with vitamin A, iron, vitamin A plus iron, or a placebo. Vitamin A supplementation produced significant elevations in the serum levels of retinol, blood hemoglobin, hematocrit, erythrocytes, serum Fe, \%ST and had no effect on total Fe binding capacity or serum ferritin.

A controlled intervention study on the effects of a single oral high dose of vitamin $\mathrm{A}$ in anemic ( $\mathrm{Hb}<7.5 \mathrm{mmol} / \mathrm{L}$ ) preschool children was recently performed by us in Northeast Thailand. We were able to show an increase in serum iron and saturation of transferrin two months after intervention (10). Seasonal influences - the end of the dry season, which apparently led to improvement of the nutritional intake of the control group as well - may have reduced the cogency of this earlier study by diminishing the difference between the supplemented and control group (10). Vitamin A supplementation affects morbidity (22). We observed a decrease in incidence of diarrhea and respiratory disease during the two-month follow-up. This may also have interfered with the results of the study. 
Moreover, the study population was selected on the basis of presence of anemia $(\mathrm{Hb}<7.5 \mathrm{mmol} / \mathrm{L})$. This anemia ma have been caused either by vitamin $\mathrm{A}$ deficiency or by iron deficiency (ferritin levels were $25 \mu \mathrm{g} / \mathrm{L}$ in this population). In the latter case the effect of supplementation with vitamin $A$ on iron status is presumably negligible. "Therefore, in the present study the children were selected on basis of signs of conjunctival xerosis, reflecting the presence of probably chronic vitamin A deficiency. The intake of iron in this population was not necessarily insufficient (the actual average ferritin level was 42 $\mu g / L)$. Furthermore, because in the previous study the effect on iron metabolism of a single high dose of vitamin A was present at two months but appears to decrease after 4 months. Therefore we used a considerably shorter study period in the present experiment, thus reducing potential confounding (10).

As a result of the vitamin A supplementation we observed, except for transferrin and ferritin, a significant increase of all measured parameters of the iron status in the intervention group compared with the control group. The significant rise of hemoglobin levels within 14 days confirms that improvement of iron metabolism probably is not the result of a direct effect on enhancement of iron absorption, but more likely the result of mobilization of available stored iron and of increased iron utilization for hemoglobin formation.

It is concluded that intervention with vitamin A can improve the iron status already on a short term (within two weeks) in areas where mild vitamin A deficiency and anemia are endemic. Improvement of iron nourishment in combination with intervention by vitamin A supplementation will exert an ewen greater impact on the prevalence of anemia than the separate application of only one of these strategies.

\section{Acknowledgments}

The authors thank Professor RJJ Hermus, TNO-CIVO Toxicology and Nutrition Institute, Zeist, The Netherlands, Professor HA Valkenburg, Erasmus University, Rotterdam, The Netherlands, and Dr. Kusuma Chusilp, Dr. Khaisaeng Rojsathaporn, Khon Kaen University, Khon Kaen, Thailand for their assistance.

\section{References}

1. Tontisirin $\mathrm{K}$, Winichagoon P. Malnutrition as a social indicator: Nutrition Problems in Thailand, Faculty of Medicine, Ramathibodi Hospital \& Institute of Nutrition Mahidol University, 1984.

2. Hodges RE, Sauberlich HE, Canham JE, et al. Hematopoietic studies in vitamin A deficiency. Am J Clin Nutr 1978;31:876-85.

3. Mejia LA, Hodges RE, Rucker RB. Role of vitamin A in absorption, retention and distribution of iron in the rat. INutr 1979;109:129-37.

4. Mejia LA, Hodges RE, Arroyave $G$, Viteri F, Torun B. Vitamin A deficiency and anemia in Central American children. Am J Clin Nutr 1977;30:1175-84.

5. Mejia LA, Hodges RE, Rucker RB. Clinical signs of anemia in vitamin A deficient rats. Am J Clin Nutr 1979;32:1439-44.

6. Mohanram M, Kulkarni KA, Reddy V. Hematological studies in vitamin A-deficient children. Int J Vit Nutr Res 1977;47:389-93.

7. Mejia LA, Arroyave G. The effect of vitamin A fortification of sugar on iron metabolism in preschool chilldren in Guatemala. Am J Clin Nutr 1982;36:87-93.

8. Sommer A. Massive Dosages of Vitamin A in Developing Countries. Abstract International Symposium on elevated Dosages of Vitamins Benefits and Hazards, Interlaken, Swisis, Sept. 7-9, 1987.

9. Bloem MW, Wedel M, Egger RJ, et al. Vitamin A deficiency in Northeast Thailand: A prevalence study of vitamin $A$ deficiency and Xerophthalmia. Am J Epidemiol (in press). 
10. Bloem MW, Wedel M, Egger RJ, Speek AJ, Schriver J, Saowakontha S, Schreurs WHP. Iron metabolism and vitamin A deficiency in children in Northeast Thailand. Am J Clin Nutr (in press).

11. Sommer A. Field guide to the detection and control of xerophthalmia, 2 nd ed. Geneva: World Health Organization, 1982.

12. Speek AJ, Wongkam, Limratana N, Saowakontha, Schreurs WHP. Microdetermination of vitamin $A$ in human plasma using-performance liquid chromatography with fluoresence detection. J Chromatogr Biomed appl 1986;382:284-9.

13. Mancini G, Carbonara A.D, Heremans JF. Immunochemical quantitation of antigens by single radial immunodiffusion. Immunochemistry, Pergamon Press, 1965:23554.

14. Kampen EJ van, Zijlstra WG. Standardization of hemoglobinometry II. The hemiglobincyanide method. Clin Chim Acta 1961;6:538-44.

15. Zettner A, Mensch A.H. The use of atomic absorption spectroscopy in hemoglobinometry. I. The determination of iron in hemoglobin. Am J Clin Pathol. $1967 ; 48: 225-8$.

16. Addison GM, Beamish MR, Hales CN, et al. An immunoradiometric assay for ferritin in the serum of normal subjects and patients with iron deficiency and iron owerload. II Clin Pathol $1972 ; 25: 326-32$.

17. Dixon WJ. BMDP-statistical software, University of California Press, Berkely, Los Angeles, London, 1985.

1.8. Alvey N. Genstat, a General Statistical Program, Rothamsted Experimental Station, Harpenden, England 1977.

19. W.H.O. Measuring Change in Nutritional Status. Geneva: World Health Organization, 1983.

20. Muhilal, Permeisih D, Idjradinata YR, Muherdiyantiningsih, Karyadi D. Impact of vitamin A fortified MSG on health, growth and survival of children: A controlled field trial. Am J Clin Nutr (in press)

21. Mejia LA, Chew F. Hematological effect of supplementation anemic children with vitamin A alone and in combination with iron. Am J Clin Nutr 1988;48:595-600

22. Sommer A, Katz J, Tarwotjo I. Increased risk of respiratory disease and diarrhea in children with preexisting mild vitamin A deficiency. Am J Clin Nutr 1984;40:10905 . 


\title{
Mild vitamin $A$ deficiency and risk of respiratory infection and diarrhea in preschool and school children in Northeast Thailland
}

\author{
Martin W. Bloem? , M.D., Michel Wedel2, M.Sc. Robbert J. Egger2, M.Sc, Andries J. \\ Speek ${ }^{1}$, M.Sc., Jaap Schrifverl, Ph.D., Sastri Saowakontha ${ }^{3}$, M.D.,Ph.D., Wh \\ H.P.Schreurs ${ }^{l}$, Ph.D.D.SC
}

\begin{abstract}
${ }^{1}$ TNO Division of Nutrition and Food Research, TNO-CrVO Toxicology and Nutrition Institute, Department of Clinical Biochemistry, Zeist, Netherlands

2 TNO Division of Nutrition and Food Research, TNO-CrVO Toxicology and Nutrition Institute, Department of Nutrition, Zeist, Netherlands

3 Khon Kaen University, Faculty of Medicine/ Central Research Division, Khon Kaen, Thailand
\end{abstract}

Abstract To inwestigate the association between mild witamin A deficiency, as eviclenced by serum retinol levells, and the occurrence of diarthea and respiratory disease, three studies were carried out: a cross-sectional study; a follow-up study; and an intervention trial.

A cross-sectional analysis was carried out for 1772 children, aged $1-8$ years, in the Sakon Nakhon province of Northeast Thailand. Biochemical data were available from a random subsample of 1060 children $(60 \%)$ and reliable information about diarthea and respiratory disease from 1646 children. Children with a history of diarrhea or respiratory disease had significantly lower levels of serum retinol and retinol-binding protein. To adjust for the possible confounding effects of age, sex, nutritional status, and protein status, logistic regression was carried out on a complete set of data of 877 children: a significant consistently negative association between serum retinol and both diarrhea and respiratory diseases was observed.

To obtain further evidence whether this observed association is a causal one, a followup and a controlled intervention trial were carried out. A follow-up study of a subsample of 146 children, who were not subject to any form of intervention, showed that children with deficient serum retinol levels $(<0.35 \mu \mathrm{mol} / \mathrm{L})$ had an about 4 times greater risk of developing respiratory diseases $(\mathrm{p}<0.0 \mathrm{I})$ than had children with adequate levels during a follow-up of three months. With regard to diarrhea no significant relationship was found. A controlled intervention trial with 166 children, aged 1.5 years, showed that during two months of follow-up after supplementation with a single oral massive dose of vitamin $A$ (200 $000 \mathrm{IU})$, the control group of children aged 3-5 years had a higher incidence of respiratory disease (2.89 times) as well as of diarrhea (3.02 times) than the intervention group. Between two and four months after the start of the intervention a significantly $(p<0.025)$ higher incidence of respiratory disease $(2.56$ times) could be observed in children aged 1 - 2 years.

This study supports earlier reports on the greater risk of children with mild vitamin $A$ deficiency of developing respiratory diseases and, to a lesser extent, diarrhea. Furthermore vitamin A supplementation seems to have beneficial effects on the incidence of both diarrhea and respiratory disease for at least a period of two months.

Key words Vitamin A deficiency, diarrhea, respiratory disease, incidence 


\section{Introduction}

Vitamin A deficiency is still one of the world's major nutritional problems. The most recent estimation of the magnitude of the problem is that $25-50$ million children may be suffering the physiological consequences of vitamin A deficiency; 5 million of them are developing xerophthalmia, of whom 250 000-500 000 go blind every year (1). From a recent prevalence study in the Sakon Nakhon province in Northeast Thailand we concluded that vitamin $A$ deficiency is still a public health problem in the rural part of that province, and that $12.6 \%$ of the preschool children had deficient and $50 \%$ marginal serum retinol levels (2).

Since the earliest studies about the impact of lack of vitamin $A$, it has been recognized that retinol plays an important role in preventing infections. Some authors even have called it the "anti-infective" vitamin (3). When animals were made deficient in retinol, they often died from infections before the eye lesions of xerophthalmia became fully evident. This association has not received serious attention until 1983. Sommer and co-workers did several studies in Indonesia. They observed an increased mortality in children with mild vitamin A deficiency (4). A greater susceptibility to respiratory infections and diarrhea, the two conditions mostly responsible for mortality in preschool children, may have been the cause (5). A subsequent carefully planned community trial on the impact of the supplementation of vitamin A (200.000 IU) on childhood mortality suggested that supplements given to vitamin A-deficient populations may decrease mortality by as much as $34 \%$ (6). In all these studies vitamin A deficiency was evidenced by night blindness or Bitot's spots.

Because of the great potential impact of vitamin A deficiency on childhood morbidity and mortality in developing countries, it has been suggested to carry out similar studies in other ecological settings before the findings of Sommer et al. can be re-commended for implementation of prevention programs all over the Third World $(7)$.

In the present study the association between occurrence of respiratory infections or diarrhea and vitamin $A$ deficiency, as evidenced by low serum retinol levels, has been studied in preschool and school children in the Sakon Nakhon province in Northeast Thailand.

\section{Materials and methods}

\section{Study population}

This study is part of the Nutrition Supplement Co-operation project (NSC project) performed by CIVO-TNO and the University of Khon Kaen between March 1985 and July 1986 in the Sakon Nakhon providence in Northeast Thailand. The aim of the project was to improve the nutritional health of ca. 6250 preschool and school children with a nutritional supplement containing protein, vitamins, and minerals. Within the framework of the NSC project several studies have been carried out.

Cross-sectional study. The baseline-data from the NSC study were used (2). The study population comprised 1772 children, aged $1-8$ years, obtained from a two-stage random sample. A sample of 16 rural villages was drawn. Only the capital city of the province could be classified as urban and was included in the study. A random sample of 1420 children was obtained from the rural villages, a sample of 352 children was obtained from the town. Biochemical data were available from a random subsample of 1060 children and reliable information about diarrhea and respiratory infections was obtained from 1646 children. A complete set of biochemical data from 877 children remained for logistic regression analyses.

Follow-up study. The study population comprised a random subsample of children $(n=146)$ from the control villages of the study population of the cross-sectional study who were not subject to any form of intervention. This population was classified into three groups differing in baseline vitamin A status according to the WHO criteria (serum retinol 
level: deficient $=<0.35 \mu \mathrm{mol} / \mathrm{L} ;$ marginal $=\geq 0.35,<0.70 \mu \mathrm{mol} / \mathrm{L} ;$ and adequate $\geq 0.70$ $\mu \mathrm{mol} / \mathrm{L})(8)$. These three groups were evenly distributed over the villages included in the study. We compared the incidence of respiratory diseases and diarthea during a three months follow-up between the three groups.

Intervention trial. A controlled intervention trial was carried out in the northem part of the Sakon Nakhon province. From four villages 166 children aged 1 -5 years were selected for the study. Children were randomly distributed over two gnoups on an individual basis. The day after the baseline examination $(T=0)$ standard capsules were given to 78 children; the other children served as controls. The capsule nipple was snipped off and the contents (200000 IU vitamin A and $40 \mathrm{IU}$ vitamin $\mathbb{E}$ ) were squeezed out into the child's mouth. After two $(\mathrm{T}=2)$ and four $(\mathrm{T}=4)$ months children were reexamined.

\section{Methods}

Two teams consisting of a pediatrician, a project physician, two biochemists, two nutritionist, and six field-workers visited and examined children. At each examination, children were gathered in the Buddhist temple or the local primary school, where their weight, height, mid upper arm circumference (muac), and triceps skinfold were recorded by the nutritionist and a field-worker. Capillary blood was taken by puncture of the finger tip: a total amount of $300 \mu \mathrm{l}$ of blood could be collected in heparinized 75- $\mu$ l capillaries. The pediatrician - who knew both the local disease pattern and vernacular symptoms descriptions, and spoke the local tongue - performed the general clinical examination and used questionnaires to obtain information about history of respiratory disease and diar rhea.

Respiratory diseases were defined by history of clinically significant respiratory complaints accompanied by fever, such as respiratory difficulties, cough, rumning nose, during the interval ( 2 or 3 months) between the examinations. Diarrhea was defined as a history of four or more loose stools per day at any time during the interval ( 2 or 3 months) between the examinations. The incidence data of both respiratory disease and diarrhea represent the number of individuals who had had at least one episode of one of these diseases during the interval between the examinations.

\section{Biochemical analyses}

At the field station plasma and cells were separated in a microhematocrit centrifuge. Plasma was collected in a $0,4-\mathrm{ml}$ sample vial and stored in the dark at $-20^{\circ} \mathrm{C}$ for analyses within two months.

The following biochemical analyses were carried out: all-trans retinol in plasma by high-performance liquid chromatography (HPLC) according to Speek et al.(9); retinolbinding protein (RBP) in plasma by the single radial immunodiffusion technique according to Mancini et al (10); albumin in plasma according to the bromcresolgreen method of Doumas et al (11), with the Boehringer kit No 263869 (Boehringer Mannheim GmbH. Mannheim, FRG); prealbumin and transferrin in plasma by the single radial immunodiffusion technique described by Mancini et al. (10), with the relevant specific antiserum of Behring (Behring Werke AG, Marburg, FRG); hemoglobin in whole blood of 1698 children according to the cyanmethemoglobin method of Van Kampen et al (12) with Boehringer kit No 124729 ; 
Table 1

Anthropometric and biochemical parameters in children with and without respiratory infections and diarrhea.

\begin{tabular}{|c|c|c|c|c|c|c|c|c|}
\hline \multirow[b]{2}{*}{ Variable } & \multicolumn{4}{|c|}{ Diamhea } & \multicolumn{4}{|c|}{ Respiratory diseases } \\
\hline & Numbe & er of children & Mean & (SD) & Numb & er of children & Mean & (SD) \\
\hline Age (years) & $\begin{array}{l}477 \\
1169\end{array}$ & $\begin{array}{l}\text { cases } \\
\text { controls }\end{array}$ & $\begin{array}{l}5.34 \\
5.28\end{array}$ & $\begin{array}{l}2.0 \\
1.7\end{array}$ & $\begin{array}{c}190 \\
1456\end{array}$ & $\begin{array}{l}\text { cases } \\
\text { controls }\end{array}$ & $\begin{array}{l}4.61^{* * * *} \\
5.38\end{array}$ & $\begin{array}{l}1.8 \\
1.7\end{array}$ \\
\hline Height (cm) & $\begin{array}{l}476 \\
1157\end{array}$ & $\begin{array}{l}\text { cases } \\
\text { controls }\end{array}$ & & $\begin{array}{l}12.7 \\
10.9\end{array}$ & $\begin{array}{l}188 \\
1445\end{array}$ & $\begin{array}{l}\text { cases } \\
\text { controls }\end{array}$ & $\begin{array}{l}97.2^{* * * *} \\
102.3\end{array}$ & $\begin{array}{l}11.4 \\
11.4\end{array}$ \\
\hline Weight (kg) & $\begin{array}{l}476 \\
1160\end{array}$ & $\begin{array}{l}\text { cases } \\
\text { controls }\end{array}$ & $\begin{array}{l}14.9 \\
15.1\end{array}$ & $\begin{array}{l}3.4 \\
3.2\end{array}$ & $\begin{array}{l}189 \\
1448\end{array}$ & $\begin{array}{l}\text { cases } \\
\text { controls }\end{array}$ & $\begin{array}{l}13.7^{* * *} \\
15.2\end{array}$ & $\begin{array}{l}3.1 \\
3.3\end{array}$ \\
\hline Muac (cm) & $\begin{array}{r}476 \\
1160\end{array}$ & $\begin{array}{l}\text { cases } \\
\text { controls }\end{array}$ & $\begin{array}{l}15.0^{\text {na }} \\
15.2^{2}\end{array}$ & $\begin{array}{l}1.2 \\
1.2\end{array}$ & $\begin{array}{c}189 \\
1448\end{array}$ & $\begin{array}{l}\text { cases } \\
\text { controls }\end{array}$ & $\begin{array}{l}14.8^{* * * *} \\
15.2\end{array}$ & $\begin{array}{l}1.2 \\
1.2\end{array}$ \\
\hline Retinol ( $\mu \mathrm{mol} / \mathrm{L})$ & $\begin{array}{l}291 \\
781\end{array}$ & $\begin{array}{l}\text { cases } \\
\text { controls }\end{array}$ & $\begin{array}{l}0.70^{*} \\
0.76\end{array}$ & $\begin{array}{l}0.31 \\
0.28\end{array}$ & $\begin{array}{l}115 \\
894\end{array}$ & $\begin{array}{l}\text { cases } \\
\text { controls }\end{array}$ & $\begin{array}{l}0.59^{* * *} \\
0.76\end{array}$ & $\begin{array}{l}0.26 \\
0.28\end{array}$ \\
\hline $\mathrm{RBP}(\mathrm{mg} / \mathrm{L})$ & $\begin{array}{l}288 \\
693\end{array}$ & $\begin{array}{l}\text { cases } \\
\text { controls }\end{array}$ & $\begin{array}{l}26.0^{* * *} \\
27.9\end{array}$ & $\begin{array}{l}8.8 \\
8.7\end{array}$ & $\begin{array}{l}103 \\
878\end{array}$ & $\begin{array}{l}\text { cases } \\
\text { controls }\end{array}$ & $\begin{array}{l}22.9^{*} \\
27.9\end{array}$ & $\begin{array}{l}7.3 \\
8.7\end{array}$ \\
\hline Ln trarisferrin $(\mathrm{g} / \mathrm{L})$ & $\begin{array}{l}286 \\
680\end{array}$ & $\begin{array}{l}\text { cases } \\
\text { controls }\end{array}$ & $\begin{array}{l}1.08^{*} \\
1.02\end{array}$ & $\begin{array}{l}0.36 \\
0.32\end{array}$ & $\begin{array}{l}101 \\
865\end{array}$ & $\begin{array}{l}\text { cases } \\
\text { controls }\end{array}$ & $\begin{array}{l}1.04 \\
1.04\end{array}$ & $\begin{array}{l}0.38 \\
0.33\end{array}$ \\
\hline Prealbumin (mg/L) & $\begin{array}{l}281 \\
680\end{array}$ & $\begin{array}{l}\text { casses } \\
\text { controls }\end{array}$ & $\begin{array}{l}202.4 \\
201.0\end{array}$ & $\begin{array}{l}68.9 \\
59.4\end{array}$ & $\begin{array}{l}103 \\
858\end{array}$ & $\begin{array}{l}\text { cases } \\
\text { controls }\end{array}$ & $\begin{array}{l}177.8^{* *} \\
204.2\end{array}$ & $\begin{array}{l}70.7 \\
60.6\end{array}$ \\
\hline Albumin $(g / L)$ & $\begin{array}{l}280 \\
672\end{array}$ & $\begin{array}{l}\text { cases } \\
\text { controls }\end{array}$ & $\begin{array}{l}41.1 \\
41.7\end{array}$ & $\begin{array}{l}5.1 \\
4.9\end{array}$ & $\begin{array}{c}97 \\
855\end{array}$ & $\begin{array}{l}\text { cases } \\
\text { controls }\end{array}$ & $\begin{array}{l}41.7 \\
41.6\end{array}$ & $\begin{array}{l}6.2 \\
4.9\end{array}$ \\
\hline $\mathrm{Hb}(\mathrm{mmol} / \mathrm{l})$ & $\begin{array}{c}457 \\
1123\end{array}$ & $\begin{array}{l}\text { cases } \\
\text { controls }\end{array}$ & $\begin{array}{l}7.0 \\
7.0\end{array}$ & $\begin{array}{l}0.9 \\
0.9\end{array}$ & $\begin{array}{r}177 \\
1403\end{array}$ & $\begin{array}{l}\text { cases } \\
\text { controls }\end{array}$ & $\begin{array}{l}7.0 \\
7.0\end{array}$ & $\begin{array}{l}1.1 \\
0.9\end{array}$ \\
\hline Ift $(\%)$ & $\begin{array}{c}453 \\
1122\end{array}$ & $\begin{array}{l}\text { cases } \\
\text { controls }\end{array}$ & $\begin{array}{l}36.6 \\
36.7\end{array}$ & $\begin{array}{l}3.1 \\
2.7\end{array}$ & $\begin{array}{r}177 \\
1398\end{array}$ & $\begin{array}{l}\text { cases } \\
\text { controls }\end{array}$ & $\begin{array}{l}36.4 \\
36.7\end{array}$ & $\begin{array}{l}3.4 \\
2.7\end{array}$ \\
\hline
\end{tabular}

${ }^{*}=\mathrm{p}<0.05,{ }^{* * *}=\mathrm{p}<0.01,{ }^{* * *}=\mathrm{p}<0.001, \mathrm{Ln}=$ natural log-transformed values.

\section{Statistical analyses}

All data were collected on precoded forms, and checked twice for accuracy and completeness before shipping to the CIVO-TNO Institutes, were data were processed with the BMDP statistical package (13). Statistical analyses comprised: i. description and logistic regression of cross-sectional baseline data to investigate the association of diarrhea and respiratory diseases with vitamin A deficiency; ii. $x^{2}$ tests and $t$-tests for values of discrete and continuous variables respectively comparing the baseline levels of children who did and those who did not develop diarrhea or respiratory diseases in the period between the baseline examination and the reexamination after 3 months; iii. $x^{2}$-tests com. paring the numbers of children with diarthea or respiratory disease in the intervention trial after 2 and 4 months.

\section{Results}

\section{Cross-sectional study}

Of the examined children $28.9 \%$ had a history of diarrhea, and a history of respiratory diseases was found in $11.5 \% ; 38.4 \%$ of children with a history of respiratory diseases showed also a history of diarrhea; of the children with a positive anamnesis of diarrhea $15.3 \%$ had also a history of respiratory disease. Table 1 shows the anthropometric and biochemical parameters in children with and without diarrhea or respiratory infections. 
Children with diarrhea had significantly smaller mid upper arm circumferences (muac) and significantly lower levels of retinol, retinol-binding protein (RBP), and ransferrin. Children with a history of respiratory disease were younger than children without history of respiratory disease and showed significantly lower levels of retinol, retinol-binding protein, prealbumin, and anthropometric measurements.

Table 2

Coefficients of the logistic regressions with diarrhea and respiratory disease as dependent variables $(n=877)$.

\begin{tabular}{|c|c|c|}
\hline \multirow[t]{2}{*}{ Independent variable } & \multicolumn{2}{|c|}{ Deppendent variable } \\
\hline & Diarthea & Respiratory Distases \\
\hline Sex & 0.00795 & 0.05154 \\
\hline Age (years) & 0.07010 & $-0.19483^{*}$ \\
\hline Height/age & -0.18458 & $-0.41832^{*}$ \\
\hline Weight /height & -0.00557 & -0.02369 \\
\hline Muac $(\mathrm{cm})$ & $.0 .22819^{*}$ & -0.06606 \\
\hline Retinol $(\mu \mathrm{mol} / \mathrm{L})$ & $-0.8103^{* *}$ & $-1.4076^{* * *}$ \\
\hline Transferrin $(\mathrm{g} / \mathrm{L})$ & 0.01971 & -0.01776 \\
\hline Prealbumin (mg/L) & 0.00124 & $-0.00645^{*}$ \\
\hline Albumin $(\mathrm{g} / \mathrm{L})$ & .0 .01237 & -0.01063 \\
\hline Hemoglobin (mmol/L) & -0.04802 & 0.01242 \\
\hline Hematocrit (\%) & 0.01871 & -0.06149 \\
\hline
\end{tabular}

* $\mathrm{p}<0.05$, ${ }^{*} \mathrm{p}<0.01$.

Table 2 shows the results of the logistic regression analyses with history of diarrhea or respiratory diseases as dependent variables. Age, sex, height for age, weight for height, left arm circumference, albumin, transferrin, prealbumin, hemoglobin, hematoctit, and retinol were used as independent variables. There was a significant negative association of retinol with both diarrhea and respiratory disease, adjusted for associations with the other variables.

\section{Follow-up study}

Follow-up study: Table 3 shows the incidence of diarrhea and respiratory diseases during a three months follow-up in the three different groups "There was a dose-dependent association between the vitamin A status and respiratory disease: the incidence rose with the degree of vitamin A deficiency. Children with a deficient serum retinol level developed significantly more $(3.6$ times, $p<0.01)$ respiratory diseases than children with adequate levels (Table 3 ). History of diarrhea was equally distributed among children with different vitamin $A$ status.

\section{Intervention study}

Table 4 shows the results of a controlled intervention in 166 preschool children. At the baseline examination the anthropometric and biochemical parameters between the intervention and the control group did not differ significantly. Children three year and older attend the day-care centers in the villages, while children aged 1-2 years stay at home. Therefore we analyzed these groups separately. Two months after intervention with a high single oral dose of vitamin $\mathrm{A}(200.000 \mathrm{IU})$, children aged 3-5 years of the control group showed 3.12 times more a history of diarrhea and 2.89 times more respiratory infections 
than those of the intervention group. However, these differences are not significant. The differences between the groups aged 1-2 years were during this first period less prominent. Between two and four months after intervention no differences were present anymore with regard to diarthea, for both age categories. However, in children aged 1-2 years respiratory infections still occurred more frequently $(2.52$ times, $p<0.025)$ in the control group.

Table 3

Incidence of respiratory diseases or diarrhea during a three months follow-up in three groups with a different vitamin A status.

\begin{tabular}{|c|c|c|c|}
\hline \multicolumn{2}{|l|}{ Vitamin A status } & \multirow{2}{*}{$\begin{array}{l}\text { Incidence of } \\
\text { diamhea during } \\
3 \text { months follow-up } \\
\text { of }\end{array}$} & \multirow{2}{*}{$\begin{array}{l}\text { Incidence of } \\
\text { respiratory diseases } \\
3 \text { months follow-up } \\
\text { \% }\end{array}$} \\
\hline & n & & \\
\hline Deficient $(<0.35 \mu \mathrm{mol} / \mathrm{l})$ & 23 & 17.4 & $39.1^{* * *}$ \\
\hline Marginal $(20.35,<0.70 \mu \mathrm{mol} / \mathrm{l})$ & 68 & 17.9 & 26.5 \\
\hline Adequate $(\geq 0.70 \mu \mathrm{mol} / \mathrm{l})$ & 55 & 16.4 & 10.9 \\
\hline
\end{tabular}

** Significant difference $(p<0.01)$ between the group of children with deficient and with adequate levels of serum retinol.

\section{Discussion}

Our results, with serum retinol levels as biochemical markers of vitamin $A$ status and as evidence for vitamin A deficiency, confirm the findings of Sommer et al. where presence of vitamin A deficiency was based on clinical criteria (5). The cross-sectional analyses showed that retinol values were significantly lower in children with history of either diarrhea or respiratory diseases. The difference of the nutritional status parameters between cases and controls was more striking in children with respiratory diseases than in children with diarrhea. In the logistic regression models retinol remained significantly associated with both diarrhea and respiratory disease after adjustment for age, sex, height for age, weight for height, muac, albumin , transferrin, prealbumin, hemoglobin and hematocrit. Serum retinol was more closely associated with occurrence of diarrhea than were most other parameters of the general nutritional status.

However, cross-sectional analyses cannot answer the question whether the disease or vitamin A deficiency comes first. The second approach was selected to investigate prospectively a group of children who were not subject to any form of intervention. We observed that children with deficient levels of retinol at the baseline examination were 4 times more likely to develop respiratory diseases in 3 months follow-up. Similar observations have been made by Solon et al. in the Philippines (14). A more recent study in India by Milton et al. observed also that during a 6 months follow-up children with mild xerophthalmia developed respiratory disease twice as often than children with nomal eyes. As in our study no association was found between mild xerophthalmia and incidence of diarrhea (15). 
Table 4

Incidence of diarthea and respiratory disease in the witamin A-supplemented group and in controls, during two months of follow-up and between two and four months atter inter.

vention.

\begin{tabular}{|c|c|c|c|c|c|c|}
\hline \multirow[t]{2}{*}{ Period } & \multicolumn{2}{|c|}{ Nurnber of children } & \multirow{2}{*}{$\begin{array}{l}\text { Diarnhea } \\
\text { (\%) } \\
\text { Suppl }\end{array}$} & \multirow{2}{*}{$\begin{array}{l}\text { (o) } \\
\text { Contr }\end{array}$} & \multicolumn{2}{|c|}{ Respiratory disease } \\
\hline & Suppl & Contr & & & Suppl & Contr \\
\hline \multicolumn{7}{|c|}{ 0-2 months } \\
\hline 1-2 years & 40 & 35 & 17.5 & 22.9 & 27.5 & 31.4 \\
\hline $3-5$ years & 26 & 30 & 7.7 & 24.1 & 11.5 & 33,3 \\
\hline Total & 66 & 65 & 13.6 & 23.4 & 21.2 & 32.3 \\
\hline
\end{tabular}

2-4. months

\begin{tabular}{lllllll}
$1-2$ years & 38 & 33 & 39.5 & 30.3 & $13.2^{*}$ & 33.3 \\
$3-5$ years & 31 & 41 & 16.1 & 19.5 & 12.9 & 14.6 \\
\hline & 69 & 74 & 29.0 & 24.3 & 13.0 & 23.0 \\
\hline
\end{tabular}

* $\chi^{2}$ atest p 90.025

As a sequel to their findings, Sommer and his colleagues planned a community trial in Indonesia to establish the effect of intervention with a high dose of vitamin A $(200,000$ IU) on childhood mortality. 450 villages in Aceh, northern Sumatra, were randomly as signed to either participate in a vitamin A supplementation scheme $(n=229)$ or serve for one year as a control $(n=221)$. The total study population comprised 25,939 preschool children. Although it was acknowledged that exposure of the two groups of villages to outside influences varied, it is unlikely that this could explain the finding of $34 \%$ reduction in the mortality of the recipient children (6).

Our intervention trial showed that the recipient children appeared to be less susceptible to diarrhea and respiratory infections than the controls. The results of the intervention trial are clinically significant differences, although most reductions did not reach statistical significance. Failure to reach statistical significance with that great a clinical difference, indicates that our sample size was far too small.

We have tried to minimize the methodological problems which are inherent to the health interviews. Problems of communication could be avoided since the national pediatricians lived in the same region, knew both the local disease pattern and vernacular symptom descriptions, and spoke the local tongue. They used questionnaires that included a list of tracer conditions and they had to score the reliability of their health interview. This is reflected by the different numbers of history of disease per study period. In Northeast Thai-land social and psychological barriers to report history of diarrhea or respiratory diseases have not been reported. Since reporting may be expected to be most accurate when the illness is salient, we restricted our definition of respiratory disease to respiratory complaints accompanied by fever (16). We chose a three-months recall period in the cross-sectional analysis and the follow-up study and a two-months recall period in the intervention trial since loss of accuracy due to the vagaries of memory over this period of time is likely to be low. In both the follow-up study and the intervention studly, underor over-reporting of these diseases, if any, is likely randomly distributed among the different study groups, and consequently did not bias the results (17).

Respiratory diseases as defined by us is a more salient condition than is diarrhea. This may explain that at the baseline examination $38.4 \%$ of the children with history of 
respiratory diseases had also history of diarncea, while only $15.3 \%$ of the children with diarthea had also a history of respiratory diseases.

The association between vitamin $A$ deficiency and systemic illness has hardly been studied. Severe vitamin A deficiency usually does not occur as an isolated problem, but is almost invariably accompanied by other nutrient deficiencies. However, early studies on lack of vitamin $A$ showed that even mild vitamin $A$ deficiency leads to patchy keratinization of the epithelial lining of the respiratory, genitourinary, and gastrointestinal tracts (18-20). The epithelial barrier is the first step of the protection mechanisms against infection, and it has been suggested that keratinization leads to bacterial colonization and infections (4). Other studies also suggested that vitamin A plays an important rolle in the immunological system $(21-23)$. Vitamin $A$ is capable of modifying immune responses, both in viwo and in vitro.

A recent randomized controlled trial in Australia about the effect of vitamin A supplementation on susceptibility to acute respiratory infections in children with adequate, but maybe suboptimal retinol levels $(1.70 \mu \mathrm{mol} / \mathrm{l})$, observed $19 \%$ fewer episodes of respiratory infections in the supplemented group than the placebo group (24). The results of this study suggest that even in developed countries the associarion between vitamin $A$ and infections plays a role.

Our study confirms the importance of attacking not only severe but also mild vitamin $A$ deficiency.

\section{Acknowledgments}

The authors thank Professor RJJ Hermus, TNO-CrVO Toxicology and Nutrition Institute, Zeist, The Netherlands, Professor HA Valkenburg, Erasmus University, Rotterdam, The Netherlands, and Dr. Kusuma Chusilp, Dr. Khaisaeng Rojsathaporn, Khon Kaen University, Khon Kaen, Thailand for their assistance.

\section{References}

1. Sommer A. Massive Dosages of vitamin A in Developing Countries. Abstracts International Symposium on Elevated dosages of vitamin Benefits and Hazards, Interlaken, Swiss, Sept. 7-9, 1987.

2. Bloem MW, Wedel M, Egger RJ, Speek A, Saowakontha S, Schreurs WHP. Prevalence of vitamin A deficiency in the Sakon Nakhon Province in Northeast Thailand. Am I Epidemiol. (accepted)

3. Green HN, Mellanby E. Vitamin A as an anti-infective agent. Br Med J 1928;ii:691. 6.

4. Sommer A, Tarwotjo I, Hussain $G$, Susanto D. Increased mortality in children with mild vitamin A deficiency. Lancet 1983;ii:585-8.

5. Sommer A, Katz J, Tarwotjo I. Increased risk of respiratory disease and diarthea in children with preaxisting mild vitamin A deficiency. Am J Clin Nutr 1984;40:10905 .

6. Sommer A, Tarwotjo 1, Djunaedi $\mathbb{E}$, West KP, Loeden AA, Tilden R. Impact of vitamin A supplementation on childhood mortality. Lancet 1986;1:1169-73.

7. Anonymous. Fall and rise of the anti-infective vitamin. Lancet $1986 ; 0 ; 1191$.

8. World Health Organization, Control of vitamin A deficiency, xerophthalmia. Geneva: Technical Report Series 672, 1982.

9. Speek AJ, Wongkam, Limratana N, Saowakontha, Schreurs WHP. Microdetermination of vitamin $A$ in human plasma using-performance liquid chromatography with fluorescence detection. J Chromatogr Biomed appl 1986;382:284-9.

10. Mancini $\mathrm{G}$, Carbonara $\mathrm{AD}$, Heremans JF. Immunochemical quantitation of antigens by single radial immunodiffusion. Immunochemistry, Pergamon Press, 1965:23554. 
11. Doumas BT, Watson W, Biggs HG. Albumin standards and the measurement of serum albumin with bromcresol green. Clin Chim Acta 1971:31:87-96.

12. Kampen EJ van, Zijlstra WG. Standardization of hemoglobinometry II. The hemiglobincyanide method. Clin Chim Acta 1961;6:538-44.

13. Dixon, W.J. BMDP-statistical software, University of Calformia Press, Berkely, Los Angeles, London, 1985.

14. Solon FS, Popkin BM, Fernandez TL, Latham MC. Vitamin A deficiency in the Philippines: A study of xerophthalmia in Cebu. Am J Clin Nutr 1978;31:360-8.

15. Milton RC, Reddy V, Naidu AN. Mild vitamin A deficiency and childhood morbidity-an Indian experience. Am J Clin Nutr 1987;46:827-9.

16. Kroeger A. Health Interview Surveys in Developing Countries: A Review of the Methods and Results. Int J Epidemiol 1983;12:465-81.

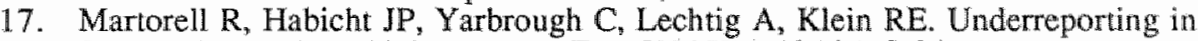
fortnightly recall morbidity surveys. Env Chld Hith 1976;129-34.

18. Wolbach SB, Howe PR. Tissue changes following deprivation of tat-soluble A wi tamin. J Exp Med 1925;42:753-77.

19. Blackfan KD, Wolbach SB. Vitamin A deficiency in infants: a clinical and pathological study. J paediatr 1933;3:679-706.

20. Sweet $L K, K$ "ang HJ. Clinical and anatomic study of avitaminosis $A$ among the Chinese. Am J Dis Child 1,935;50:699-734.

21. Scrimshaw NS. Synergistic and antogonistic interactions of nutrition and infection. Fed Proc 1966;25:1679-81.

22. Ludovici PP, Axelrod AE. Circulating antibodies in vitamin A deficiency states. Proc Soc Exp Biol Med 1951;77:526-30.

23. Krisnan S, Bjuyan UN, Talwar GP, Ramalingawsami V. Effect of vitamin A and protein-calorie malnutrition on immune responses. Immunology 1974;27:383-92.

24. Pinnock CB, Douglas RM, Badcock NR. Vitamin A status in children who are prone to respiratory tract infections. Aust Pediatr J 1986;22:95-9. 

Chapter 8.

\section{GENERAL DISCUSSION}

\subsection{Introduction}

The primary aim of the studies described in this thesis was to obtain information on the magnitude of vitamin A deficiency and xerophthalmia in the Sakon Nakhon province and to elucidate the secondary complications of vitamin A deficiency. The studies were part of the Nutrition Supplement Co-operation Project (NSC Project) performed by the TNOCIVO Toxicology and Nutrition Institute and the University of Khon Kaen between March 1985 and July 1986 in the Sakon Nakhon province in Northeast Thailand and financially supported by the Dutch Ministry of Foreign Affairs. The aim of the project was to improve the nutritional health of 6250 preschool and school children with a nutritional supplement containing protein, vitamins and minerals. As a consequence, the results of these studies ought to contribute more information for implementation in Thailand's Sixth National Economic and Social Development Plan (1).

In spite of the lack of data on the prevalence of xerophthalmia, Thailand is cliassified by the $\mathrm{WHO}$ as a country where xerophthalmia/vitamin A deficiency is not a public health problem, but where the situation should be closely monitored. However, a recent study carried out by Sakon et al. in 1977 showed that $17.6 \%$ of 146 preschool children examined had deficient serum retinol levels and $\pm 70 \%$ showed marginal serum retinol levels (2). Severe forms of xerophthalmia were not observed, which might be attributed to the restricted size of the sample. This observation indicated a high level of subclinical vitamin A deficiency. When the NSC project started we wished to obtain insight into the magnitude of vitamin A deficiency in the Sakon Nakhon province.

\section{2 factors affecting the vitamin $A$ status in Northeast Thailand}

\subsubsection{The prevalence study}

The most prominent finding in our prevalence study was a high number of children with subclinical vitamin A deficiency and mild xerophthalmia. Night blindness and Bitot's spots were found in the rural population in percentages $(1.3 \%$ and $0.4 \%$ respectively) comparable to the WHO criteria $(1.0 \%$ and $0.5 \%$ respectively) for a public health problem. Deficient serum retinol levels were found among $12.7 \%(95 \% \mathrm{CI}=9.9-15.5)$ of the preschool children examined. After standardization for age the percentage of children with deficient serum retinol levels (16.3) were comparable to that found by Sakon at al.(2).

Recent onset of night blindness in preschool children is practically pathognomonic of vitamin A deficiency (3). Although the history method is recommended by the WHO, the literature provides only little reliable information on the association between night blind. ness and the vitamin A status (4). Our data confirm the conclusion drawn from studies in Indonesia: when a mother complains that her child is night blind, this is almost certainly correct $(5,6)$. One of our findings was the lack of association between serum vitamin $A$ level and conjunctival xerosis. The affected children were of school age, and we may conclude that signs of conjunctival xerosis do not represent active vitamin A deficiency.

McLaren recommends the use of the host-agent-environment concept to describe the warious factors playing a role in the pathogenesis of vitamin $\mathrm{A}$ : the human being can be seen as the host, the diet in its various forms as the agent ${ }_{\text {n }}$ and the environment is constituted by the physical, socioeconomic, and psychological factors that influence vitamin $\mathrm{A}$ intake and consequently vitamin $A$ status (7). 


\subsubsection{Host factors}

\subsubsection{Age}

The peak prevalence of xerophthalmia is during the early childhood when growth rate is high. Furthermore, common childhood infections such as diarrhea, upper respiratory infections, bronchitis and chicken pox, greatly speed up metabolism and consequently increase requirements of vitamin $A$. However, our data suggest that environmental factors may greatly affect the association between age and vitamin $A$ deficiency. The age distribution of children with deficient serum retinol levels differed between the rural and urban areas. There was a positive significant correlation $(R=0.25, p<0.001)$ between age and serum retinol among the rural children and a negative significant correlation $(R=-0.25$, $\mathrm{p}<0.001$ ) among the urban children. This difference is mainly due to differences between rural. and urban preschool children. We have not gathered data on urban children aged 1-2 years, but the children aged 3-5 years in the rural area had significantly lower serum retimol lewels than chilldren of the same age group in the urban area. However, the vitamin A status of children over six years did not differ between the rural and urban areas. The urban preschool children had a higher vitamin A intake (88\% of RDA) than the urban school children (66\% of RDA). School children, an age group often ignored by Public Heal th authorities, seem to need more attention concerning vitamin $A$ intake. Night blindness was equally distributed among the different age groups, and Bitot's spots were only observed among the children aged 3-5 years.

\section{$8.2 .2 .2 \mathrm{Sex}$}

Although many reports have concluded that boys are at greater risk of night blindness we observed that night blindness was equally distributed among boys and girls. However, differences in serum retinol levels were significant among the rural children aged 35 years, boys having lower serum retinol levels than girls.

\subsubsection{Agent factors}

\subsubsection{Vitamin A sources}

In the rural area of the Sakon Nakhon province sticky rice, which does not contains any carotene, is the staple food and provides $70 \%$ of energy intake. Rice, vegetables and fish sauce constitute the main ingredients of each meal. In the rural area wegetables (32\%) and fruits $(21 \%)$ are the main sources of carotenoids. Carotenoids are red and yellow fat soluble pigments composed of a class of hydrocarbons (carotenes) and their oxygenated derivatives (oxycarotenoids or xanthophylls). Of the 500 or more carotenoids identified, only about $10 \%$ may act as precursors of vitamin A. The most effective provitamin A carotenoid is all-trans- $\beta$-carotene, which is a common but not predominant carotenoid in most colored fruits and dark-green leafy vegetables. The current tables of food composition are based on contestable methods of determining the provitamin $A$ activity of foodstuffs. These methods do not distinguish between carotenoids with and without provitamin $A$ activity and often overestimate the vitamin $A$ content of certain foodstuffs. Furthermore, considerable losses can be expected as a result of processing. Speek et al. have investigated the total carotenoid and $\beta$-carotenoid contents of Thai vegetables and the effect of processing (8). They conclude that the provitamin A activity of the vegetables investigated is markedly lower than that stated in the Thai Food Composition Table of 1978. The average losses of vitamin A activity as a result of local processing, i.e. cooking, frying, fermenting, drying and drying followed by cooking, were found to be $14,24,29,44$ and $60 \%$, respectively. 


\subsubsection{Other mutrients}

There was no association between protein-energy malnutrition as evaluated by anthropometric measurements, and xerophthalmia or vitamin $A$ deficiency. This suggests that vitamin $A$ deficiency in this region is specifically due to lack of vitamin $A$ intake and is not secondary to protein malnourishment. The results of the statistical analysis of food consumption data agree with the clinical and biochemical observations mentioned. It has long been established that the level of dietary fat is important in facilitating absorption of carotenoids. Studies conducted in developing countries, where dietary fat usually represents a low percentage of total energy intake, have demonstrated a significantly increased absorption of dietary carotenoids upon a small supplement of fat $(9,10)$. Therefore, when the main source of vitamin $A$ is in the carotenoid form, it is obvious that the intestinal utilization of dietary vitamin A can be improved by increasing the intake of dietary fat, and that this should be recommended as well for the rural areas of Northeast Thailand.

\subsubsection{Environmental factors}

\subsubsection{Season}

As early as 1957 Moore reported the annual periodicity in the fluctuation in dietary intake of vitamin $A(11)$. Vegetables and fruits are an important source of vitamin $A$ in the Asian diet. In Northeast Thailand, about $50 \%$ of available vitamin A comes from vegetables and fruits. Fruits and vegetables are available in rather short seasons. Iron intake, however, comes from rice (33\%) and animal products (49\%) and consequently will show less seasonal variation. Only $16 \%$ of the iron intake is provided by vegetables and fruits. Our prevalence study was carried out just at the end of the dry season when mangoes started becoming available. The medium and long-term intervention trial, discussed in chapter 5, showed an increase in vitamin A status of the control group which was probably due to this seasonal influence. The strong improvement of the vitamin A status leads us to recommend vitamin $A$ supplementation especially at the beginning of the dry season.

\subsubsection{Geographical and agricultural factors}

The Northeast is one of the four regions of Thailand surrounding the Korat plateau. The southern and western sides of the Korat plateau forms a rim rising some $300 \mathrm{~m}$ above sea level. The other parts of the plateau have a relatively low and undulating surface, draining eastwards, via the Man and Chi rivers, to the river Mekong, which flows along Korat's entire northern and eastern edges. There is barely adequate rain and during the dry season the country has a desiccated appearance. The soil is barren, except along the rivers. The Northeast has most unpredictable growing conditions, the lowest level of irrigation prowision and the largest proportion of people directly dependent on agriculture. Not until the late 1950 s the uplands have been opened up for cultivation. However, much land has been cleared that is unsuitable for permanent cultivation, and there are now serious problems of land shortage and soil erosion.

Rice, cassava and kenaf are the predominant crops of the Northeast. The most impoverished farmers are those solely dependent on rice cultivation, with little or no off-farm employment or other cash crops for supplementary income. Other farmers alternate cassava and kenaf cultivation in response to changes in relative price levels. The poverty of the farmers are due to low prices on the world market, which I will explain in further detail.

Since 1981, Thailand has been the world's largest exporter of rice. In 1985 the country accounted for about $40 \%$ of the world's rice exports. In 1986, the US government expressed its concern about the continuing expansion of Thai rice exports. The USA flooded the world market with high quality, heavily subsidized, and hence low-price rice, 
thus putting pressure on export prices of rice, especially high-grade rice. As a result farmers' incomes decreased so that they could no longer afford the fertilizers, which are mainly imported and relatively expensive. The viclous circle was completed with low yields, reduced incomess and increasing debts (12).

Thailand's cassava production is almost entirely exported as tapioca pellets for cattle food, principally to the Netherlands, but also to France, Belgium and the Federal Republic of Germaliy. Between 1979 to 1983 cassava ranked second to rice as an export produce, contributing as much as $13 \%$ of export eamings. However, in the subsequent three years the EEC restricted imports of cassava. Although Thalland has since penetrated some non-EEC markets, the exports declined (12).

Kenaf, a low-grade fibre resembling jute, is grown almost exclusively in the Northeast. When the crop was introduced in the 1960 s, many of the region's farmers entered the world market. Where kenaf accounted for $11.5 \%$ of the export in 1966, its share had declined to $0.1 \%$ by 1980 . The causes were the low quality of the fibre, a general fall in world demand for hard fibres, and the potential of the land for the cultivation of cassava (12).

Since the Northeast is almost entirely dependent on agriculture, it has to cope with many difficulties. Whereas between 1984 and 1986 the Thai economy has undergone a marked improvement and the Bangkok and Central plain regions have sharply increased their share of the national gross domestic product (GDP), the Northeast has fallen further behind, with a per caput income of only $43.4 \%$ of the national average.

In the rural area there is a significant association between socioeconomic status and vitamin A deficiency. A study in the province of Nakhon Rachasima, about $400 \mathrm{~km}$ from Sakon Nakhon, showed a significant positive correlation between fruitconsumption and fruit production (13). Fruitconsumption being almost ten times higher among those who grow fruits than among those who do not. So, growing of vegetables and fruits seems to be important to improve the vitamin A status in this area. Fortunately some farmers tend to make themselves less dependent on world market prices by growing crops for the local market and for private use. This trend may generate employment and reduce migration to urban areas, which is now $50 \%$ for the youngsters.

\subsection{Vitamin A deficiency, infections, and anemia}

\subsubsection{Physiology}

Xerophthalmia is the most evident manifestation of vitamin A deficiency. The magnitude of the problem of xerophthalmia and the potentially devastating effects of vitamin A deficiency on the eye, has led many to consider vitamin A deficiency as an ocular disease. However, it is actually a systemic disorder (14).

Vitamin $A$ has at least two essential functions. First of all, vitamin A as 11-cisretinaldehyde is the chromophore for all four visual pigments and as such essential to vision. Second, vitamin $A$ has long been known for its importance in promoting growtli, regulating proliferation and differentiation of epithelial tissues, and regulating reproduction. In particular, the effect of vitamin A on the maintenance of normal mucosal epithelium has attracted much attention. The basic physiological role of vitamin $A$ is to control proliferative activity in the various secretory and ductular epithelial tissues of the body. Vitamin A deficiency leads to impaiment of the visual cycle (night blindness) and squamous metaplasia of mucosal epithelium with focal areas of keratinization.

\subsubsection{Effect of infection on the vitamin A-status}

Although vitamin A deficiency is one of the most important nutritional problems in the Third World and long has been associated with infectious diseases, there are only few well documented studies on this association. A plausible explanation is that vitamin A deficiency has always been accompanied by other nutritional deficiencies. Furthermore, 


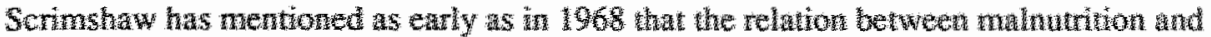

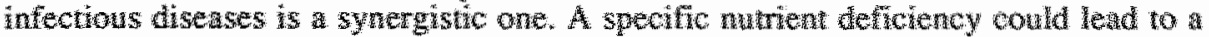

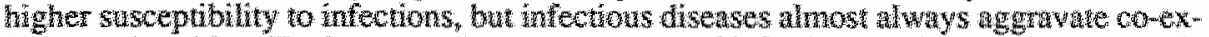

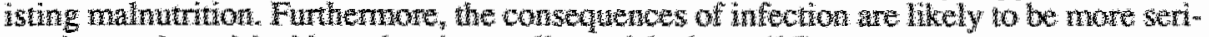

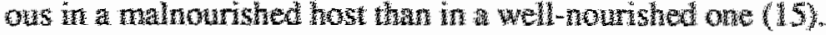

\subsubsection{Food hata}

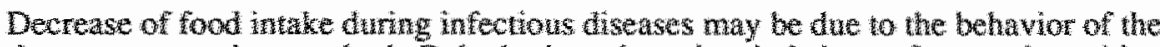

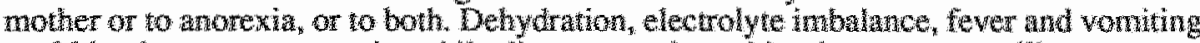

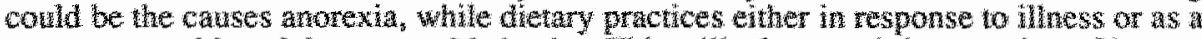

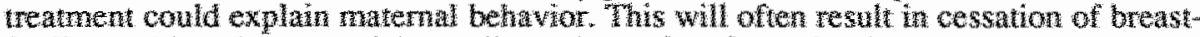

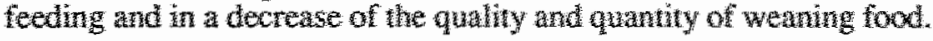

\subsection{2 .2 Astrpion}

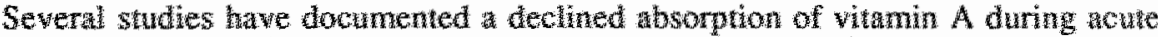

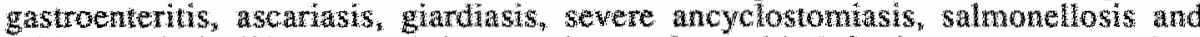
schistosomiasis. We assessed the prevalence of parasitic infections among andom

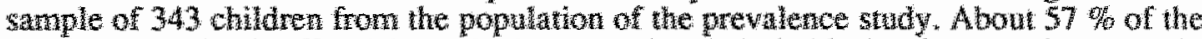
chadren examined suffered from single or multiple hemminasis. However, in our sudy

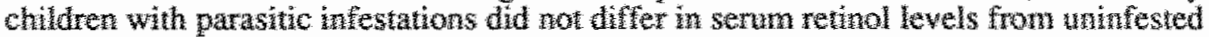

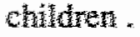

\subsubsection{Menabohism}

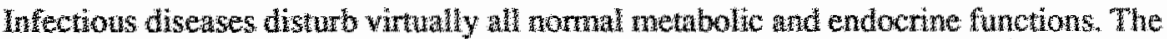

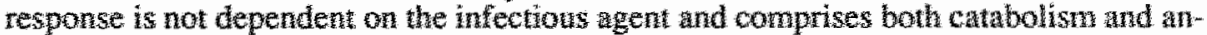

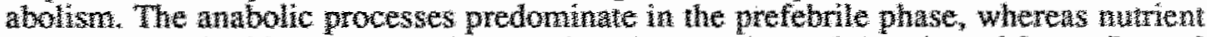
loss associated with catabolism is related to the severuty atad duration of fover. Severat

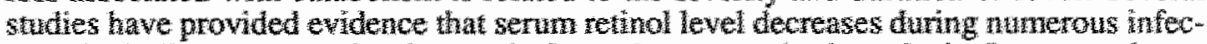

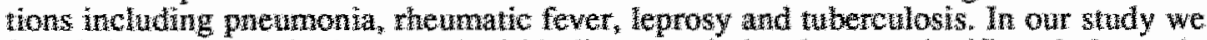
fond that serum retinol and Retinol-binding protein levels were significantly lower in

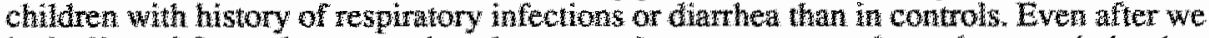

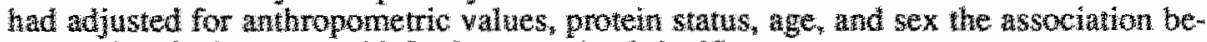

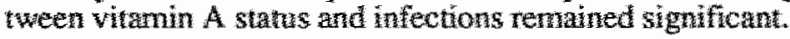

\subsubsection{Effect of vitamin A deficiency on infections}

Vitamin A deficiency is associated with an increased susceptibility to infection. At the turn of the century, vitamin A was known as the "anti-infective vitamin" (16). The nature of this anti-infective role is not known. Two plausible explanations are: there is a direct relation with the immune system, particularly the cell-mediated immune system, or loss of normal mucosal epithelium in a variety of organ systems creates a predisposition for infection.

Mortality among children with severe xerophthalmia (X3A, X3B) is extremely high $(50 \%)$. Only recently, however, it has also been observed that children with mild xerophthalmia $(X N, X 1 B$ ) have a higher mortality (4-12 times) than children without these clinical symptoms (17). The more clinical symptoms of xerophthalmia were found, the higher was mortality. Risks of diarrhea and respiratory diseases were commoner in persistently vitamin A-deficient children (18). Sommer et al. felt that vitamin A deficiency on itself has a considerable effect on mortality.

Vitamin A deficiency causes the loss of normal ciliated mucosal epithelium in the tracheobronchial tree and the development of focal areas of keratinization. Normal homeostatic mechanisms to clear the respiratory tract of inhaled particles, bacteria, and debris 
are no longer present. Squamous metaplasia are present in the urinary tract, in parts of the gastrointestinal tract such as the pancreatic duct, and in the middle ear and the auditory tubes.

We investigated the association between witamin $A$ deficiency as assessed by serum retinol levels, and infectious diseases by several epidemiologic study models: a crosssectional study; a follow-up study; and an intervention trial.

A cross-sectional analysis was carried out for 1772 children, aged $1-8$ years and biochemical data were avaliable from a random subsample of 1060 children (60\%) and reliable information about diarrhea and respiratory disease from 1646 children. Children with a history of diarthea or respiratory disease had significantly lower levels of serum retinol and retinol-binding protein. To adjust for the possible confounding effects of age, sex, mutritional status, and protein status, logistic regression was carried out on a complete set of data of 877 children: a significant consistently negative association between serum retinol and both diarrhea and respiratory diseases was observed.

To obtain further evidence whether this observed association is a causal one, a followup and a controlled intervention trial were carried out. A follow-up study of a subsample of 146 children, who were not subject to any form of intervention, showed that children with deficient serum retinol levels $(<0.35 \mu \mathrm{mol} / \mathrm{L})$ had an about 4 times greater risk of developing respiratory diseases $(p<0.01)$ than had children with adequate levels during a follow-up of three months. With regard to diarrhea no significant relationship was found. A controlled intervention trial with 166 children, aged $1-5$ years, showed that during two months of follow-up after supplementation with a single oral massive dose of witamin $A$ (200 000 IU), children, aged 3-5 of the control group had a higher incidence of respiratory disease ( 2.89 times) as well as of diarthea ( 3.02 times) than the intervention group. Howewer, the differences were not significant, probably due to the low number of children surveyed. In the age group 1-2 years very little differences were observed. Between two and four months after the start of the intervention children, aged 1-2 years of the control group had 2.5 times as often a history of respiratory disease $(p<0.025)$ than the intervention group. Little differences were found in children, aged 3-5 years old. The susceptibility to infectious diseases is often different between children playing at home and children attending day ${ }^{-c a r e}$ centers. The effect of intervention with witamin $A$ is dependent on the environmental differences during certain time periods. With our history method we can not differentiate between different kinds of respiratory diseases and severity of diarrhea. Therefore it seems to be very important to repeat the intervention study with a greater number of children and better morbidity data to understand better the pathophysiologic mechanism at work. However, it seems to be appropriate to advise Thailand mounting high dose vitamin A programs, because reduction of child morbidity is a reasonable expectation.

\subsubsection{Anemia and vitamin A deficiency}

Since the beginning of this century several reports have described anemia as a secondary complication of vitamin A deficiency. Although in the past decade much research had been done on this subject, the pathogenesis is still not clear. The prevailing hypotheses explaining this association are: vitamin $A$ influences the differentiation of the red blood cell ; vitamin A deficiency is responsible for a "blockade" of reticuloendothelial iron deposits, thus inhibiting their mobilization; vitamin A deficiency increases susceptibility to infectious diseases and consequently to an impaired hematopoiesis.

In three studies we have tried to obtain more information to elucidate this mechanism. We conducted the cross-sectional study to repeat the study of Mejia in an other ecological setting (19). We found that vitamin $A$, adjusted for the effects of age, sex, protein status, and morbidity data, was significantly associated with the iron status. However, we cannot exclude the possibility that children with a low intake of vitamin $A$ also happen to have a low intake of iron. Although the evaluation of a fortification program in Guatemala has shown an improvement of the iron status, controlled intervention trials had not been pub- 
lished before the start of our project. Therefore we also designed a controlled intervention trial among 166 preschool anemic children. When we designed this study we did not realize the potential impact of seasonal differences on vitamin $A$ sources and that differences in morbidity as a result of the intervention could also influence the intervention trial. $A$. though these factors interfered with our study model, vitamin A intervention resulted in a significant increase in serum iron and \%ST. To exclude these possible confounding factors we designed a two-week intervention trial. This study showed that two weeks after intervention with vitamin A there was an significant increase of serum iron, oST, hemoglobin and hematocrit. This study showed that, besides the effect of vitamin $A$ on morbidity and hence indirectly on the iron status, there is a direct effect of vitamin. $A$ on hematopoiesis.

\subsection{Conclusions and recommendations}

1) Xerophthalmia/vitamin A deficiency seems to be a public health problem in the rural area in the Sakon Nakhon province in Northeast Thailand according to the World Health Organization criteria.

2) In the urban area, xerophthalmia/ vitamin A deficiency seems to be no public health problem, although the situation of the school children should be monitored.

3) Stimulation of home-gardening of vegetables and fruits could be important in attacking the vitamin A problems in Northeast Thailand, because children from farmers of the low socioeconomic class are more susceptible to xerophthalmia than children from a high socioeconomic class, fruits and vegetables are the most important sources of vitamin $\mathrm{A}$, and there is a positive correlation between food consumption and food production in this area.

4) Our studies confirm previous reports that subclinical vitamin A deficiency can lead to a greater susceptibility to infections and that intervention with a high dose of vitamin A can improve the resistance against these infections.

5) Our studies provide evidence for a causal association between vitamin $A$ and iron metabolism. In Northeast Thailand where subclinical vitamin A deficiency is endemic, periodic massive vitamin A dose programs can improve the iron status of the population as well.

\subsection{References}

1. Food and Nutrition Policy. In: The Fifth National Economics and Social Development Plans 1982-1987, Bangkok: NESDB, 1981.

2. Dhanamitta S, Stoecker B, Valyasevi A. Community Approaches to Prevention of Vitamin A Deficiency. Paper presented at the IVACG Meeting, Jakarta, Indonesia, 11-13 October, 1980.

3. Sommer A. Nutritional Blindness; xerophthalmia and keratomalacia. New York: Oxford University Press, 1982.

4. Sommer A. Field guide to the detection and control of xerophthalmia. Genewa: WHO, 1982.

5. Sommer A, Hussaini $G$, Muhilal I, et al. History of Night blindness a simple tool for Xerophthalmia screening. Am J Clin Nutr 1980;33:887-91.

6. Gupta MC, Tandon BN. Night blindness as a Tool for Xerophthalmia Screening. Am J Clin Nutr 1981;34:1985.

7. McLaren DS. "Pathogenesis of vitamin A deficiency" in Vitamin A deficiency and its control (eds. Bauernfeind JC), pp 153-76, Academic Press, Gainesville", Florida, 1986.

8. Speek AJ, Saichua-Speek S, Schreurs WHP. Total carotenoid and $\beta$-carotene content of Thai vegetables and the effect of processing. Food Chem $1988 ; 27: 245-58$. 
9. Roels $\mathrm{OA}, \mathrm{Dj}$ aeni $\mathrm{S}$, Trout $\mathrm{ME}$, et al. The effect of protein and fat supplements on vitamir A-deficient Indonesian children. Am J Clin Nutr 1963:12:380-7.

10. Reddy $V$, Sivakumar D. Studies on vitamin A absorption. Indian Pediatr 1972;9:307-10.

11. Moore T. Vitamin A. Elsevier, Amsterdam, 1957.

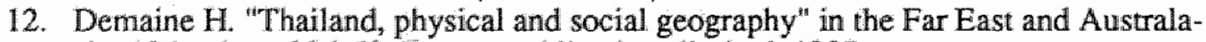
sia, 19th ed, pp 926-58, Europa publications limited, 1987.

13. Savasdira T, Tips WEJ, Fordeyn D, Chaiwut R. Malnutrition and basic needs surveys in Thailand. Soc Sci Med 1986;23:485-91.

14. Sommer A. Massive Dosages of vitamin A in Developing Countries. Abstracts International Symposium on Elevated dosages of witamin Benefits and Hazards, Interlaken, Swiss, Sept. 7-9, 1987.

15. Scrimshaw NS. Synergistic and antogonistic interactions of nutrition and infection. Fed Proc 1966;25:1679-81.

16. Anonymous. Fall and rise of the anti-infective vitamin. Lancet 1986;1:1191.

17. Sommer $A$, Tarwotjo $I$, Hussaini $G$, Susanto $D$. Increased mortality in children with mild vitamin A deficiency, Lancet 1983 ;ii:585-8.

18. Sommer A, Katz J, Tarwotjo I. Increased risk of respiratory disease and diarrhea in children with preexisting mild vitamin A deficiency. Am J Clin Nutr 1984;40:1090-5.

19. Mejia LA, Hodges RE, Arroyave G, Viteri F, Torun B. Vitamin A deficiency and anemia in Central American children. Am J Clin Nutr 1977;30:1175-84. 
Vitamin A is one of the most important nutrients for both man and animal. The vitamin is essential for normal vision, growth, reproduction, and it modulates the differentiation of epithelial cells. Xerophthalmia is the most prominent manifestation of lack of vitamin A or provitamin carotenoids. Literally, xerophthalmia means "disease of the dry eye", but since 1974 the term is used for all ocular manifestations of impaired vitamin A metabolism. In spite of the fact that xerophthalmia has already been known for many ages, the magnitude of the problem has only been established since the second World War. In the 1960s Oomen, McLaren and Escapini carried out a worldwide prevalence study. Although the world magnitude of the problem has been recognized, and the WHO has given high priority to the eradication of xerophthalmia, vitamin $A$ deficiency is still one of the world's major nutritional problems. The most recent estimation of the magnitude of the problem is that 25-50 million children may be suffering the physiological consequences of vitamin A deficiency; 5 million of them are developing xerophthalmia, of whom 500000 go blind every year

Chapter 1 describes the rationale and the outline of this thesis. Chapter 2 reviews the metabolism of vitamin A deficiency and the epidemiology of xerophthalmia.

Since the beginning of this century it has been known that vitamin $A$ and its derivatives are necessary for the maintenance of normal mucosal epithelium in several organ systems. Lack of vitamin A will lead to keratinizing squamous metaplasia affecting the respiratory, urinary, and alimentary systems, which has clinical consequences. The first studies have reported anemia and infections in some animals deprived of vitamin A, long before the clinical manifestations of xerophthalmia became fully evident. These associations have not received serious attention until the past decade. The group of Arroyave in Central America and the group of Sommer in Indonesia have conducted several studies on these subjects. This thesis describes several studies on the effects of subclinical vitamin A deficiency in Thailand.

Chapter 3 presents a review on the association between vitamin A metabolism and anemia.

Chapter 4 describes an epidemiologic survey of the prevalence of xerophthalmia and vitamin A deficiency in a multistage random sample of 1772 children, 1-8 years old, from 16 rural villages and the capital city of the Sakorn Nakhon province in Northeast Thailand. The distribution of clinical signs of xerophthalmia and serum retinol levels differed between the rural and urban area. In the urban area no signs of xerophthalmia were found in the preschool children examined, while only a small percentage of the school children showed deficient serum retinol levels. The situation in the rural area, howewer, is far less reassuring. The prevalence of night blindness in the rural area was $1.3 \%$ in the age group $1-5$ years $195 \%$ confidence interval $(\mathrm{CI})=$ $0.7-1.9)$; Bitot's spots were seen in $0.4 \%(95 \% \mathrm{CI}=0.1-1.0) ; 12.7 \%(95 \% \mathrm{CI}=$ $9.9-15.5)$ of these children showed deficient serum retinol levels $(<0.35 \mu \mathrm{mol} / \mathrm{L})$. Among the children $11-8$ years old, $9.6 \%(95 \% \mathrm{Cl}=7.8-11.4)$ showed deficient serum retinol levels. In the rural areas the prevalence of night blindness, Bitot's spots and deficient serum retinol levels indicates a problem of public health importance according to the criteria of the WHO.

Chapters 5 and 6 report three studies on the relation between vitamin $A$ deficiency and anemia. The first study is a cross-sectional analysis carried out among 1060 children aged 1-8 years. Levels of hematocrit, serum iron, ferritin, and saturation of transferrin correlated significantly with both retinol and retinol-binding protein (RBP). Only RBP had a significant positive correllation with hemoglobin. Both retinol and RBP showed a significant negative correlation with transferrin. Multiple regression 
analysis was used to adjust for effects of age, sex, parameters of the protein nutritional status, and infections. Retinol and RBP remained significantly associated with all parameters mentioned. To obtain further evidence as to whether this observed association is a causal one, two intervention trials were carried out. Both studies showed that a single high oral dose of vitamin A (200 000 TU) can improve the iron status. The impact of the first intervention trial may have reduced because of the seasonal influence. Furthermore this study could not exclude morbidity changes as a consequence of the intervention. The second study was carried out to evade these possible confounders. From this study it may be concluded that there is a significant association between vitamin $A$ and iron metabolism and that intervention with a single high dose of vitamin A can improve the iron status.

Although vitamin A deficiency is one of the most important nutritional problems in the Third World and long has been associated with infectious diseases, there are only few well documented studies on this association. A plausible explanation is that vitamin A deficiency is always accompanied by other nutritional deficiencies. Furthermore, Scrimshaw thas mentioned as early as in 1968 that the relation between malnutrition and infectious diseases is a synergistic one; a specific nutrient deficiency could lead to a higher susceptibility to infections, but infectious diseases almost always aggravate co-existing malnutrition.

Chapter 7 describes three different studies about the relation between vitamin A deficiency and infections. By means of a cross-sectional study, a follow-up study, and an intervention trial significant associations between vitamin $A$ deficiency and anemia have been shown. Adjusted for the effects of age, sex, protein status, and nutritional status, children with a history of diarrhea or respiratory infections had significantly lower levels of serum retinol and RBP. A follow-up study of a subsample of 146 children, who were not subject to any form of intervention, showed that children with deficient serum retinol levels $(<0.35 \mu \mathrm{mol} / \mathrm{L})$ had an about 4 times greater risk of developing respiratory diseases $(\mathrm{p}<0.01)$ than had children with adequate levels during a follow-up of three months. No significant association with diarrhea was found. $A$ controlled intervention trial with 166 children, aged $1-5$ years, showed that during two months of follow-up after supplementation with a single oral massive dose of vitamin A, the control group of children aged 3-5 years had a higher incidence of respiratory disease ( 2.89 times) as well as of diarrhea (3.02 times) than the intervention group. Between two and four months after the start of the intervention a significantly $(p<0.025)$ higher incidence of respiratory disease ( 2.56 times) could be observed among children aged $1-2$ years.

In chapter 8 the socioeconomic situation of Northeast Thailand and its relation with the problem of vitamin A deficiency is discussed. Recommendations based on the results of this investigation are given. 


\section{SAMENVATTING}

Vitamin $\mathrm{A}$ is een belangrijk nutriënt voor zowel mens als dier. Her vitamine is essentieel voor een normale visus, groei, voortplanting, en differentiatie van epitheelweefsel. Bij een tekort aan vitamine $\mathrm{A}$ of provitamine $\mathrm{A}$ carotenoïlen is xerofthalmie de belangrijkste klinische afwijking. Letterlijk betekent xerofthalmie "de ziekte van het droge oog", maar sinds 1974 omvat deze term alle afwijkingen in en aan het oog die het gevolg zijn van vitamine A-deficiëntie. Ondanks het feit dat de klinische verschijnselen van vitamine A-tekort een van de oudstebeschreven ziektebeelden vormen, werd de omvang wan het probleem op wereldniveau pas na de tweede wereldoorlog onderzocht. In de jaren ' 60 verrichtte de Nederlander Oomen met McLaren en Escapini een wereldomvattend onderzoek naar de prevalentie van xerofthalmie en vitamine A-deficiëntie. Hoewel de enome omvang en emst van xerofthalmie door dit onderzoek werd aangetoond en de Wereldgezondheidsorganisatie hoge prioriteit verleende aan de bestrijding, is dit voedingsprobleen nog lang niet de wereld uit: jaarlijks wordt een half miljoen kinderen blind als gevolg van xerofthalmie; ongeveer 5 miljoen kinderent ontwikkelen lichtere gradaties van xerofthalmie; subklinische vitamine A-deficiëntie treedt op bij 25-50 miljoen kinderen per jaar.

In hoofdstuk 1 wordt de motivatie achter het onderzoek en de indeling van het proefschrift beschreven. In hoofdstuk 2 wordt een kort overzicht gegeven van het metabolisme van vitamine A en de epidemiologie van xerofthalmie.

Sedert het begin van deze eeuw is reeds bekend dat vitamine A belangrijk is voor meer lichaamsfuncties dan alleen een normale donkeradaptatie en het normaal functioneren van het externe oog. Door de eerste dierexperimenten en autopsiestudies bleek dat vitamine A essentieel is voor de normale proliferatie en differentiatie van mucus-secernerend epitheel in velerlei orgaansystemen. Bij afwezigheid van vitamine A wordt dit epitheel door keratiniserende metaplasie getransformeerd in op huid lijkend meerlagig plaveilselcelepitheel. Dit heeft ook klinische consequenties. In de eerste experimentele studies waarin proefdieren vitamine A-deficiënt werden gemaakt, zag men complicaties zoals anemie en infectieziekten lang voordat de eerste klinische verschijnselen van vitamine A-deficiëntie manifest werden.

Toch is pas onlangs veel aandacht gegeven aan de systemische complicaties van vitamine A-deficiëntie. Het is vooral te danken aan de groep van Arroyave in MiddenAmerika en de groep van Sommer in Indonesië dat ook de gevolgen van subklinisch vitamine A-tekort opnieuw onder de loep zijn genomen. Arroyave et al. lrebben zich vooral bezig gehouden met de relatie tussen vitamine $\mathrm{A}$ en anemie, terwijl de groep van Sommer vooral de associatie tussen vitamine A en infectieziekten heeft onderzocht. Het onderzoek beschreven in dit proefschrift heeft zich vooral bezig gehouden met de systemische complicaties van vitamine A-deficiëntie als een onderdeel van het Nutritional Supplement Cooperation project.

Hoofdstuk 3 beschrijft de verschillende onderzoekingen over de relatie tussen vitamine A en anemie dat de aanleiding zijn geweest tot het onderzoek dat in dit proefschrift is beschreven.

In hoofdstuk 4 wordt een onderzoek naar de prevalentie van xerofthalmie en vita mine A-deficiëntie besproken. Door middel van een getrapte steekproef werden 1.772 1-8-jarige kinderen uit 16 plattelandsdorpen en uit de hoofdstad van de provincie Sakorn Nakhon geselecteerd. Er was een duidelijk verschill in prewalentie van xerofthalmie en vitamine A-deficiëntie tussen kinderen van het platteland en de stad. In de stad wer-den geen symptomen van xerofthalmie gevonden terwijl alleen bij een gering aantal 6-8-jarigen deficiënte serumretinolwaarden gevonden werden. Op het platteland echter was de situatie niet zo rooskleurig. Van de 1-5-jarige plattelandskin- 
deren waren $1,3 \%(\mathrm{BI}=0,7-1,9)$ nachtblind en Bitot-vlekken werden bij $0,4 \%(\mathrm{BI}=$ $0,1-1,0)$ van deze kinderen gevonden. Deficiënte serumretinolwaarden $(<0,35$ Hmol/L) zag men bij 12,7\% (BI $=9,9-15,5$ ) binnen deze populatie. Van de 1-8 jarige plattelandskinderen hadden $9,6 \%(95 \% \mathrm{BI}=7,8-11,4)$ deficiënte serumretinolspiegels. Uit deze gegevens mag worden geconcludeerd dat vitamine A-deficiêntie een volksgezondheidsprobleem is volgens de criteria van de Werellgezondheidszorg.

Hoofdstuk 5 en 6 beschrijven drie studies over de relatie tussen vitamine A-deficientie en anernie. De eerste studie is dwarsdoorsnede-onderzoek met behulp van de biochernische gegevens van 1060 kinderen. Retinol en retinol-bindend eiwit (RBP) correleren positief significant met de hematocriet, serumijzer, ferritine en de saturatie van transferrine. RBP correleert naast de genoemde ijzerparameters ook nog met hemoglobine. Transferrine correleert negatief significant met zowel retinol als RBP. Verwolgens werd met behulp van multipele regressievergelijkingen gecorrigeerd voor de mogellike verstrengelde variabelen. Ook binnen deze modellen verklaarde zowel retinol alls RBP een significant deel van de variantie van de reeds genoemde parameters van de ijzerstatus. Om meer te weten over de causaliteit van deze associatie zijn twee interventiestudies uitgevoerd. Zowel de eerste als de tweede studie tonen aan dat een eenmalige hoge dosis vitamine A (200.000 IU) de ijzerstatus significant kan verbeteren. Het effect van de eerste studie werd echter beinvloed door een seizoenseffect en bovendien kon in deze studie een effect op morbiditeitsveranderingen van infectieziekten niet worden uitgesloten. De tweede studie werd dan ook uitgevoerd om deze mogelijke verstorende factoren uit te sluiten. Uit deze studie mag worden geconcludeerd dat er een relatie bestaat tussen vitamine $A$ en de ijzerstatus en dat interventie met een hoge dosis vitamine A de ijzerstatus kan verbeteren.

Ondanks het feit dat vitamine A-deficiëntie één van de belangrijkste voedingsproblemen in de Derde-Wereldlanden is en al zeer lang geassocieerd wordt met vele typen infectieziekten, zijn er slechts weinig goed gedocumenteerde studies. De meest plausibele verklaring voor deze paradox is dat vitamine A-deficièntie slechts zelden als een geïsoleerd probleem voorkomt, maar bijna altijd gepaard gaat met andere nutriënttekorten. Scrimshaw schreef al in 1968 dat de relatie tussen ondervoeding en infecties synergistisch van aard is. Een specifiek nutriënttekort zall misschien leiden tot infectieziekten, maar infectieziekten op hun beurt kunnen leiden tot verminderde absorptie van deze nutriënten.

In hoofdstuk 7 worden drie verschillende studies beschreven naar de relatie tussen vitamine A-deficiëntie en infectieziekten. Door middlel van een dwarsdoorsnede-, een follow-up-en ten interventiestudie werden significante associaties aangetoond tussen de vitamine A-status en zowel diarree als luchtweginfecties. Gecorrigeerd voor leeftijd, geslacht, eiwitstatus en de voedingsstatus waren zowel retinol als RBP significant lager bij kinderen met diarree of luchtweginfecties in de anamnese. De followup-studie liet zien dat kinderen met deficiënte serumretinolwaarden een vier keer zo grote kans hadden om luchtweginfecties te ontwrikkelen als kinderen met een adequate vitamine A-status. Als gevolg van eenmalige interventie met een hoge dosis vitamine A bleek de controlegroep van 3-5-jarige kinderen gedurende de eerste twee maanden van follow-up 3 keer zo vaak diarree en 3 keer zo valak luchtweginfecties te ontwikkelen als de interventiegroep. Tussen twee en vier manden na de interventie kwamen alleen nog bij de 1-2-jarige kinderen van de controlegroep 3 keer zo veell luchtweginfecties voor als in de interventiegroep.

In het slothoofdstuk wordt ingegaan op de economische achtergrond van Noordoost -Thailand en op de relatie met het probleem van vitamine A-deficièntie. Verder worden aanbevelingen gegeven voortkomend uit de resultaten van dit onderzoek. 
CURRICULUM VITAE

Martin William Bloem werd op 29 jumi 1955 te Soesterberg geboren. Na het behalen van het eindexamen H.B.S.-B op het Eemland College te Amersfoort studeerde hij geneeskunde aan de Rijksuniversiteit van Utrecht. Van januari 1982 tot mei 1983 vervulde hij zijn dienstplicht als kazerne-arts van de Koninklijke Palm Kazerne te Bussum. Van juni 1982 tot september 1986 is hij verantwoordelijk geweest woor de opzer van de medische kommissie van de Nederlandse Taekwondo Bond. De actieve sportbegeleiding beêindigde hij in februari 1985, maar hij bleef adviserend lid van de medische kommissie tot september 1986. Bovendien vervulde hij wan september 1984 tot september 1986 de functie van algemeen voorzitter van deze bond. Van mei 1983 tot december 1984 was hij in het kader van een experimentele opleiding voeding voor attsen werkzaam op de afdeling Voeding van het Instituut CIVO-Toxicologie en Voeding TNO te Zeist (hoofd: prof. Ruud J.J. Hermus/ dr. Theo Ockhuizen), Gedurende deze periode heeft hij zich beziggehouden met onderzoek naar de relatie tussen voeding en sport en was hij lid van het onderzoeksteam van het Voedingspeilingsonderzoek onder oudere Nederlanders. Bovendien volgde hij in deze tijd verschillende cursussen aan de Landbouwuniversiteit te Wageningen, Rijksuniversiteit van Leiden en de Vrije Universiteit van Berlijn. Van maart 1985 tot september 1988 is hij werkzaam geweest als arts-wetenschappelijk medewerker op de afdeling Klinische Biochemie van het Instituut CIVO-Toxicologie en Voeding TNO te Zeist (hoofd: prof. Wil H.P. Schreurs). Van april 1985 tot juli 1986 is hij tweemaal uitgezonden als wetenschappelijk adviseur in het 'Nutrition Supplement Cooperation Project' (projektleider: prof. Will H.P. Schreurs), een samenwerkingsproject met de Khon Kaen Universiteit te Khon Kaen in Thailand. In januari 1988 begon hij met de opleiding tot sociaal-geneeskundige zonder takaanduiding bij het Nederlands Instituut voor Praeventieve Gezondheidszorg (NIPG/TNO) te Leiden. Per 1 september trad hij in dienst bij de sector Gezondheidszorg en Epidemiologie wan het Nederlands Instituut voor Praeventive Gezondheidszorg TNO te Leiden (hoofd: Harry P.A. van de Water, arts); sindsdien is hij nog voor $20 \%$ van zijn tijd verbonden aan het CIVO. 
Nutrition Supplement Cooperation project: sequence of the various activities of the nutrition field survey
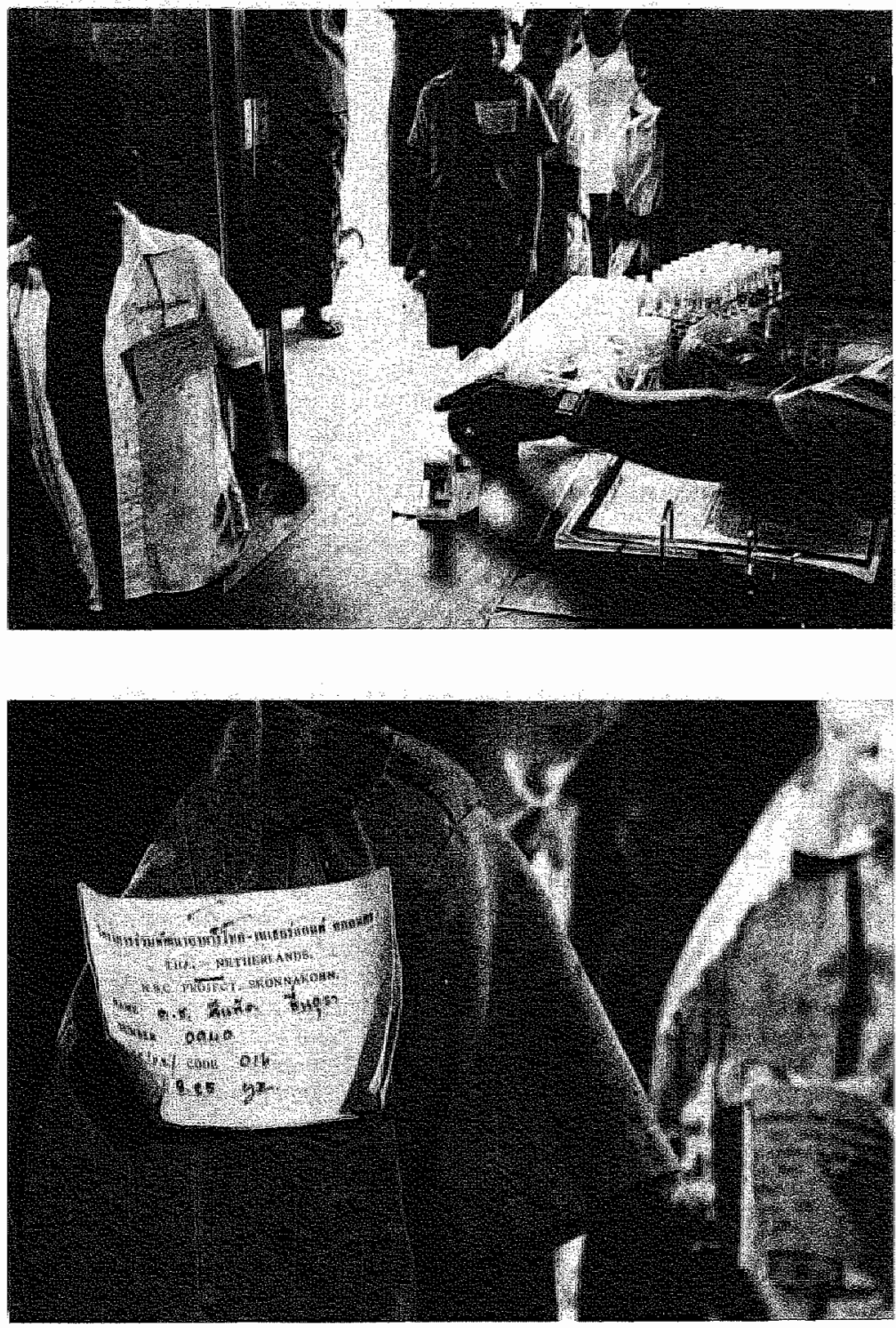

Fig. I., Fig. 2. Registration and identification of the children 
Appendix:

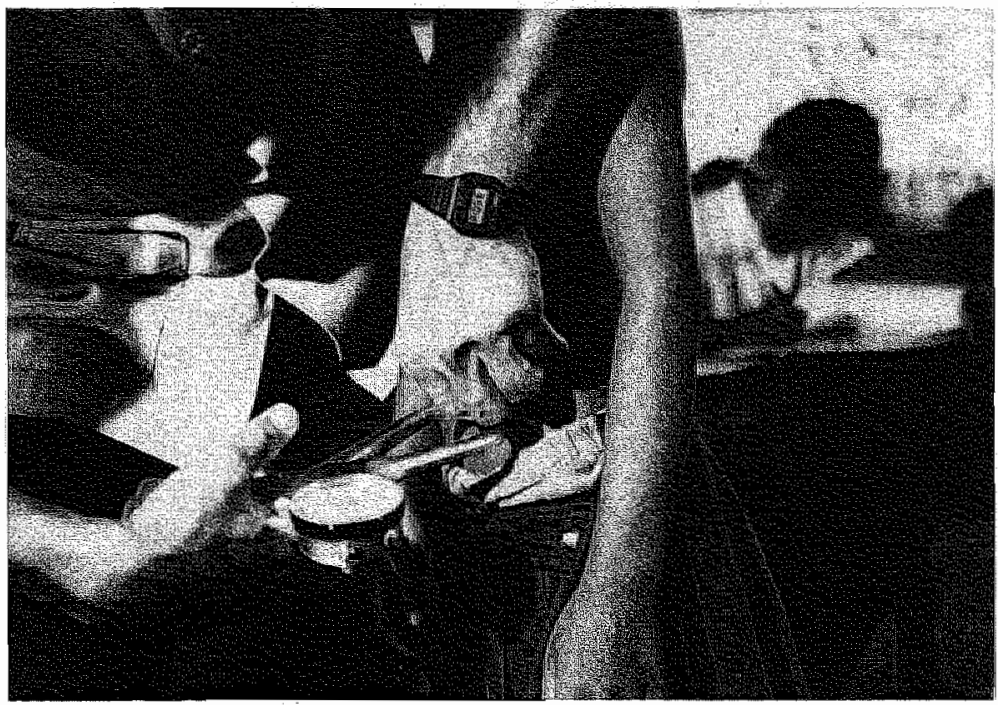

Fig. 3. Anthropometric measurements: skinfold caliper

Fig. 4. Medical examination by Thai pediatrician

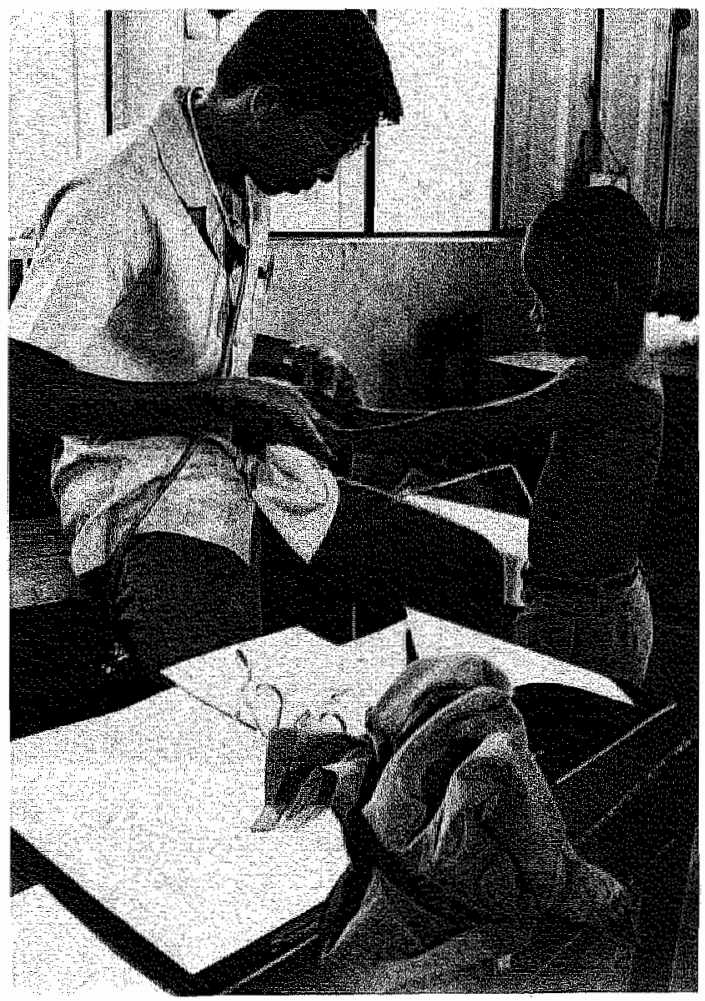



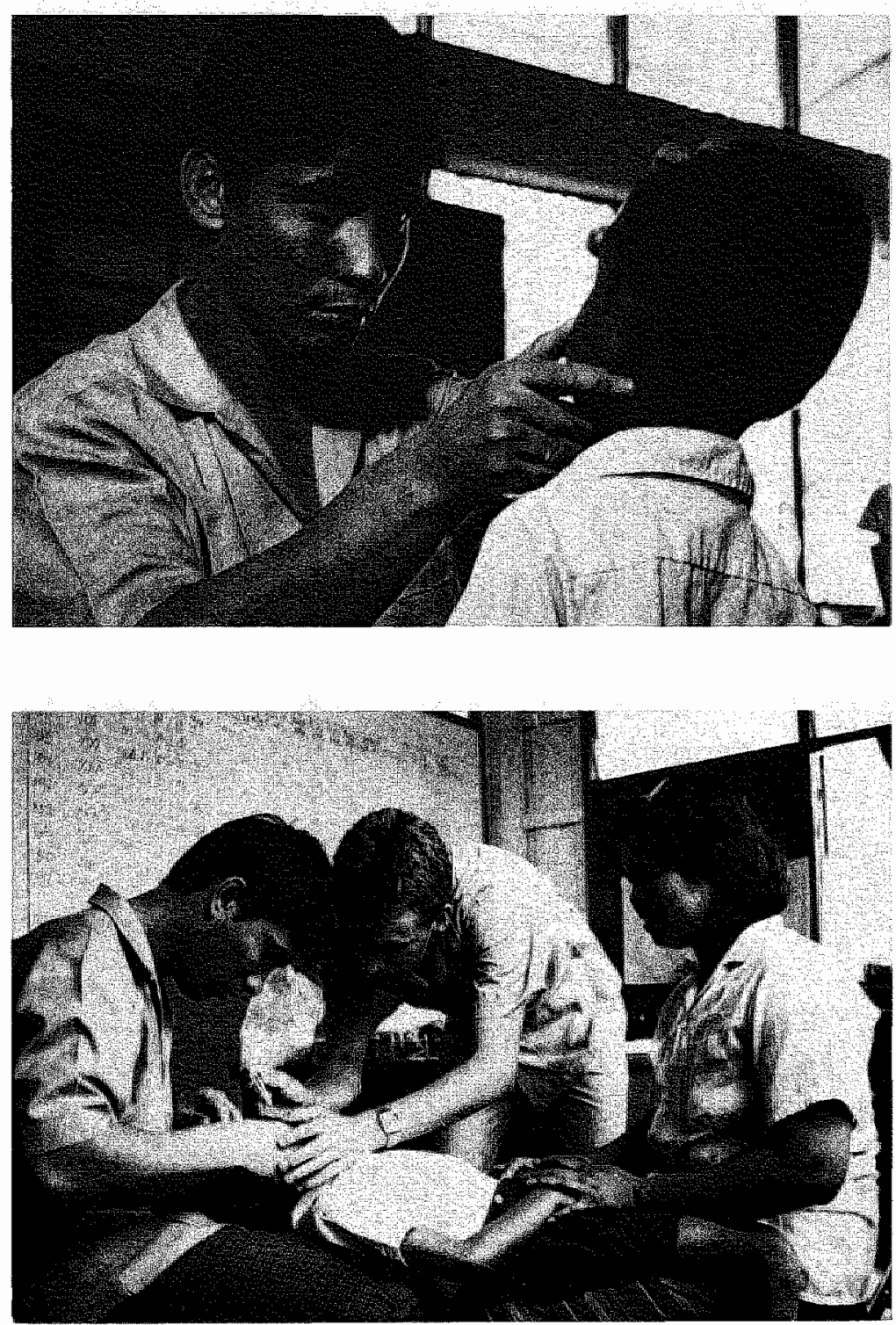

Fig. S. Eye examination

Fig. 6. Collection of tearfluid 

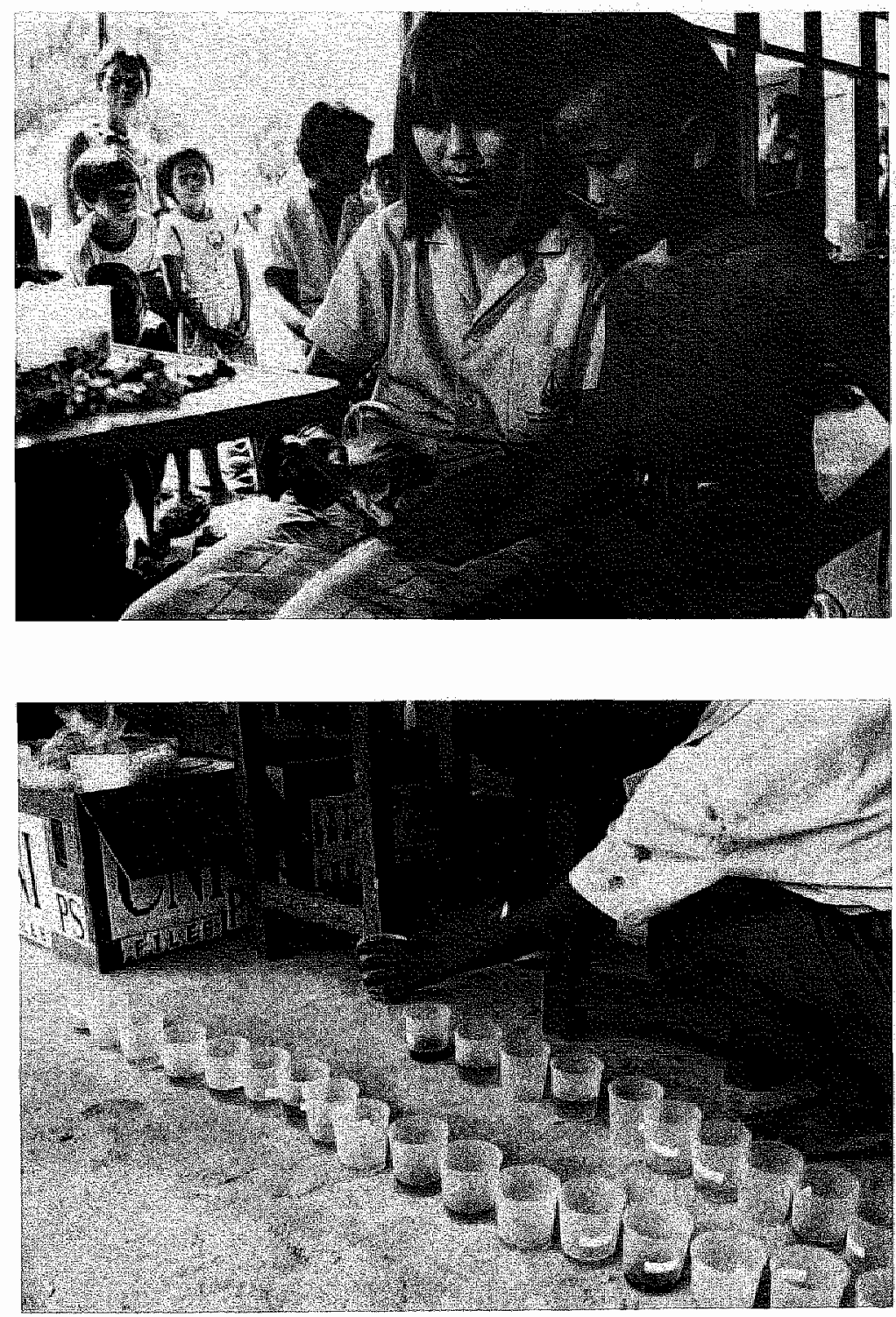

Fig. 7. Bloodcollection by fingerprick

Fig. 8. Urine collection 

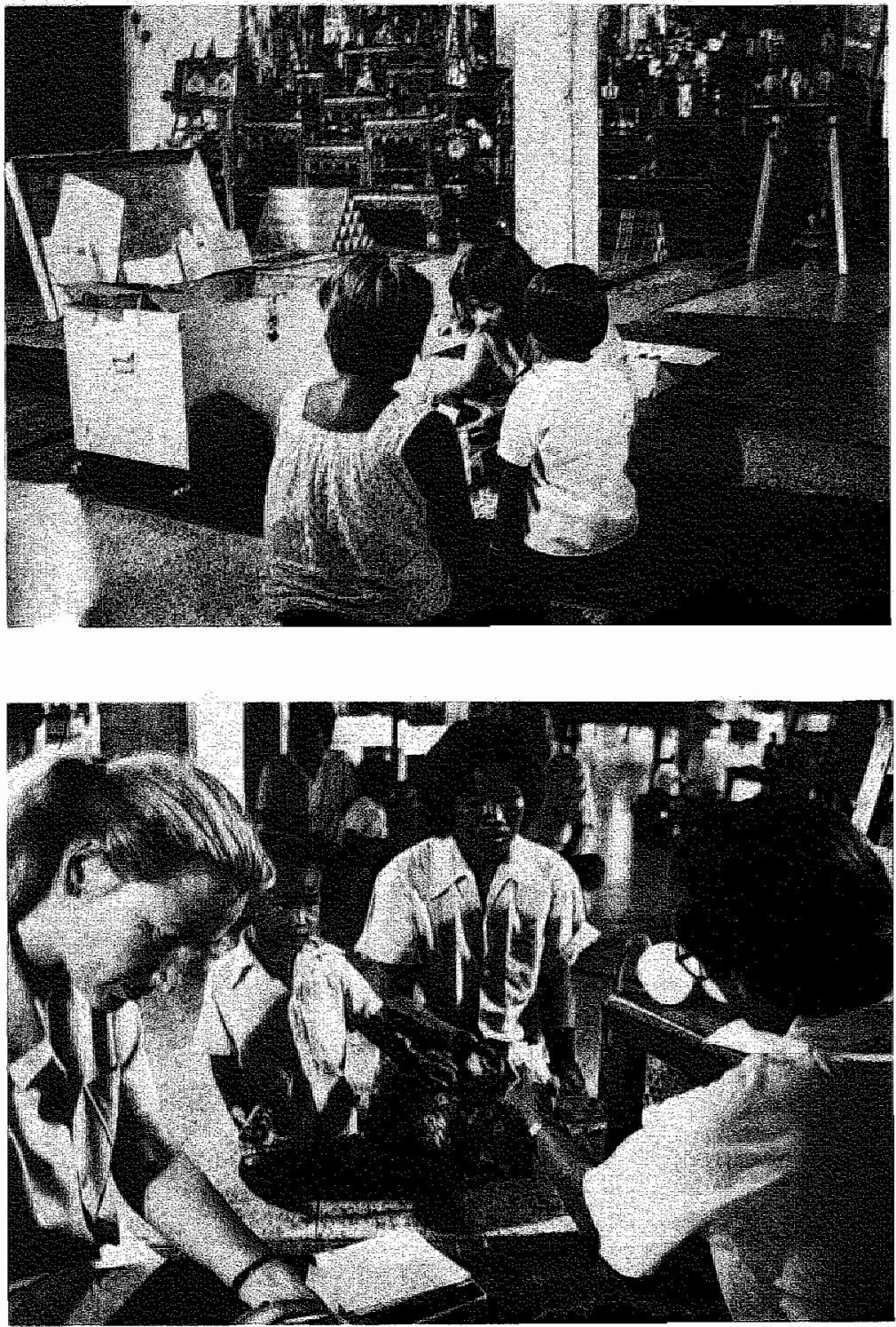

Fig. 9. Pharmacist supplying medicines prescribed by the pediatrician Fig.10. Food consumption interview 

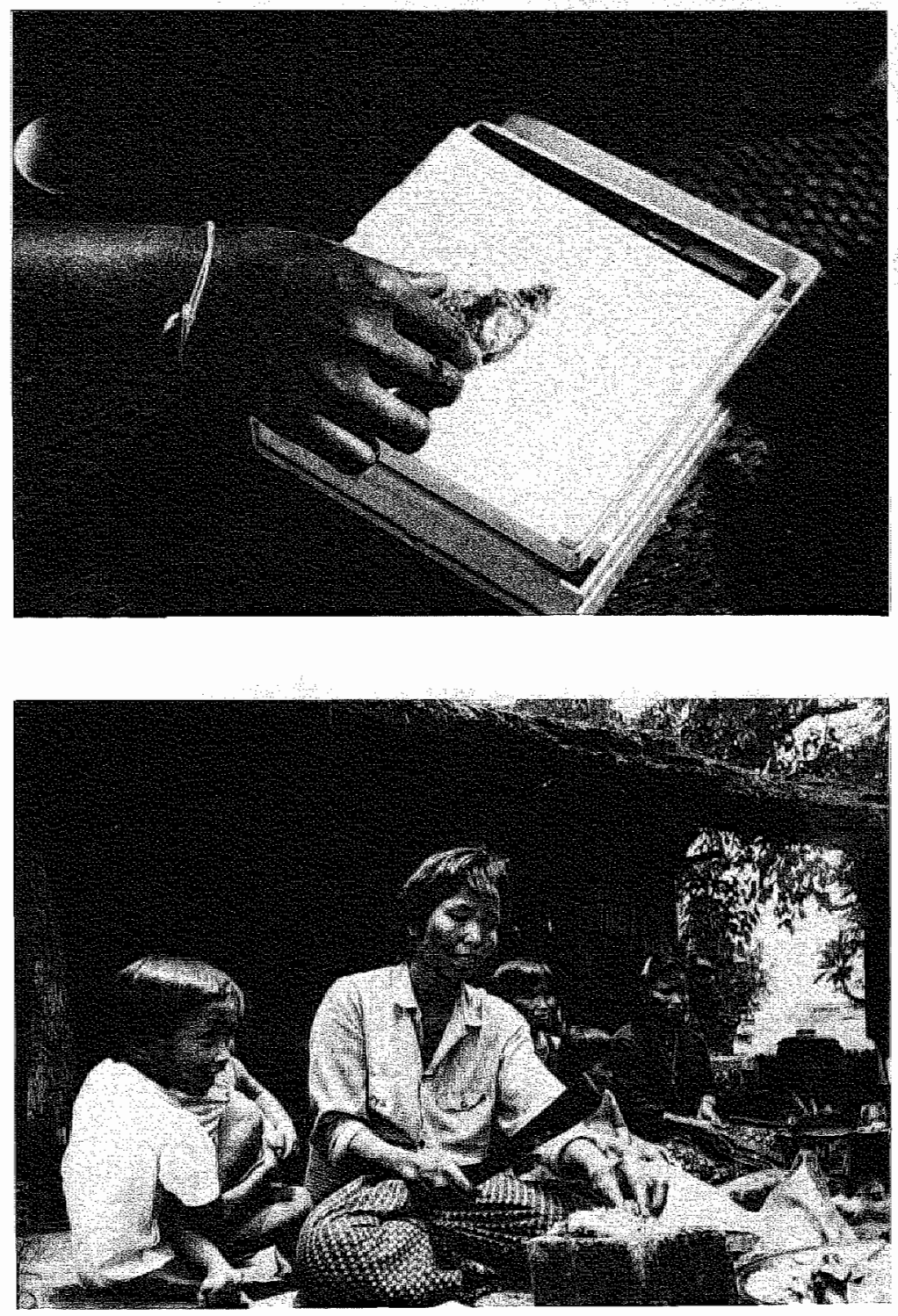

Fig. 11. Weighing of dietary components

Fig. 12. Food consumption interview at the parent's home 
Appendix
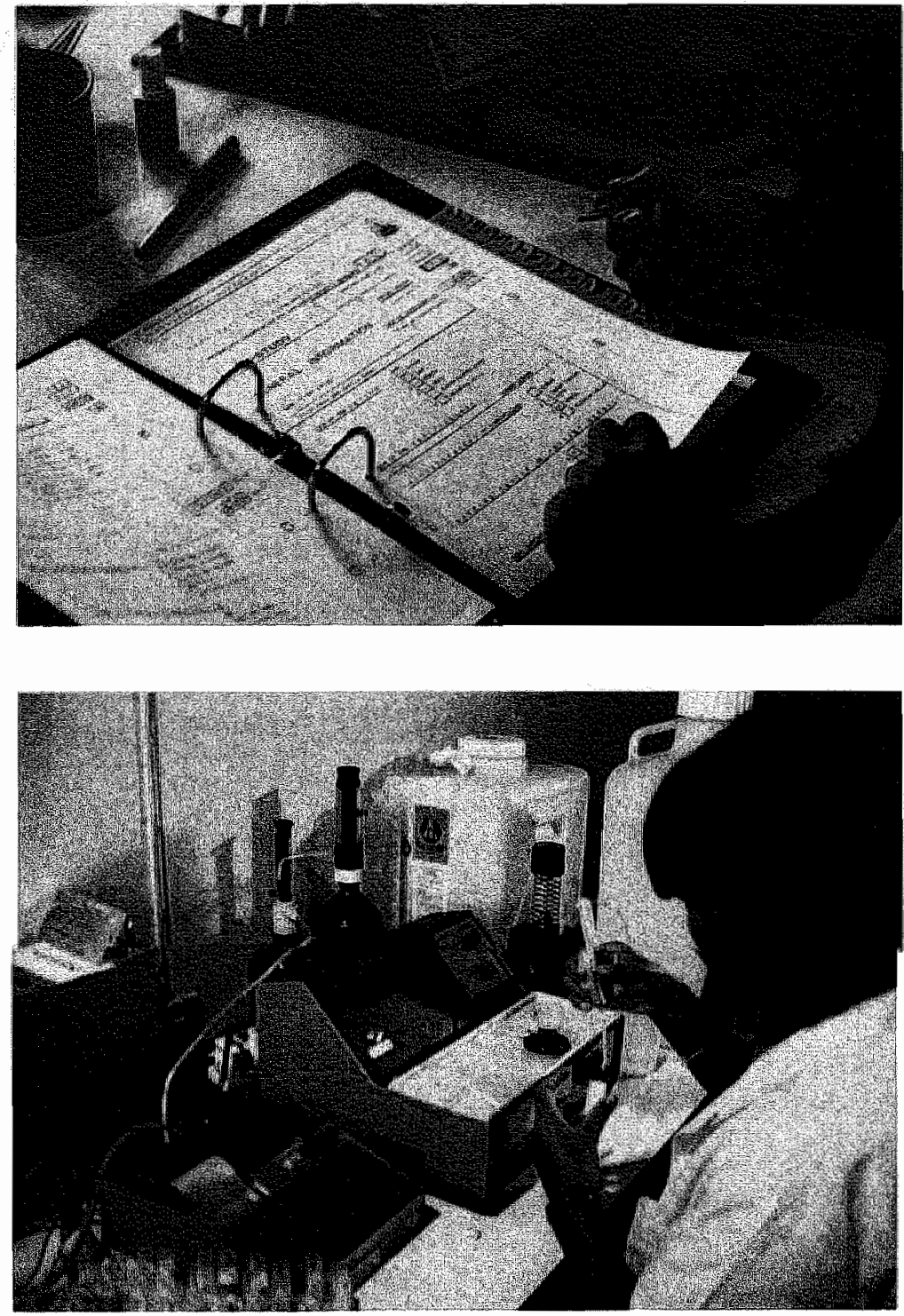

Fig. 13. Checking the results on precoded forms for accuracy and completeness at the field station

Fig. 14. Hemoglobin measurements at the field laboratory 